\title{
Response of clonal genotypes of Juncus effusus L. to different environmental regimes
}

\author{
Daniel Benjamin Stover \\ West Virginia University
}

Follow this and additional works at: https://researchrepository.wvu.edu/etd

\section{Recommended Citation}

Stover, Daniel Benjamin, "Response of clonal genotypes of Juncus effusus L. to different environmental regimes" (2005). Graduate Theses, Dissertations, and Problem Reports. 2292.

https://researchrepository.wvu.edu/etd/2292

This Thesis is protected by copyright and/or related rights. It has been brought to you by the The Research Repository @ WVU with permission from the rights-holder(s). You are free to use this Thesis in any way that is permitted by the copyright and related rights legislation that applies to your use. For other uses you must obtain permission from the rights-holder(s) directly, unless additional rights are indicated by a Creative Commons license in the record and/ or on the work itself. This Thesis has been accepted for inclusion in WVU Graduate Theses, Dissertations, and Problem Reports collection by an authorized administrator of The Research Repository @ WVU. For more information, please contact researchrepository@mail.wvu.edu. 


\title{
Response of clonal genotypes of Juncus effusus L. to different environmental regimes
}

\author{
Daniel Benjamin Stover \\ Thesis submitted to the \\ Eberly College of Arts and Sciences \\ at West Virginia University \\ in partial fulfillment of the requirements \\ for the degree of \\ Master of Science \\ in \\ Environmental Plant Biology
}

Keith Garbutt, Ph.D., Chair Jonathan Cumming, Ph.D. Alan Sexstone, Ph.D.

Department of Biology

Morgantown, West Virginia 2005

Keywords: Juncus effusus, Phenotypic plasticity, Resource use efficiency, Resource acquisition rate, Reciprocal transplant, Root growth 


\begin{abstract}
Response of clonal genotypes of Juncus effusus L. to different environmental regimes
\end{abstract}

Daniel B. Stover

A genetic tradeoff is hypothesized between resource use efficiency (RUE) and resource acquisition rate (RAR) in that it is impossible for selection to maximize both traits. In lowresource environments, RUE is expected to be favored while in high-resource environments RAR will be maximized. Growth rates and allocations of reciprocally transplanted clonal genotypes of $J$. effusus from differing nitrogen and elevation sites were examined. Highnitrogen populations outperformed their low-nitrogen counterparts, which were more nitrogen efficient. Plants originating from high-elevation sites grew larger irrespective of transplant environment. Elevation appears to be the dominant factor on biomass, nutrient allocation and growth at high elevation whereas nitrogen is the dominant factor in lower elevation. Minirhizotrons showed root growth was a function of origin site, with highelevation populations outperforming others regardless of nitrogen treatment. Our results support the hypothesized negative correlation between the physiological traits for RUE and RAR. 


\section{ACKNOWLEDGMENTS}

I would like to express my appreciation to Dr. Keith Garbutt for his excellent council and support of both the execution and documentation of my research. His guidance and subtle common sense have continually forced me to look at the world in a much larger view while not forgetting the beautifully intricate details. His dedication to teaching and adding the human aspect to research has provided me a new appreciation of the scientific exploration process. I especially want to express my gratitude in his confidence in my abilities as a graduate student. I would also like to thank my committee members Drs. Jonathan Cumming and Alan Sexstone. I sincerely appreciate their comments and suggestions on my proposals and thesis.

I must also recognize many people that have assisted my first research endeavor. I want to thank Julia Showalter, Larrni Hancock, Charla Dolly and Rebecca Puher for their support as research aids. I truly appreciate their numerous long and tedious hours of "exciting" work in the field, greenhouse and lab. This project could also not have been accomplished without the physical and mental help of fellow graduate student Frank Secreto. Much appreciation goes to Rachel Bell, Katrina Klugh, Rebecca Rummer, Brett McMillan and Dr. Kris Krajnak for their support and help from both the scientific and motivation areas of graduate life. Many thanks must also go to the WVU Department of Biology support staff (Marlene DeWitt, Susanne Lenhart, Heather Malone, and Fonda Perkins) for their support to my project and mental health. I would also like to thank Dr. Richard Thomas and Clint Springer for their grateful assistance in completing my carbon and nitrogen analysis. It is doubtful that this project could have been executed without the assistance of Pat Lutsie. She not only provided excellent assistance in acquiring supplies, equipment and research space, but also in helping me deal with numerous roadblocks in my tenure. Pat's kindhearted assistance will never be forgotten. Ultimately, I would like to recognize the support of my parents throughout this whole endeavor.

I am grateful for the allocation of research space that was provided by WVU Davis College of Agriculture, Forestry and Consumer Sciences, Chestnut Ridge Regional Parks, and Morgantown Board of Park and Recreation Commissioners (BOPARC).

Finally I would like to thank the West Virginia University Department of Biology for making a teaching assistantship available to me during my tenure. This research project was funded by an award from the United States Department of Agriculture, Water Resources Assessment and Protection Grant (WVA00138). 
"I speculated whether a species very liable to repeated and great changes of conditions might not assume a fluctuating condition ready to be adapted to either condition."

—Charles Darwin, letter to Karl Semper (1881)

"Nothing in biology makes sense except in the light of evolution."

—Th. Dobzhansky (1973)

"I may not have gone where I intended to go, but I think I have ended up where I intended to be."

—Douglas Adams 


\section{TABLE OF CONTENTS}

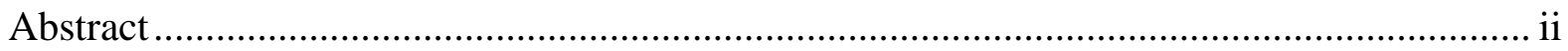

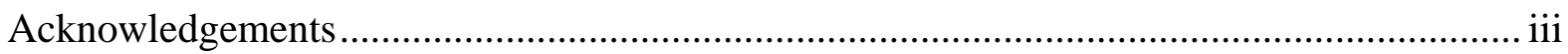

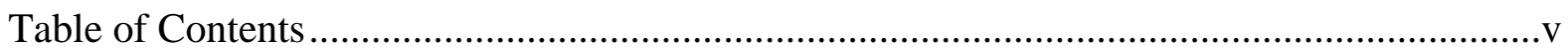

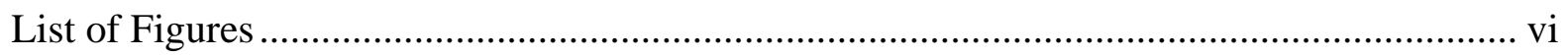

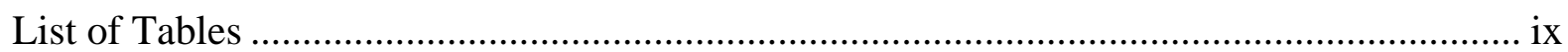

Chapter 1 - General Introduction: Ecological Genetics and Phenotypic Plasticity Within Nutrient Impacted Watersheds...............................................................................................

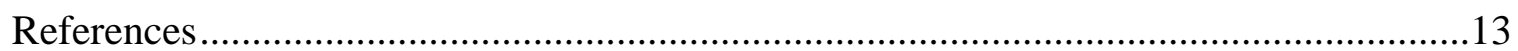

Chapter 2 - Fundamental Tradeoffs Resource Use Efficiency and Acquisition Rates in Populations of Juncus effusus L. from Opposing Nitrogen and Elevation Regimes ...............16

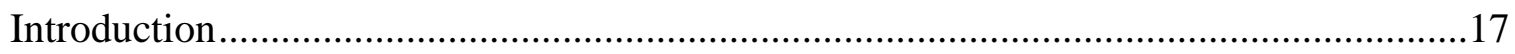

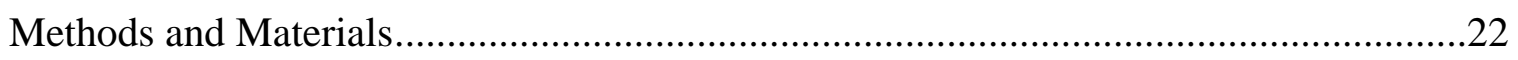

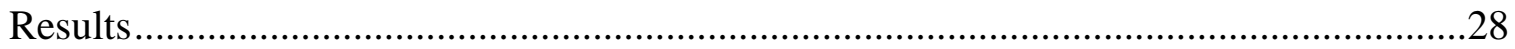

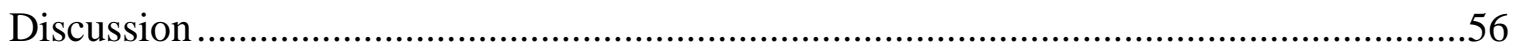

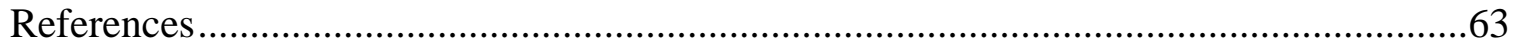

Chapter 3 - Changes in Juncus effusus L. Root Morphology in Relation to Nitrogen

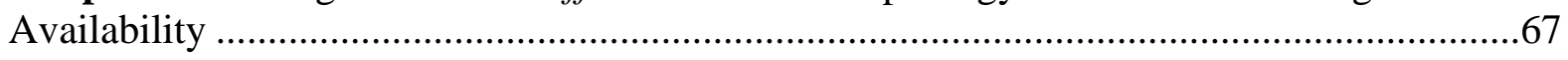

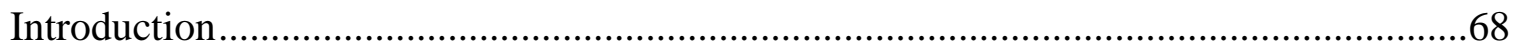

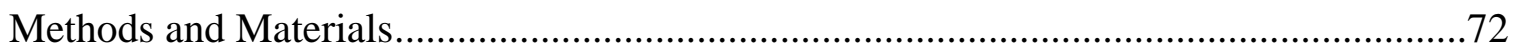

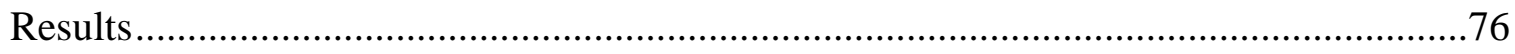

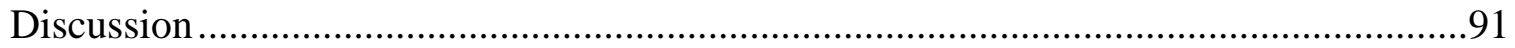

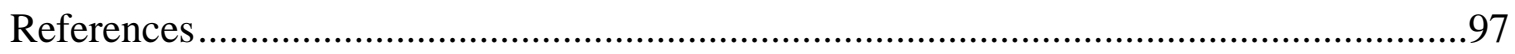

Chapter 4 - Conclusions and Synthesis ..............................................................................101 


\section{Chapter 1}

\section{TABLE OF FIGURES}

1.1. Predicted relationships between resource acquisition, utilization, growth rate and fitness in plants. Sign indicates directionality of correlation.

1.2: The hypothesized response of resource use efficiency (RUE), resource acquisition rate, and fitness of Juncus effusus across an environmental nutrient gradient (low

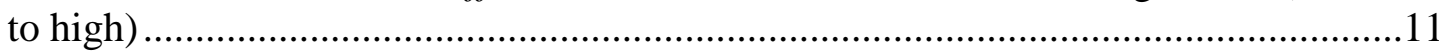

1.3: Juncus effusus L., a common wetland plant .......................................................12

\section{Chapter 2}

2.1: Site map and characteristics of research plots located in Monongalia County, West Virginia

2.2A. Site locations of reciprocal transplant: Agricultural Farm and Trout Pond................25

2.2B. Site locations of reciprocal transplant: White Park and Chestnut Ridge Park............26

2.3: Vegetative propagation of $J$. effusus inside an environmental growth chamber .........27

2.4: $\quad$ Mean tiller area of genotypes grown within their populations .................................33

2.5: $\quad$ Mean productivity of tiller area of populations over time …....................................33

2.6: Mean tiller area growth of individual genotypes grown within each site...................34

2.7: $\quad$ Genotype by environment (magnitude and equability plot) for genotypes from four field sites

2.8: $\quad$ Tiller area relative growth rate over the duration of the experiment of genotypes grown within each field site.

2.9: Tiller area absolute growth rate of tillers grown in differing nitrogen transplant sites over the duration of the experiment

2.10: Tiller area relative growth rate of tillers grown in differing nitrogen transplant sites over the duration of the experiment

2.11: Final mean dry weight of tillers based on origin field site ....................................38

2.12: Final mean dry weight of tillers based on transplant field site ................................38

2.13: Final nitrogen concentration within tiller tissue based on transplant field site. .39 
2.14: Final carbon:nitrogen ratio within tillers based on origin field site...........................39

2.15: Final carbon:nitrogen ratio within tillers based on transplant field site.....................40

2.16: Mean C:N ratios of populations grown in differing nitrogen environments ..............40

2.17: The effect of origin site elevation on tiller area .................................................45

2.18: The interactive effect of transplant and origin sites elevation on tiller area ..............45

2.19: The interactive effect of origin site elevation and nutrient level on tiller area ..........46

2.20: The interactive effect of transplant elevation, origin nitrogen level and origin elevation on tiller area ...............................................................................46

2.21: The interactive effect of transplant and origin site elevation on tiller area absolute growth rates

2.22: The interactive effect of transplant and origin site elevation on tiller area relative growth rates

2.23: The interactive effect of transplant nitrogen and elevation and origin nitrogen level

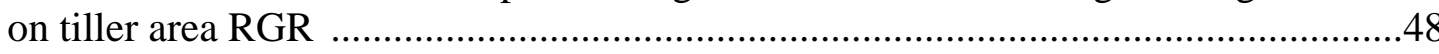

2.24: The interactive effect of origin nitrogen level and elevation on tiller biomass ...........50

2.25: The interactive effect of transplant nitrogen level and site elevation on biomass .......50

2.26: The effect of transplant site elevation on tiller biomass ........................................51

2.27: The effect of transplant nitrogen level on tiller carbon concentration .......................51

2.28: The effect of transplant elevation on tiller nitrogen concentration ...........................52

2.29: The interactive effect of transplant site nitrogen level and elevation on tiller

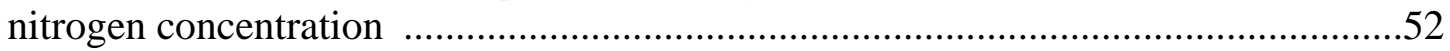

2.30: The interactive effect of transplant nitrogen level, elevation and origin nitrogen level on tiller nitrogen concentration ...................................................................53

2.31: The effect of transplant site elevation on tiller $\mathrm{C}: \mathrm{N}$ ratio ......................................53

2.32: The effect of transplant site elevation and nutrient level on tiller $\mathrm{C}: \mathrm{N}$ ratio ...............54

2.33: The interactive effect of transplant nitrogen level, elevation and origin nitrogen level on tiller $\mathrm{C}: \mathrm{N}$ ratio 
2.34: The interactive effect of transplant elevation, nitrogen and origin elevation on tiller C:N ratio

\section{Chapter 3}

3.1: $\quad$ Minirhizotron design for root morphology observation ...............................................75

3.2: The effects of elevation on tiller area from differing nitrogen populations..................82

3.3: The effect of high- and low-nitrogen treatments on tiller area from differing nutrient and elevation populations

3.4: Differences in root length between differing nitrogen populations ..............................84

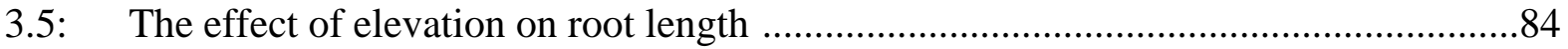

3.6: The effects of elevation on root surface area in two nitrogen populations ...................85

3.7: The effects of elevation on root diameter in differing nitrogen populations ...............85

3.8: Differences in number of root tips in two nitrogen populations ....................................86

3.9: The number of root tips in opposing elevations........................................................86

3.10: The effect of elevation on the number of root tips over time …..................................87

3.11: Differences in tiller biomass between two nitrogen populations..................................87

3.12: Differences in whole plant biomass between two nitrogen populations........................88

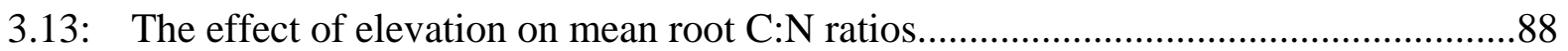

3.14: The effect of nitrogen on mean root C:N ratios.........................................................89

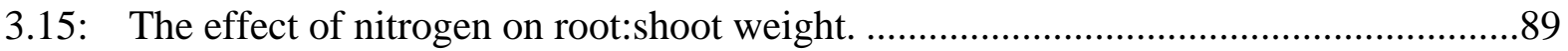

3.16: The effect of origin nitrogen level on $\mathrm{N}$ concentration within root:shoot ratios.........90

3.17: The effect of nitrogen on root:shoot C:N ratios.........................................................90

\section{Chapter 4}

4.1: Response of Juncus effusus to differing nitrogen and elevation regimes .105 


\section{LIST OF TABLES}

\section{Chapter 2}

Table 2.1: Tiller area repeated measures analysis of variance

Table 2.2: $\quad$ Analysis of variance of tiller area absolute and relative growth rates with tiller number as a covariate

Table 2.3: Analysis of variance of final tiller biomass, nitrogen concentration and carbon:nitrogen ratio

Table 2.4: Analysis of variance for Tiller area, absolute and relative growth rates

Table 2.5: $\quad$ Analysis of variance for tiller biomass, carbon and nitrogen concentrations and carbon:nitrogen ratios

\section{Chapter 3}

Table 3.1:

Repeated measures analysis of variance for tiller area

Table 3.2: $\quad$ Repeated measures analysis of root length, surface area, diameter and number of root tips

Table 3.3: Analysis of variance of absolute and relative growth rates for root surface area, diameter and number of root tips

Table 3.4: Analysis of variance of tiller and whole plant biomass, root carbon:nitrogen ratios, and root:shoot biomass, nitrogen concentrations and carbon:nitrogen ratios 
CHAPTER 1

GENERAL INTRODUCTION

ECOLOGICAL GENETICS AND PHENOTYPIC PLASTICITY WITHIN NUTRIENT IMPACTED WATERSHEDS 
Human impacts on natural systems have become a focus of concern for a wide range of reasons. These impacts range from purely aesthetic to impacts that could have severe economic implications. In some ecosystems, impacts of excess nutrients have the potential to cause significant economic and public health problems (Richter et al. 1997, Turner et al. 1999). Agricultural runoff in particular has become a major contributor to this nutrient enrichment process. With the continual degradation of the environment, it is necessary to understand the relative consequences of applied nutrient stresses to aquatic systems. Transitional zones, such as wetlands, have been known to provide a buffer to excess nutrient impact. As a result, wetlands provide the ideal system to understand the level and magnitude of disruption that will occur in transitional systems (Mitsch and Wilson 1996).

Environmental changes can force a plant population to become extinct, migrate, or adapt. Adaptation of plant species to heavily stressed and impacted environments can create natural tools for bio-remediation of soils. A population's level of intraspecific variation defines its ability to survive and continue after disturbance has occurred (Brewer and Bertness 1996, Bennington and McGraw 1996). There are two distinct outcomes of plant adaptations to extreme environments: tolerance or avoidance (Bennington and McGraw 1995). By changing location (spatially) or ontogenetic patterns (temporally), a plant population can adapt to meet the specific demands of a changing environment. It is this spatially-based component of variation in adaptation that is the focus of this study.

Nutrient enrichment of the environment can have multiple effects on plant populations. Genetic diversity provides two alternative routes for individuals within a population to become plastic or labile in response to environmental change (Bradshaw 1965, West-Eberhard 1989, Sultan and Bazzaz 1993, Via et al. 1995). The generalist route allows 
all individuals to be plastic as the environment changes. The specialist route allows individuals to become specialized to the specific environmental conditions (Via 1994a, Via 1994b, Pigliucci 2001, Taylor and Aarssen 1988). This allows for a large gradient of phenotypes across the population niche (Garbutt and Bazzaz 1987).

A significant amount of research exists for differential responses among individuals within a population, however there are only a few interpretive studies that examine the underlying mechanism(s) that control such results. It has been postulated that individuals within a population would not have the ability to efficiently utilize resources in a lowresource environment and be able to rapidly respond to the same resources when available in high abundance (high-resource environments; Garbutt and McGraw unpublished). Conversely, individuals with high acquisition rates can respond rapidly in high-resource environment, but not maintain this efficiency in a low-resource environment. In effect, populations have adapted their physiological response to meet the constraints placed upon them by the availability of resources and therefore should maximize fitness within their site of origin. This differentiation leads to ecotypic variation within a plant species. As a result, a plant species can theoretically occupy a much larger fundamental niche. It is this filling of an underutilized niche that allows for the genetic differences to become clear and defined in relation to fitness (Brewer et al. 1998).

Individuals originating from a low resource environment tend to have high resource use efficiency (RUE) and a relatively low growth rate (Nault and Gagnon 1988). This tradeoff increases an individual plant's relative fitness in its environment. According to our hypothesis, in an environment with high resource availability, the most fit plants tend to have 
both high resource acquisition and growth rates, although this leads to decreased resource use efficiency (Figure 1.1).

Selection pressures upon phenotypes within a population result in differentiation of genotypes depending on the stress (e.g. low nutrient levels) imposed by the environment. Evolutionary pressures can act on populations of a plant species to potentially express extreme phenotypic variation across its range (Lortie and Aarssen 1996). Fluctuating environmental pressures can select for individuals that can respond to variable resource availability rapidly. For example, strong selection pressures may result in populations that have high fitness values within low resource availability environments (low nitrogen). Plants from these environments are typically shorter than average because available resources are used for the maintenance and longevity of existing biomass (Figure 1.2A). Conversely, selection may favor individuals with high acquisition efficiency and, therefore, will allocate the ample resources to biomass (Figure 1.2B). In this idealized model, in high-resource environments, genotypes that produce large amounts of biomass will be able to maximize their acquisition of resources (i.e. light and nutrients) and thus will have the highest fitness. An assumption of this experiment is that these environmental and evolutionary selection pressures have resulted in a negative genetic correlation between resource acquisition rates (RAR) and resource utilization efficiency (RUE). This negative correlation denies individuals the ability to show positive growth and reproductive fitness within both high and low resource environments (Figure 1.2).

Growth rates are the key features defining RAR and RUE responses in relation to a plants fitness. For example, we expect an individual located in a high-resource environment and having a high RAR to have a relatively high growth rate (biomass production) of 
aboveground and belowground structures (Levin et al. 1998). Individuals with high RUE within a low-resource environment should respond with lower allocations to growth, but more efficient biomass production. This decreased allocation to gross structural components should result in a much higher development (and therefore allocation) in fine plant structures (i.e. secondary and tertiary roots and tillers) and may result in increased plant fitness in the given low resource environment. In this example, an individual would allocate more resources into root development for nutrient foraging in attempts to obtain a higher return rate for the carbon investment. This allocation to roots, as opposed to an investment in photosynthetic structures, is a direct result of nutrient level limiting growth and development. This tradeoff leads us to believe that plants have developed or evolved a "home-siteadvantage” to their particular environment (Antonovics 1971).

Individuals from populations with high RAR will quickly acquire nutrients (such as nitrogen,) in a nutrient-rich environment, resulting in a lower nitrogen utilization efficiency. In this case, the plant would produce more above- and belowground structures with emphasis on storage (because of a competition pressure). Well-developed belowground structures allow quick acquisition of nutrients and storage, potentially discouraging competition. Later in the growing season, when nutrient resources are in highest demand, these previously acquired resources could then ensure maximum individual fitness. In wetland plants, the ability of individual to compete for these resources assists in determining overall fitness (Weiher and Keddy 1995).

In the natural environment, plants compete both above- and belowground for resources (Ryser and Eek 2000). The capacity to acquire aboveground resources is associated with leaf area and the capacity to acquire belowground resources is associated 
with root length (Ryser 1998). However, the ability to acquire nutrients from the soil is not only based on the simple definition of root length, but also in the spatial configuration of the root system, or "root architecture”. We hypothesize that root architecture plays a greater role in acquisition than just gross root length (Lynch 1995, Nielsen et al. 1997). Root architecture is clearly controlled by the genetics of the plant as result of strong environmental influences. This genetic $\mathrm{x}$ environmental interaction controls a root systems plasticity and ability to function efficiently in complex environmental conditions. Changes in root patterns or phenologies can lead to belowground niche separation (Parrish and Bazzaz 1976, Lamont and Bergl 1991).

Research on root architecture often focuses on root system functionality as determined by root development and morphology. The architecture of the belowground system is defined by five major characteristics: distribution of branches within the system (topology); lengths; diameters of internodes or links; and angles of branching (Fitter and Strickland 1991).

Development of the root architecture concept has resulted a wide range of questions that examine the efficiency by which plants forage for resources in soils. To quantify an individual's ability to mine the soils, an index of efficiency was created. Exploitation efficiency (EE) is operationally defined as a known column of soil exploited per unit volume of root biomass (Berntson 1994, Fitter 1987). A series of studies in the early 1990's showed that large diameter roots have high exploitation of resources, but a low overall efficiency, and the converse relationship exists for smaller root systems (Berntson 1994, Fitter 1991).

There is a strong negative relationship between total root branching and EE. Overall, potential soil exploitation was more strongly correlated with root architecture than efficiency 
(Berntson 1994, Fitter 1991). However, it is still unclear as to which specific part of root architecture is more important: changes in the overall size of root systems or changes in sizeindependent aspects of its architecture (Berntson 1994).

Soil moisture and nutrient availability fluctuate spatially as well as temporally and may lead to specialized adaptive features in the root system (Bazzaz and Sultan 1987, Caldwell 1994, Fitter 1994, Bazzaz 1996, Bell and Sultan 1999). The inherent ability to alter the rhizosphere, in attempts to ensure functionality and overall growth when soil resources become limiting, serves as the crucial element of individual adaptive plasticity in plants (Grime 1994). “Because root growth and deployment are critical to maintaining function in different environmental conditions, plasticity of these traits may influence the ecological tolerance of individuals and hence the field distribution of species” (Bell and Sultan 1999). Plasticity in the specific deployment of roots is critical for acquisition of nutrients (Fitter 1994). Again, relatively little research has been conducted to understand the differences in root systems among ecotypes of the same species.

A wetland ecosystem provides an excellent system to study our proposed physiological tradeoffs in fitness. Wetlands are often the recipient of excess agricultural nutrient runoff and serve as a "biofilter" to many farms. Sequestration of excess nutrients prevents eutrophication of aquatic ecosystem. In this situation, it is expected that the plant community may adapt to the elevated availability of nutrients, with nitrogen being in the highest concentration. Quantitatively, nitrogen is the highest applied agricultural amendment in the world. The Chesapeake Bay Foundation's 2001 State of the Bay Report reported roughly 331 million pounds of nitrogen reach the Chesapeake Bay annually. In addition, the 
number one source of nutrient pollution in the Chesapeake Bay watershed is agricultural runoff, which contributes to more than 40 percent of total raw nitrogen inputs.

By studying the ecological genetics of representative wetland species, I aim to determine the underlying relationships between nitrogen availability and its effects on plant population's responses to the negative correlation between RAR and RUE. This research should provide a critical understanding of the plastic adaptive ability of plants to respond to excess nitrogen in heavily impacted aquatic systems such as the Chesapeake watershed in the eastern United States. I believe these data will potentially provide a strong selective tool for development of constructed systems with native plants for remediation of these impacted and heavily disturbed systems. Utilization of indigenous plant species that can adapt to the temporal and spatial variability of excess nitrogen inputs is essential to protecting the ecosystem and ensuring the health and economic stability of the system.

In this study, Juncus effusus L. (common rush) was used as my model species to evaluate evolutionary adaptation of wetland plants in response to nitrogen availability (Figure 1.3). J. effusus is a common representative in most northern freshwater wetlands. The ability of $J$. effusus to reproduce clonally makes it an ideal candidate to examine the effects of high- and low-nutrient environments in relation to different genotypes because of the ability to subject the same clonal genotype to multiple experimental conditions. The final goal of this thesis is to suggest practical applications for wetland remediation by appropriate selection of $J$. effusus ecotypes.

In conclusion, I hypothesize that populations of $J$. effusus will respond according to the model proposed by Garbutt and McGraw (figure 1.1). This study will lend the initial support for negative physiological correlations between RAR and RUE traits in plant 
populations. Plant populations from high-nitrogen environments will maximize growth only within similar environments. Conversely, low-nitrogen populations will maintain its growth form and efficiency among all environments. In addition, I hypothesized above- and belowground portions of $J$. effusus will respond in a similar manner based on its life history responses to specific environmental conditions (home-site-advantage). Furthermore, I expected to find a more developed root morphology and architecture in individuals originating in high-nitrogen environments. In addition, we will examine the response of $J$. effusus to additional environmental constraints to determine if nitrogen is the only controlling factor affecting the proposed model. 
Figure 1.1. Predicted relationships between resource acquisition, utilization, growth rate and fitness in plants. Sign indicates directionality of genetic correlation (Garbutt and McGraw unpublished).

\section{ENVIRONMENT}

High Resource Availability Low Resource Availability

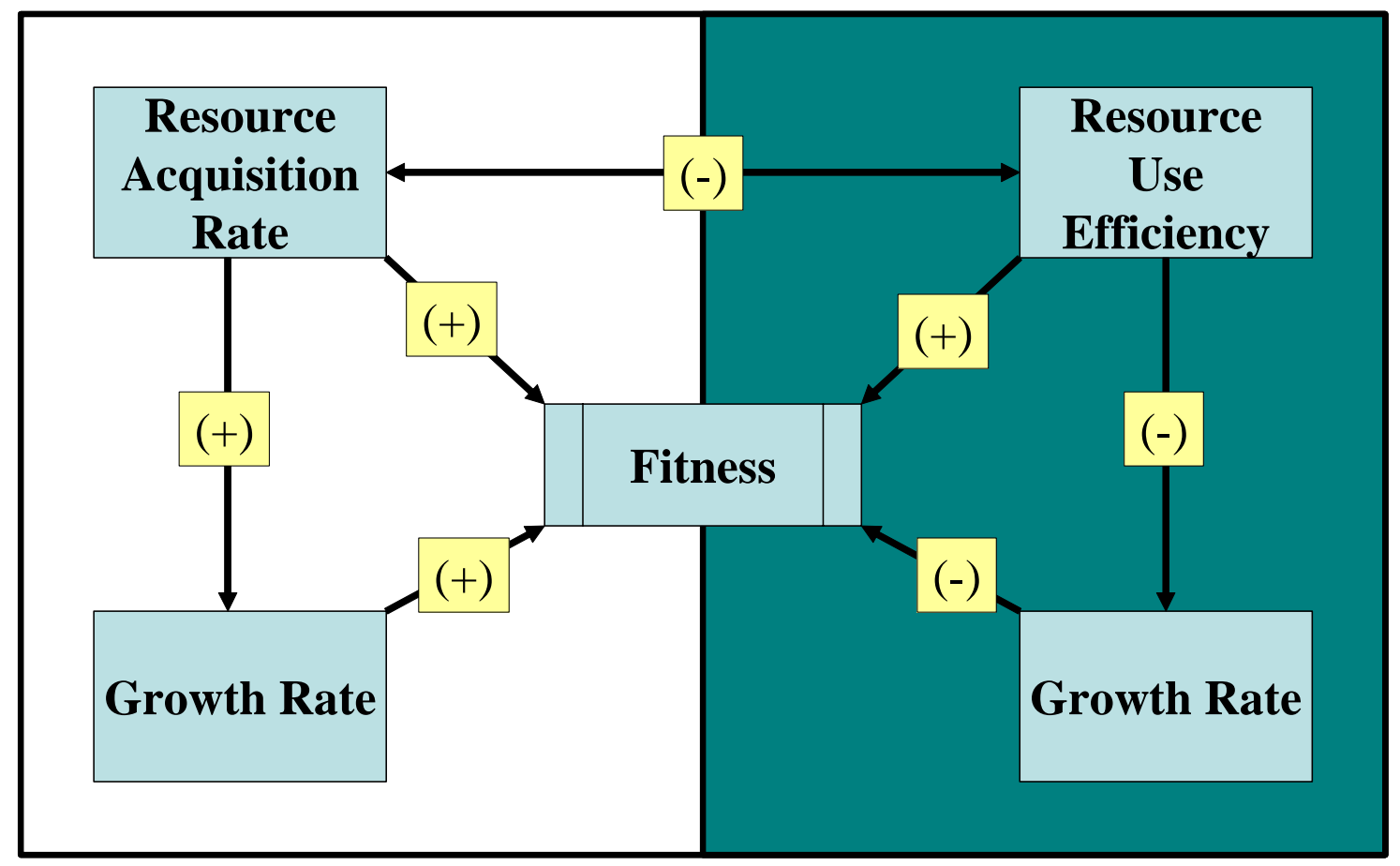


Figure 1.2: The hypothesized response of the a) resource use efficiency (RUE), b) resource acquisition rate (RAR), and c) fitness of Juncus effusus across an environmental nutrient gradient (low to high).
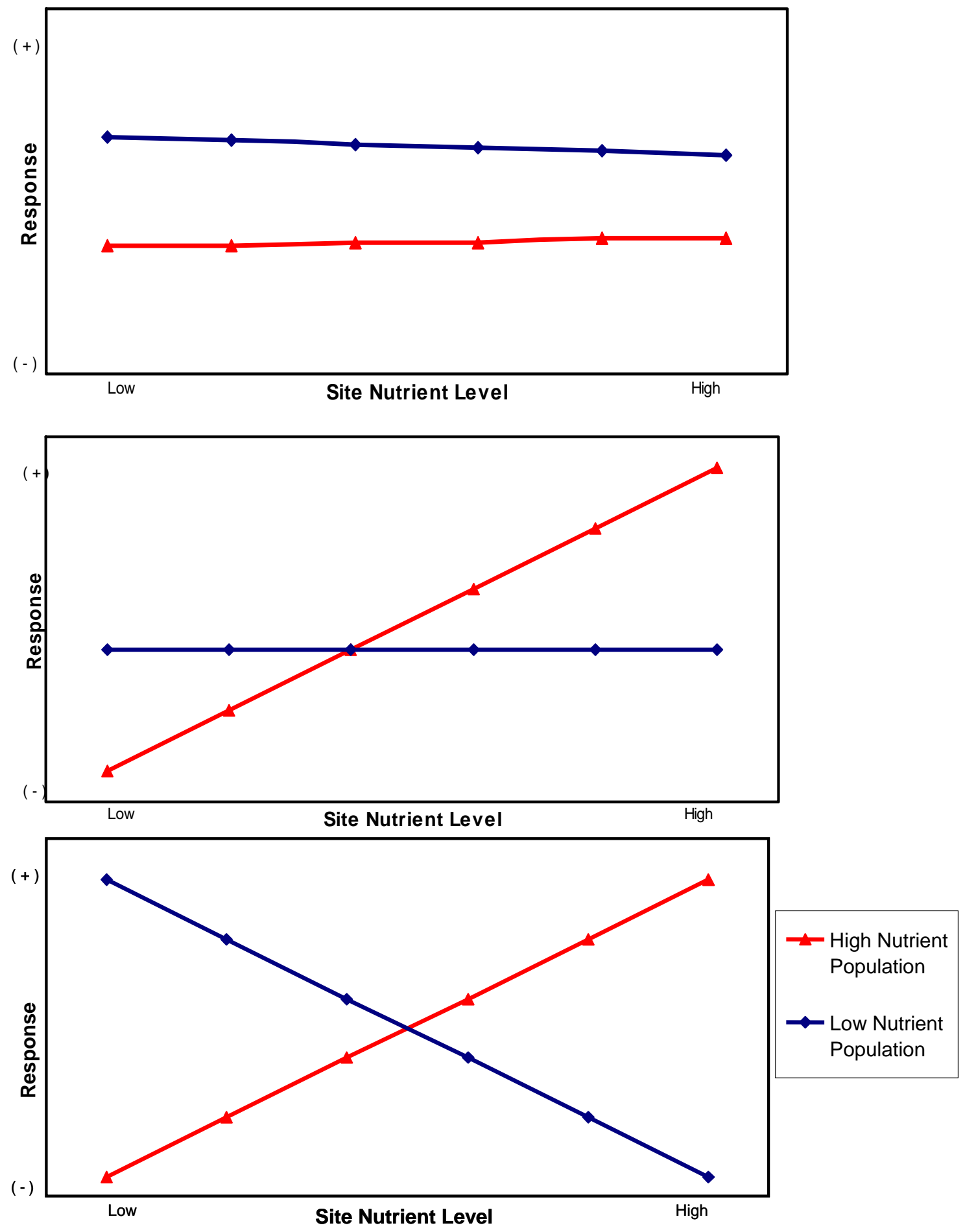
Figure 1.3: Juncus effusus L., a common wetland plant.

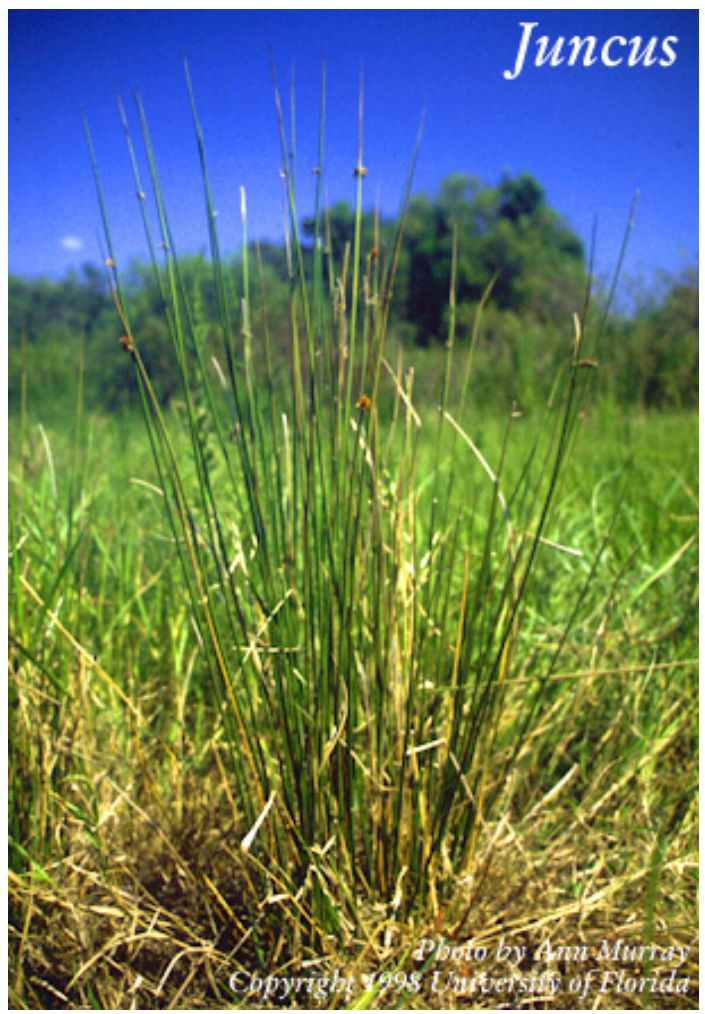




\section{REFERENCES}

Antonovics, A.E. 1971. The effects of a heterogeneous environment on the genetics of natural populations. American Scientist 59:593-599.

Bazzaz, F.A. 1996. Plants In A Changing Environment. Cambridge University Press, Cambridge.

Bazzaz, F.A. and S.E. Sultan. 1987. Ecological variation and the maintenance of plant diversity. In K.M. Urbanska [ed.], Differentiation Patterns in Higher Plants, pp69-93. Academic Press, London.

Bell, D.L. and S.E. Sultan. 1999. Dynamic phenotypic plasticity for root growth in Polygonum: a comparative study. American Journal of Botany 86: 807-819.

Bennington, C.C. and J.B. McGraw. 1995. Natural selection and ecotypic differentiation in Impatiens pallida. Ecological Monograph 65: 303-323.

Bennington, C.C. and J.B. McGraw. 1996. Environmental-dependence of quantitative genetic parameters in Impatiens pallida. Evolution 50: 1083-1097.

Bernson, G.M. 1994. Modeling root architecture: Are there tradeoffs between efficiency and potential of resource acquisition? New Phytologist 127:483-493.

Bradshaw, A.D. 1965. Evolutionary significance of phenotypic plasticity in plants. Advances in Genetics 13:115-155.

Brewer, S.J. and M.D. Bertness. 1996. Disturbance and intraspecific variation in the clonal morphology of salt marsh perennials. Oikos 77:107-116.

Brewer, S.J., T. Rand, J.M. Levine, and M.D. Bertness. 1998. Biomass allocation, clonal dispersal, and competitive success in three salt marsh plants. Oikos 82: 347-353.

Caldwell, M.M. 1994. Exploiting nutrients in fertile microsites. IN M.M. Caldwell and R.W. Pearcy [eds.], Exploitation of Environmental Heterogeneity by Plants, pp 324-347. Academic press, New York, NY.

Chesapeake Bay Foundation. 2001. Chesapeake Bay Program: State of the Bay Report. Annapolis, Maryland.

Fitter, A.H. 1987. An Architectural approach to the comparative ecology of plant root systems. New Phytologist 106:61-77. 
Fitter, A.H. 1994. Architecture and biomass allocation as components of the plastic response of root systems to soil heterogeneity. IN M.M. Caldwell and R.W. Pearcy [eds.], Exploitation of environmental heterogeneity by plants, pp305-323. Academic Press, New York, NY.

Fitter, A.H. and T.R. Stickland. 1991. Architectural analysis of plant root systems.3. Studies on plants under field conditions. New Phytologist 121:243-248.

Garbutt, K. and F.A. Bazzaz. 1987. Population niche structure. Differential response of Abutilon theophrasti progeny to resource gradient. Oecologia 71:291-296.

Grime, J.P. 1994. The role of plasticity in exploiting environmental heterogeneity. IN M.M. Caldwell and R.W. Pearcy [eds.], Exploitation of environmental heterogeneity by plants, pp1-21. Academic press, New York, NY.

Lamont, B.B. and S.M. Bergl. 1991. Water relations, shoot and root architecture and phenology of three co-occurring Banksia spp: No evidence for niche differentiation in the pattern of water use. Okios 60:291-298.

Levine, J.M., J.S. Brewer, and M.D. Bertness. 1998. Nutrients, competition and plant zonation in New England salt marsh. Journal of Ecology 86: 285-292.

Lortie, C.J. and L.W. Aarssen. 1996. The specialization hypothesis for phenotypic plasticity in plants. International Journal for Plant Science 157: 484-487.

Lynch, J.P. 1995. Root architecture and plant productivity. Plant Physiology 109:7-13.

Mitsch, W.J. and R.F. Wilson. 1996. Improving the success of wetland creation and restoration with know-how, time and self design. Ecological Applications 6:77-83.

Nault, A. and D. Gagnon. 1988. Seasonal biomass and nutrient allocation patterns in wild leek (Allium tricoccum Ait.), a spring geophyte. Bulletin of the Torrey Botanical Club 115: 45-54.

Nielsen, K.L., J.P. Lynch and H.N. Weiss. 1997. Fractal geometry of bean root systems: Correlations between spatial and fractal dimension. American Journal of Botany 84:26-33.

Parrish, J.A.D. and F.A. Bazzaz. 1976. Underground niche separation in successional plants. Ecology 57:1281-1288.

Pigliucci, M. 2001. Phenotypic Plasticity: Beyond Nature and Nurture. John Hopkins University Press. Baltimore, Maryland.

Richter, B.D., D.P. Braun, M.A. Mendelson, and L.L. Master. 1997. Threats to imperiled freshwater fauna. Conservation Biology 11:1081-1093. 
Ryser, P. 1998. Intra- and interspecific variation in root length, root turnover and the underlying parameters. In H. Lambers, H. Poorter and M.M.I. Van Vuuren [eds], Variation in Plant Growth, Physiological Mechanisms and Ecological Consequences, pp 441-465. Blackhuys Publishers, Leiden, Neterlands.

Ryser, P. and L. Eek. 2000. Consequences of phenotypic plasticity vs. interspecific differences in leaf and root traits for acquisition of aboveground and belowground resources. American Journal of Botany 87:402-411.

Sultan, S.E. and F.A. Bazzaz. 1993. Phenotypic plasticity in Polygonum persicaria. II. Norms of reaction to soil moisture and the maintenance of genetic diversity. Evolution 47:1032-1049.

Taylor, D.R. and L.W. Aarssen. 1988. An interpretation of phenotypic plasticity in Argopyron repend (graminae). American Journal of Botany 75:401-413.

Turner, A.M., J.C. Trexler, C.F. Jordan, S.J. Slack, P. Geddes, J.H. Chick, amd W.F. Loftus. 1999. Targeting ecosystem features for conservation: Standing crops in the Florida everglades. Conservation Biology 13:989-911.

Via, S, R. Gomulkiewicz, G. De Jong, S.M. Schlicting, and P.H.Van Tienderen. 1995. Adaptive phenotypic plasticity: consensus and controversy. Trends in Ecology and Evolution 10:212-217.

Via, S. 1994a. Evolution of phenotypic plasticity: What do we really know?. In L.A. Real [ed], Ecological Genetics, 35-57. Princeton University Press, Princeton, New Jersey.

Via, S. 1994b. Population structure and local adaptation in a clonal herbivore. In L.A. Real [ed], Ecological Genetics, 58-85. Princeton University Press, Princeton, New Jersey.

Weiher, E. and P.A. Keddy. 1995. The assembly of experimental wetland plant communities. Oikos 73:323-335.

West-Eberhard, M.J. 1989. Phenotypic Plasticity and the origins of diversity. Annual Review of Ecology and Systemmatics 20:249-278. 
CHAPTER 2

IMPACT OF SITE ELECATION AND NITROGEN LEVEL ON GROWTH IN JUNCUS EFFUSUS L. POPULATIONS 


\section{INTRODUCTION}

Plants are faced with multiple obstacles to growth within their habitat. Variation in light, water, predation pressures, temperature and nutrients can greatly influence plant development and growth strategies. Nutrients in the environment can act as the primary selective force on plant populations. Lack of essential nutrients can result in stunted, physiologically immature individuals, whereas nutrient excess can result in toxicities that can produce similar growth trends. However, mechanisms have evolved that allow plants to survive in these conditions.

Genetic variation may exist within plant species that allow utilization or toleration of high levels of nutrients (Brewer and Bertness 1996; Bennington and McGraw 1996). Similarly, it has been postulated that individual plants do not have the ability to simultaneously utilize resources in a low-resource environment and rapidly respond to the same resources in high resource availability environments (Chapter 1; Figure 1.1; Garbutt and McGraw unpublished). Thus, if both high- and low-resource environments exist within a species range, a potential divergence within the fundamental niche in response to nutrient availability would be expected (Garbutt and McGraw unpublished). This model for plant growth opposes earlier models in which plants showed a lagged developmental phase (Garbutt and McGraw unpublished; Grime 1994, 1979).

Individuals originating from a low resource availability environment tend to have high resource use efficiency (RUE) and a relatively low growth rate (Nault and Gagnon 1988). This genetically-based tradeoff increases a plant's relative fitness in a low-resource environment. In high-resource availability environments, native plants tend to have high resource acquisition rates (RAR), leading to a high growth rate and potentially decreased 
RUE. Under these environmental constraints, plants are expected to have an increased relative fitness. Selection pressures upon individuals within a population will result in different phenotypic expression types depending on the nutrient level in the environment (Briggs and Walters 1984; Lortie and Aarssen 1996). Naturally, these phenotypes and their resulting characters will be strongly correlated to the nutrient status of their respective environments. It is assumed that these pressures result in a negative correlation between RAR and RUE and prevent adaptation to both environments. It is these variable responses of populations that allow for wide scale occupation and utilization of habitats (Harper 1977).

For more than a century, much research effort has been focused on the effects of nutrient limitations and excess induced toxicity on plant fitness (Mooney et al. 1987, Marschner 1995, Ernest and Brown 2001). As a result, many other external and intrinsic factors have been ignored or simplified in experimental design considerations (Hutchings et al. 2003). Elevation is a prime example of an important environmental characteristic that is often oversimplified and underrepresented in classic experimental designs used in studies of ecological genetics. Nutrient poor soils, colder temperatures, and shorter growing seasons often characterize high-elevation sites (Archibold 1995). These sites should therefore place a strong selective environmental stress upon genotypes and populations grown in these sites. However, little information is available about the effect and magnitude high-nitrogen would have on these sites and the resulting impact on indigenous genotypes.

The interactive effect of elevation on species and populations has been extensively studied over the past century (Clausen et al. 1940, Walter 1973, Chapin and Chapin 1981, Bennington and McGraw 1995, Santamaria et al. 2003). Understanding the physiological ecology of the interaction with elevation has been the primary goal of these studies, but often 
the importance of genotypic responses within a population has been omitted. These studies demonstrate the strong control that elevation has upon growth of common morphological characters (i.e. leaves, stems etc.). In addition, the environmental conditions that are characteristic of these sites (i.e. lower temperatures, shorter growing degree-days, lower nutrient quality etc.) often result in expression of phenotypes that are small and more efficient at nutrient utilization. Most species that are common at high elevations have shorter growth cycles and fast reproductive outputs (Mencuccini et al. 1995). It is reasonable to conclude that individuals from these conditions have developed adaptations to meet the need of these specific environments.

The ability for populations to respond to changes in the environment is a broad phenomenon called phenotypic plasticity. Pigliucci (2001) defined phenotypic plasticity as the property of a given genotype to produce different phenotypes in response to environmental conditions. Grime et al. (1986) provide insight to the general linkage between ecology and the significance of phenotypic plasticity. They hypothesized three primary types of plasticity in contrasting ecological scenarios. Each of these three potential routes of plasticity is controlled by a specific environmental conditioning. The first option suggested by Grime et al. (1986) is Stress-Tolerant. Here, plasticity should be expressed via reversible mechanisms, such as acclimation, and permits individuals of the population to survive the current environmental conditions. This "wait and see" strategy delays reproductive events until the stress has passed and is the physiological form of plasticity. The second form of plasticity is the Competitive strategy. In this strategy, morphological and developmental plasticity interact and provide alternate nutrient foraging mechanisms. These alternative mechanisms maximize an individual's competitive ability by redirecting growth and 
acquisition from an unfavorable to favorable resource zone (i.e. root growth into a nutrient patch or phototropism by the stem to reach a light source). The final type of plasticity is a ruderal strategy. This method is characterized by plasticity in life history and phenology. In this situation, an environmental cue triggers premature reproduction to escape stress and permits at least some reproductive fitness.

It is important to remove environmental bias to the genotype. Sultan (1987) correctly summarized Lewontin’s (1978) interpretation of need to remove this bias, "by virtue of this capacity for response (i.e. plasticity), the relation of organism to environment is no longer to be considered a "problem" that the organism has to "solve". Plants and their genetics as a whole, along with the environment, are in a continuous feedback process. Ultimately, the environment is not a problem to be solved by individuals, but rather dynamic interactions since the each strongly affect each other at the same time.

Understanding the dynamic interactions between plants and their environment is the essential and has a number of applications such as development of remediation techniques. Fertilizer and excess nutrient application is recognized as having the predominant negative impact on watersheds in the mid-Atlantic region of the United States. Poor agricultural practices, land-use changes and human wastes have resulted in roughly 331 million pounds of nitrogen reaching the Chesapeake Bay annually (Chesapeake Bay Foundation 2001). Natural biological/environmental “filters", such as forests, oysters, underwater grasses and wetlands, can be utilized to reduce the impact of nitrogen in ecosystems. Wetlands in particular hold the most promise for managing excess nutrients in aquatic systems due to recent advances in management and frequent utilization as a remediation too for increasing environmental quality. However, poor understanding of ecosystem function, rapid land-use 
changes, increasingly severe environmental degradation, and a general lack of legal control have resulted in massive loss and degradation of wetlands.

In this study, we have sought to understand the interactions between phenotypic variations and different environmental (nitrogen and elevation) regimes in wetland communities. We have used Juncus effusus L. (common rush) as a model system to investigate the impacts of limited and excess nitrogen availability on growth. The potential for $J$. effusus to reproduce sexually (via a seed) and asexually (via vegetative propagation) makes this plant an ideal candidate to examine the effects of high- and low-nutrient environments in relation to different genotypes (Bertness and Ellison 1987, Brewer et al. 1998). We hypothesize that, as a result of inherent negative correlations between resource utilization and acquisition, genotypes within populations that have become strongly adapted to their native environmental conditions (i.e. nitrogen availability or elevation) will not rapidly respond to the opposite environmental conditions while maintaining the same level of fitness. The power of this study lies in its ability to examine the interactions of both nitrogen and elevation interactions while describing the individual relationships within each population. To our knowledge, no previous studies have examined the potentially powerful role of elevation as a selective pressure on the wetland plants from the Juncaceae family. 


\section{METHODS AND MATERIALS}

\section{$\underline{\text { Plant Source }}$}

Juncus effusus L. plants were collected from two high-elevation sites (Trout Pond and Chestnut Ridge Park Pond) and two low-elevation sites (WVU Agricultural and Animal Science Farm and White Park) in Monongalia County, WV (Figure 2.1 and 2.2). Site nutrient status were identified by standard total soil carbon:nitrogen content analysis at the WVU Department of Biology: two high-nutrient sites (Animal Sciences Farm and Trout Pond) and two low-nutrient (White Park and Chestnut Ridge Park) (Figure 2.1). Tillers were collected from twenty widely spaced clumps of $J$. effusus at each site (four in all). Given the phalanx growth pattern of this species, it is reasonable to assume that each clump is the offspring of a single seed and hence each tiller represents a single genotype. All plants were then vegetativly propagated through a hydroponics technique using 0.25 strength Johnson's stock nutrient solution (Johnson et al. 1957; Figure 2.3).

\section{Experimental Set-up}

In this experiment, sixteen clones of each respective genotype from each site were produced (764 plants total). In June 2001, clones were reciprocally transplanted back into a field setting with which each site receiving four clones of each of the forty potential genotypes (McGraw 1987). Once planted, the clones grower until completion of the field experiment in mid November 2001. Total number of tillers, tallest tiller length, and date of first reproductive tiller were censused twice monthly. A surrogate for tiller area was calculated by multiplying tiller number by tiller height.

\section{Sample Preparation}

Harvested plant material was placed into individually label paper bags that were 
then air dried at $70^{0} \mathrm{C}$ in a mechanical convection oven. Each sample was then weighed for total biomass and processed using a UDY Cyclone Sample Mill (Fort Collins, CO) with a 20mm filter screen and underwent total Carbon-Nitrogen analysis using the Carlo Erba CHNS model NA 1500 Analyzer (Carlo Erba, Milan, Italy) using a Acetanilide standard.

$\underline{\text { Data Analysis }}$

Data collected from this experiment were subjected to two separate analyses. The first examines population level responses of $J$. effusus to differing nitrogen availability. The second analysis compares ecotypic differences in growth based on variations in nutrient and elevation. Growth rates were calculated to provide a more detailed understanding of changes that had occurred within the field setting. Absolute growth rates (AGR) were calculated to show changes in growth over time and are calculated as follows:

$$
\text { Absolute Growth Rate }=\frac{\left(x_{2}-x_{1}\right)}{\left(t_{1}-t_{2}\right)}
$$

Where $\mathrm{x}$ is the size of a plant component at time $\mathrm{t}$ (Demchik and Garbutt 1999; McGraw and Garbutt 1990). Relative growth rate (RGR) implies the changes in the efficiency of J. effusus within nitrogen or elevation factor. This index is calculated by the following equation:

$$
\text { Relative Growth Rate }=\frac{\left(\ln x_{2}-\ln x_{1}\right)}{\left(t_{1}-t_{2}\right)}
$$

where $x$ is size of plant component at time $t$ (Fisher 1920, Bazzaz and Harper 1977). A repeated measures analysis of variance was preformed on time related data to determine significant differences in the growth of $J$. effusus as a response to differing environmental conditions. All statistical analyses were conducted using JMP 3.0.1 (SAS Institute, Cary, NC). 
Figure 2.1: Site map and characteristics of research plots located in Monongalia County, West Virginia. Low-nitrogen sites included Chestnut Ridge Park and White Park. Highnitrogen sites were Trout Pond and WVU Agricultural Farm.

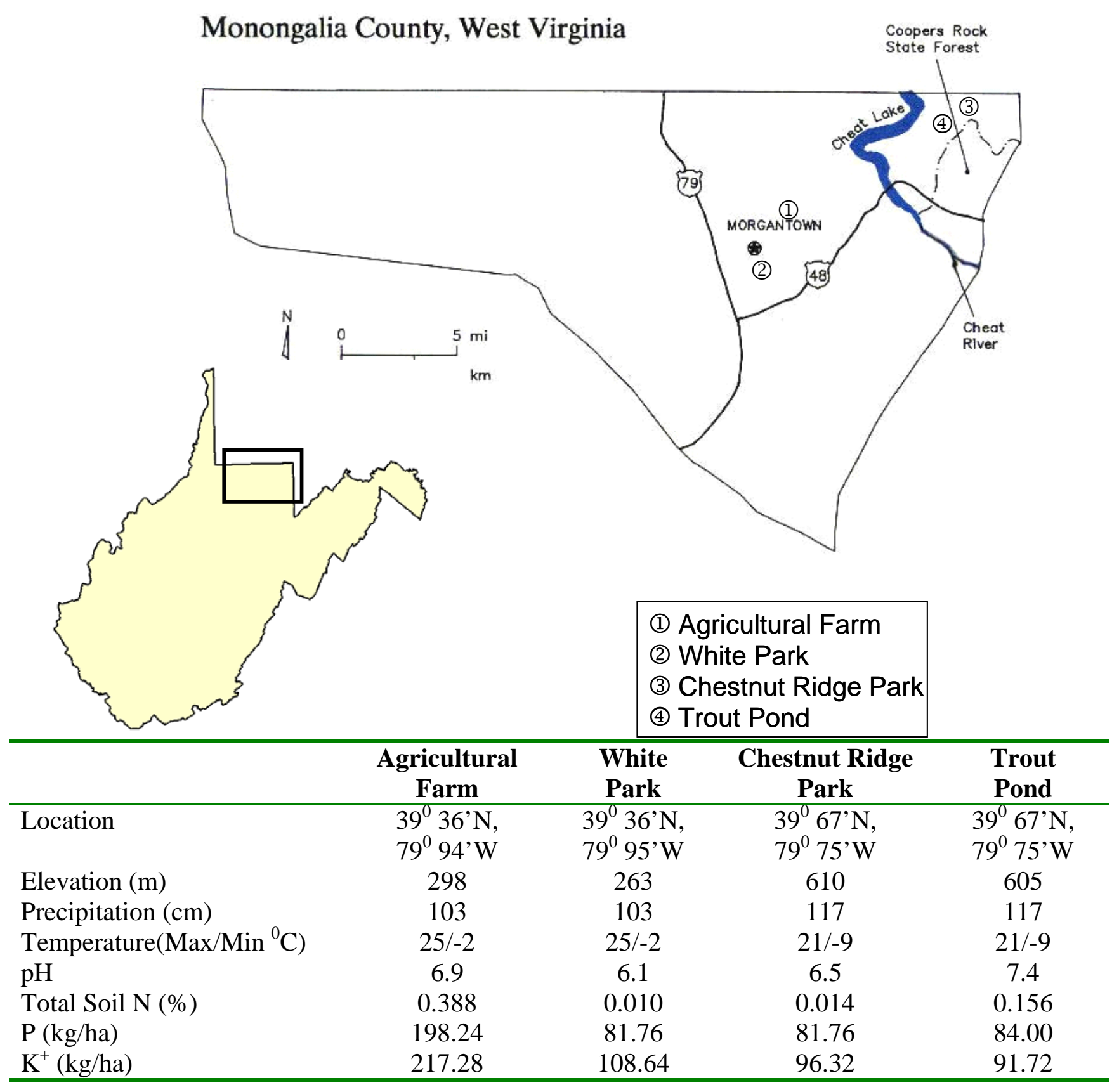


Figure 2.2A. Site locations of reciprocal transplant: Agricultural Farm (top) and Trout Pond (bottom).
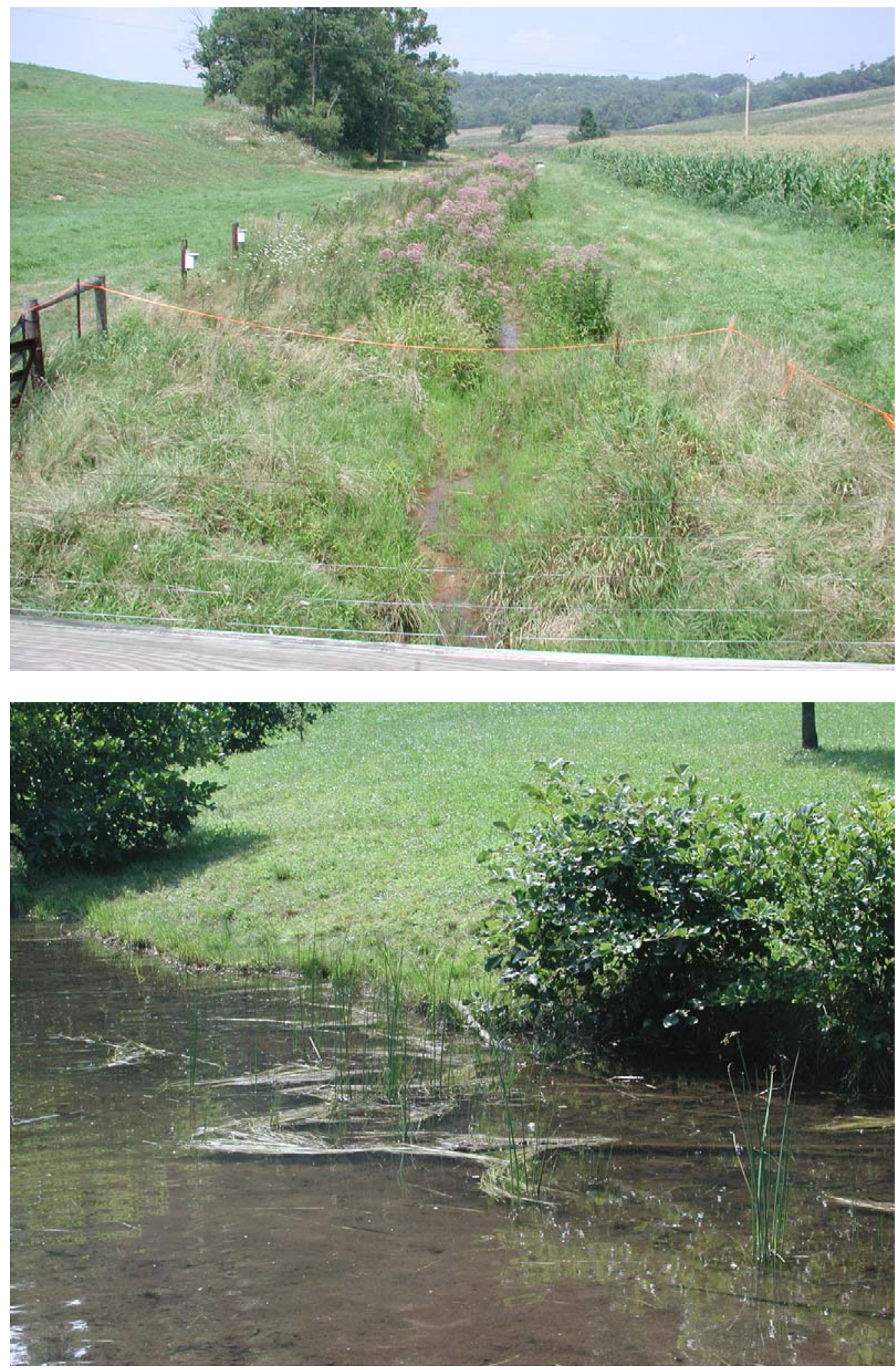
Figure 2.2B. Site locations of reciprocal transplant: White Park (top) and Chestnut Ridge Park (bottom).
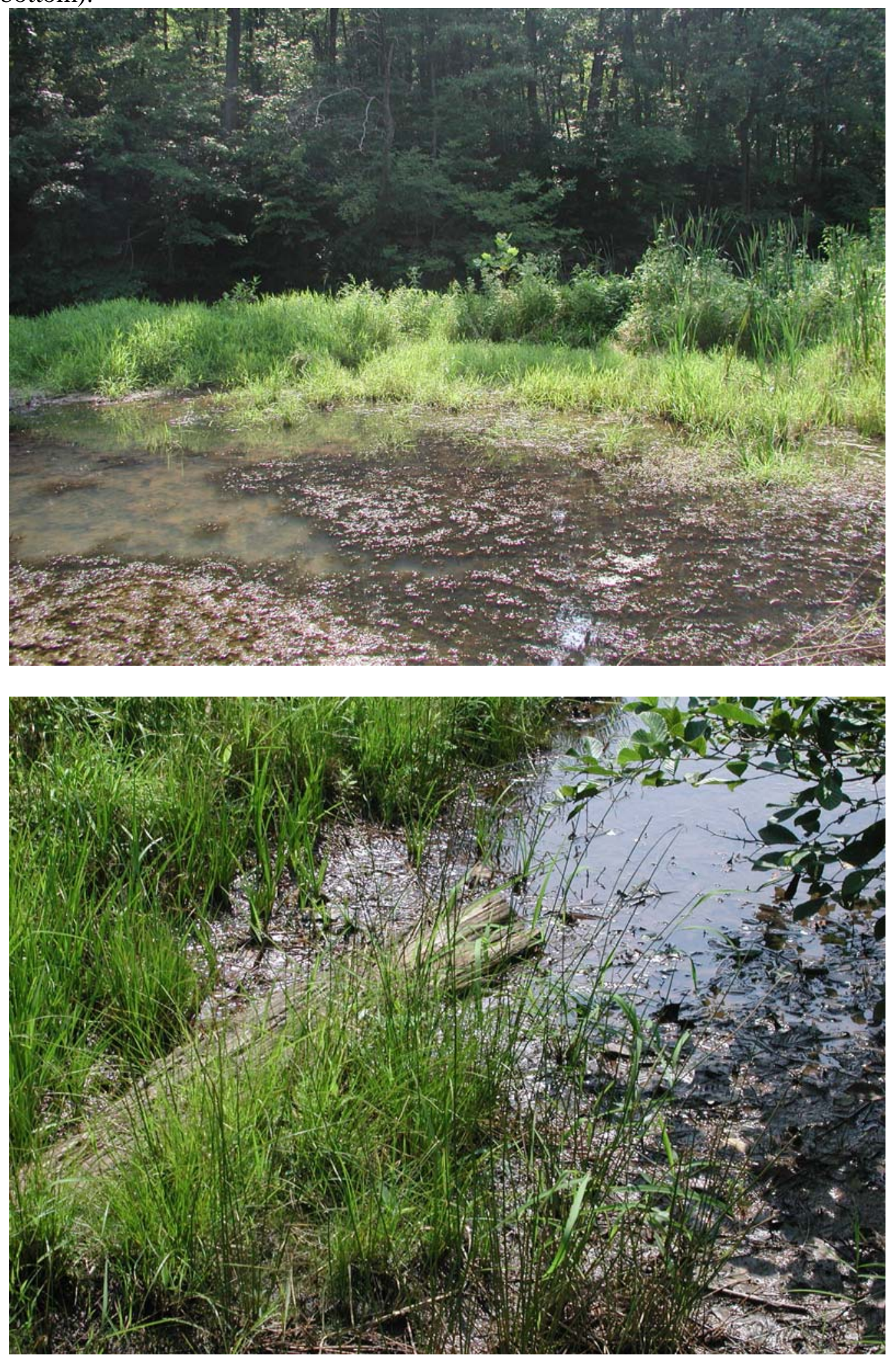
Figure 2.3: Vegetative propagation of J. effusus inside an environmental growth chamber.

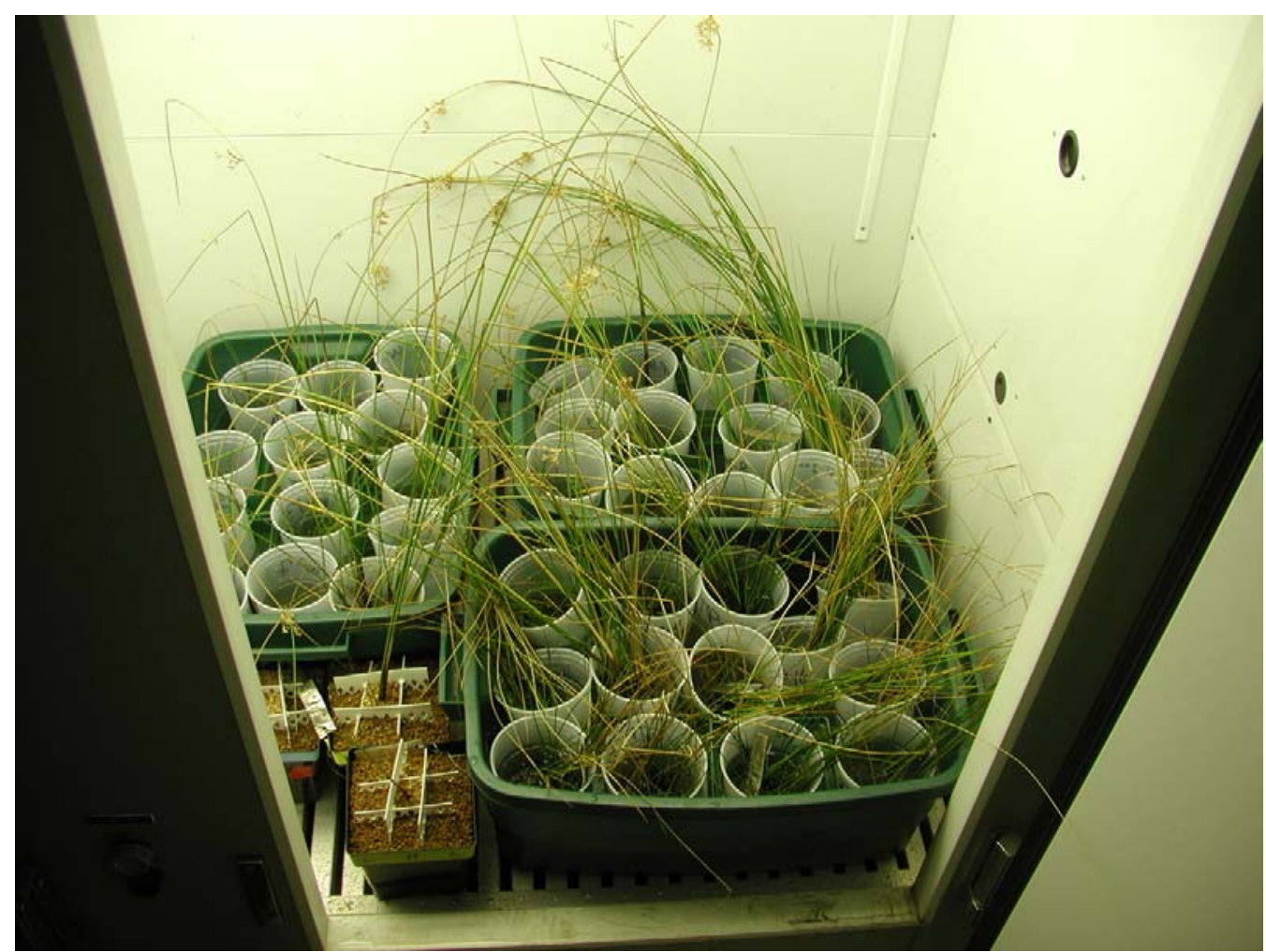




\section{RESULTS}

\section{Analysis I: Differential Genotypic and Population Responses}

\section{$\underline{\text { Tiller Area }}$}

Across all environments, the size (tiller area) of plants changed over time (Table 2.1; Julian date $\mathrm{p}<0.0001)$. Individual populations also showed variations between one another (Figure 2.4; Population $\mathrm{p}<0.0001$ ) with Chestnut Ridge having the highest mean photosynthetic area and White Park the least. However, there were also population variations over time (Figure 2.5; Population*date $\mathrm{p}=0.0218$ ). Here, White Park and Agricultural Farm populations more rapidly produced tiller area and therefore diverged from the Chestnut Ridge and Trout Pond populations by final harvest. In addition, there were significant increases in tiller area with respect to time with the shape of the growth curves of the individual treatments significantly differ with respect to population (Transplant Site Nitrogen Level *date p<0.0001, Figure 2.5 Date* Transplant Site Nitrogen Level *population $\mathrm{p}=0.0002)$.

Genotypic analysis shows both generalist and specialist responses of genotypes (Figure 2.6; Genotype[population] p=0.0005). Genotypes originating from the Agricultural Farm and Chestnut Ridge sites showed little variation among sites or nitrogen treatments. With the exception of genotype WP-10, genotypes from the White Park were also generalists as can be seen by the relatively flat slope within the reaction of norm. Genotype WP-10's divergent shape of its response suggests that it is a specialist within the Agricultural Farm site environmental conditions. Three genotypes (TP-1, TP-2 and TP-3) from the Trout Pond site showed a specialist response to specific environments. These genotypes tended to show a more positive response to high-nitrogen environments. In addition, genotypes responded 
differently with respect to nutrient treatment over time (Date* Transplant Site Nitrogen Level *genotype[population] p=0.0001).

Genotype by environment interactions analysis (Garbutt and Zangerl 1986) (magnitude and equability plot) is shown in Figure 2.7. Chestnut Ridge genotypes had an above average equability (i.e. a flat slope) whereas White Park genotypes had a below average magnitude which supports the hypothesis of nutrient efficiency limiting their ability to respond to higher nutrient availability. High-nutrient populations were positively correlated between magnitude of response and equability, implying a possible tradeoff between equability and magnitude response.

Tiller area growth rates (AGR and RGR) were analyzed with the initial tiller number census data as a covariate (Table 2.2). Tiller area growth rate (AGR) and growth efficiency (RGR) differed over time with respect to transplant site nitrogen level (Measurement Interval* Transplant Site Nitrogen Level $\mathrm{p}=0.0161$ and $\mathrm{p}=0.0494$; Figures 2.8A-D respectively). Plants from low-nutrient sites had higher tiller area growth rates early in the study, but were surpassed later in the growing season by plants grown in high-nitrogen sites (Figure 2.9). Low-nutrient transplant sites were typically less efficient at producing tiller area over time compared to high-nutrient transplant sites (Figure 2.10). Tiller area growth rate significantly differed between genotypes grown in each site (Genotype[population] $\mathrm{p}=0.0438)$.

\section{Biomass and Composition}

The Chestnut Ridge population (Figure 2.11) produced the highest mean dry weight (Table 2.3; Population $\mathrm{p}=0.0009$ ). Transplant site also had a significant effect on biomass (Transplant Site Nitrogen Level $\mathrm{p}=0.0270$ ) with more biomass produced in the Agricultural 
Farm and the White Park sites (Figure 2.12). A strong genotype effect is also present on the overall mean biomass (Genotype[population] $\mathrm{p}<0.0001$ ). The nutrient content of the biomass shows no significant differences in accumulation of carbon within the tiller tissue. Figure 2.13 (Table 2.3) illustrates the unexpected increase in nitrogen concentration the lownitrogen treatment site of White Park (Transplant Site Nitrogen Level $p=0.0003$ ). The carbon:nitrogen ratios were significantly different within populations (Table 2.3; Population $\mathrm{p}=0.0429$ ). Here the low-nitrogen populations produced higher tissue quality (C:N ratio) compared to high-nitrogen counterparts (Figure 2.14). A significant transplant site treatment effect occurred in tissue concentration (Transplant Site Nitrogen Level $\mathrm{p}<0.0001$ ). In this case, mean C:N ratio was highest at Chestnut Ridge sites and lowest in White Park (Figure 2.15). Finally, there was a significant interaction on $\mathrm{C}: \mathrm{N}$ ratios from population grown in opposing transplant nitrogen levels (Transplant Site Nitrogen Level *Population p=0.0329). Populations originating from high-nitrogen sites generally produced a higher C:N within high-nitrogen sites (Figure 2.16). 
Table 2.1: Tiller area $\left(\mathrm{cm}^{2}\right)$ repeated measures analysis of variance. Type III mean squares are reported $(*=\mathrm{p}<0.05)$.

\begin{tabular}{llc}
\hline \hline Source & DF & Tiller Area \\
\hline Julian Date (D) & 1 & $4575689.3^{*}$ \\
Transplant Site Nitrogen Level (T) & 3 & 468511.8 \\
Population (P) & 3 & $1897880.9 *$ \\
$\mathrm{D}^{*} \mathrm{~T}$ & 3 & $2370203.8^{*}$ \\
$\mathrm{D}^{*} \mathrm{P}$ & 3 & $744087.7^{*}$ \\
$\mathrm{D}^{*} \mathrm{~T}^{*} \mathrm{P}$ & 9 & $2482503.3^{*}$ \\
$\mathrm{Genotype} \#[$ Population] $(\mathrm{G}[\mathrm{P}])$ & 4 & $1535519.1^{*}$ \\
$\mathrm{D}^{*}(\mathrm{G}[\mathrm{P}])$ & 4 & $766960.2^{*}$ \\
$\mathrm{~T}^{*}(\mathrm{G}[\mathrm{P}])$ & 12 & 718647.7 \\
$\mathrm{D}^{*} \mathrm{~T}(\mathrm{G}[\mathrm{P}])$ & 12 & $2969924.9 *$ \\
\hline
\end{tabular}

Table 2.2: Analysis of variance of tiller area absolute $\left(\mathrm{cm}^{2} /\right.$ day) and relative $\left(\mathrm{cm}^{2} / \mathrm{cm}^{2} /\right.$ day) growth rates with tiller number as a covariate. Type III mean squares are reported $(*=\mathrm{p}<0.05)$.

\begin{tabular}{lccc}
\hline \hline Source & DF & $\begin{array}{c}\text { Absolute } \\
\text { Growth Rate }\end{array}$ & $\begin{array}{c}\text { Relative } \\
\text { Growth Rate }\end{array}$ \\
\hline Tiller Number Covariate & 1 & 914.1809 & 0.029462 \\
Measurement Interval (M) & 1 & 471.8284 & 0.000522 \\
Transplant Site Nitrogen Level (T) & 3 & 172.3637 & 0.002811 \\
Population (P) & 3 & 231.0374 & 0.003430 \\
$\mathrm{M}^{*} \mathrm{~T}$ & 3 & $1689.9675 *$ & $0.010355^{*}$ \\
$\mathrm{M}^{*} \mathrm{P}$ & 3 & 425.9061 & 0.004501 \\
$\mathrm{~T}^{*} \mathrm{P}$ & 9 & 918.2840 & 0.005635 \\
$\mathrm{M}^{*} \mathrm{~T} * \mathrm{P}$ & 9 & 868.8071 & 0.003140 \\
$\mathrm{Genotype} \#[$ Population] (G[P]) & 4 & 543.3155 & $0.012955^{*}$ \\
$\mathrm{M}^{*}(\mathrm{G}[\mathrm{P}])$ & 4 & 367.8862 & 0.007702 \\
$\mathrm{~T}^{*}(\mathrm{G}[\mathrm{P}])$ & 12 & 530.3418 & 0.007023 \\
$\mathrm{M}^{*} \mathrm{~T}(\mathrm{G}[\mathrm{P}])$ & 12 & 1055.7236 & 0.008273 \\
\hline
\end{tabular}


Table 2.3: Analysis of variance of final tiller biomass (g), nitrogen concentration (mg/g N) and carbon:nitrogen ratio. Type III mean squares are reported $(*=p<0.05)$.

\begin{tabular}{lcccc}
\hline \hline Source & DF & $\begin{array}{c}\text { Tiller } \\
\text { Biomass }\end{array}$ & $\begin{array}{c}\text { Nitrogen } \\
\text { Concentration }\end{array}$ & $\begin{array}{c}\text { C:N } \\
\text { Ratio }\end{array}$ \\
\hline Transplant Site Nitrogen Level (T) & 3 & $9.365^{*}$ & $479.745^{*}$ & $14296.256^{*}$ \\
Population (P) & 3 & $16.964^{*}$ & 34.247 & $4815.834^{*}$ \\
$\mathrm{~T}^{*} \mathrm{P}$ & 9 & 3.138 & 75.521 & $10811.641^{*}$ \\
Genotype \#[Population] (G[P]) & 4 & $28.122^{*}$ & 47.799 & 4454.948 \\
$\mathrm{~T}^{*}(\mathrm{G}[\mathrm{P}])$ & 12 & 5.979 & 175.331 & 8739.231 \\
\hline
\end{tabular}


Figure 2.4: Mean tiller area $\left(\mathrm{cm}^{2}\right)$ of populations. AG= Agricultural Farm, $\mathrm{CR}=$ Chestnut Ridge, $\mathrm{TP}=$ Trout Pond and $\mathrm{WP}=$ White Park.

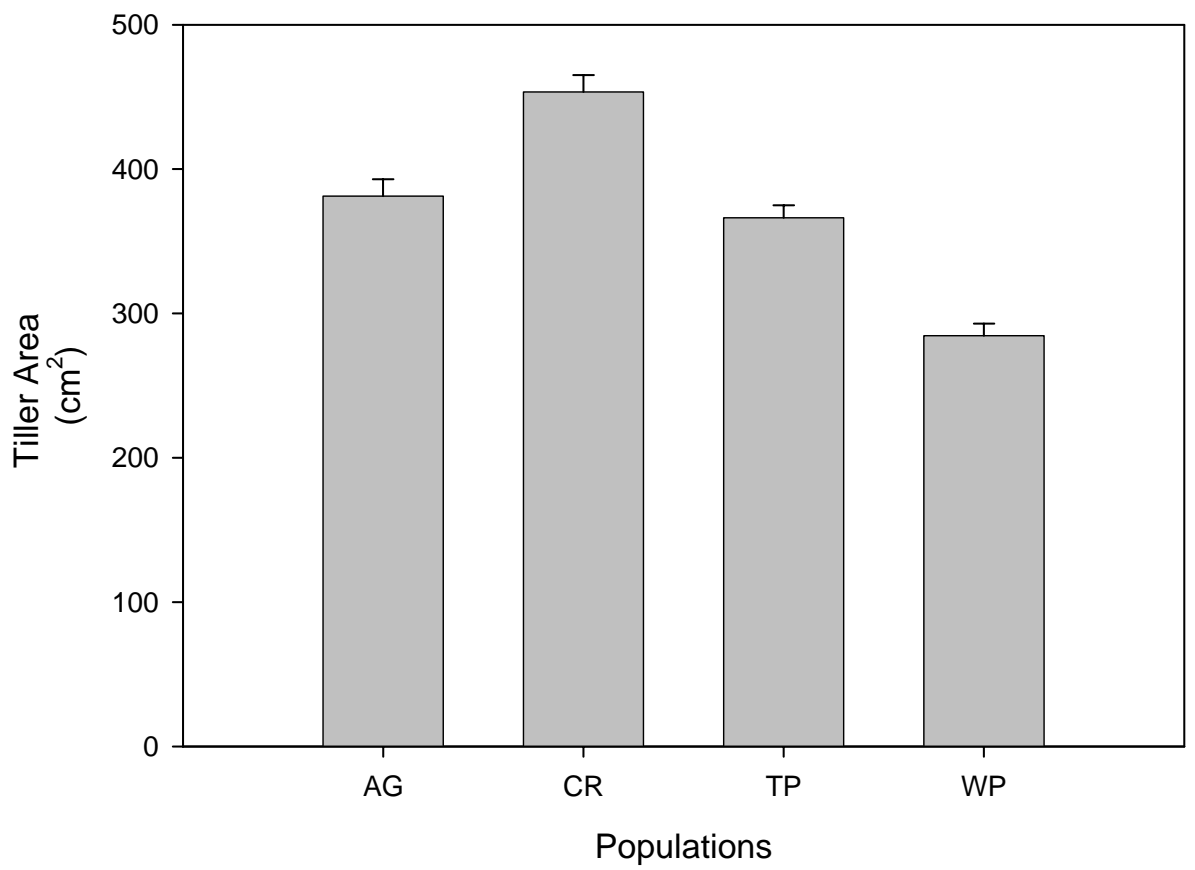

Figure 2.5: Mean productivity of tiller area $\left(\mathrm{cm}^{2}\right)$ of populations over time.

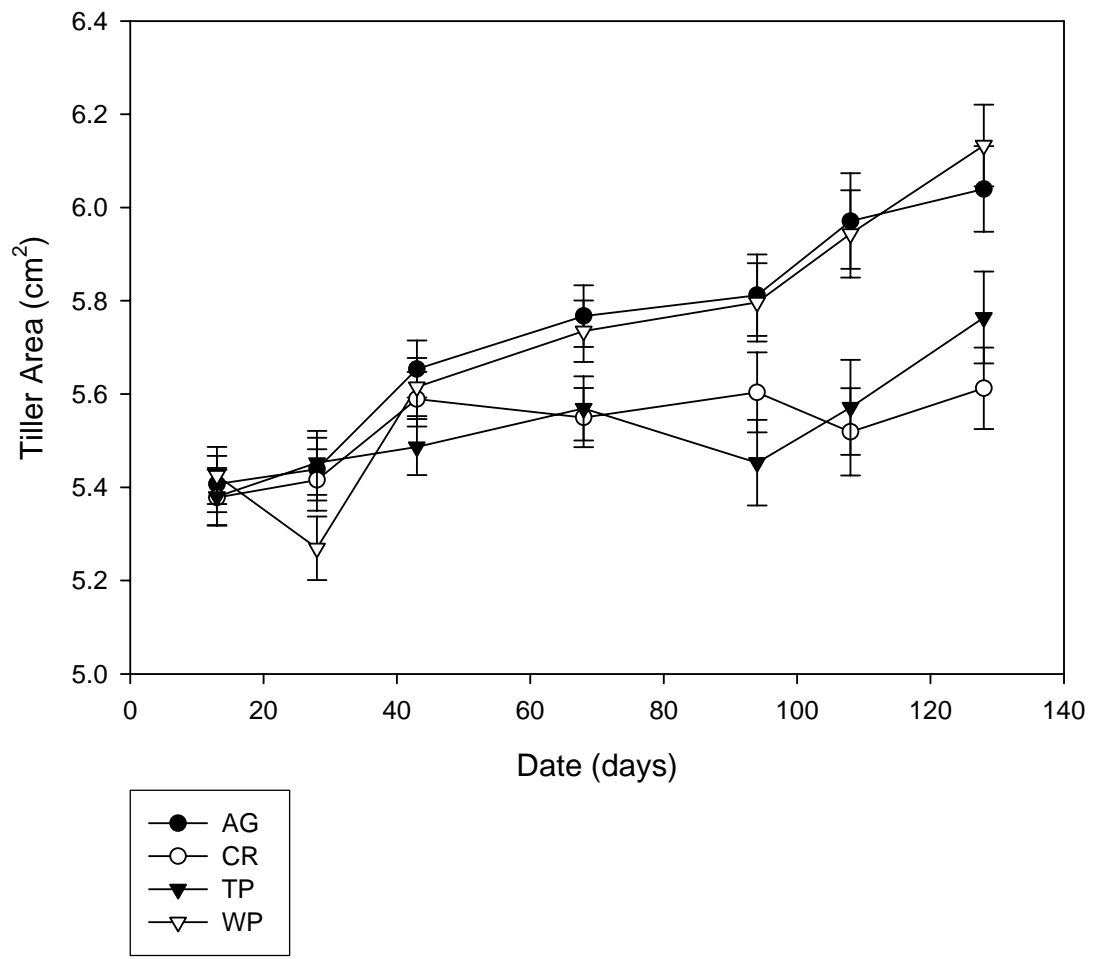


Figure 2.6: Mean tiller area absolute growth rate reaction of norms for individual genotypes grown within each site.
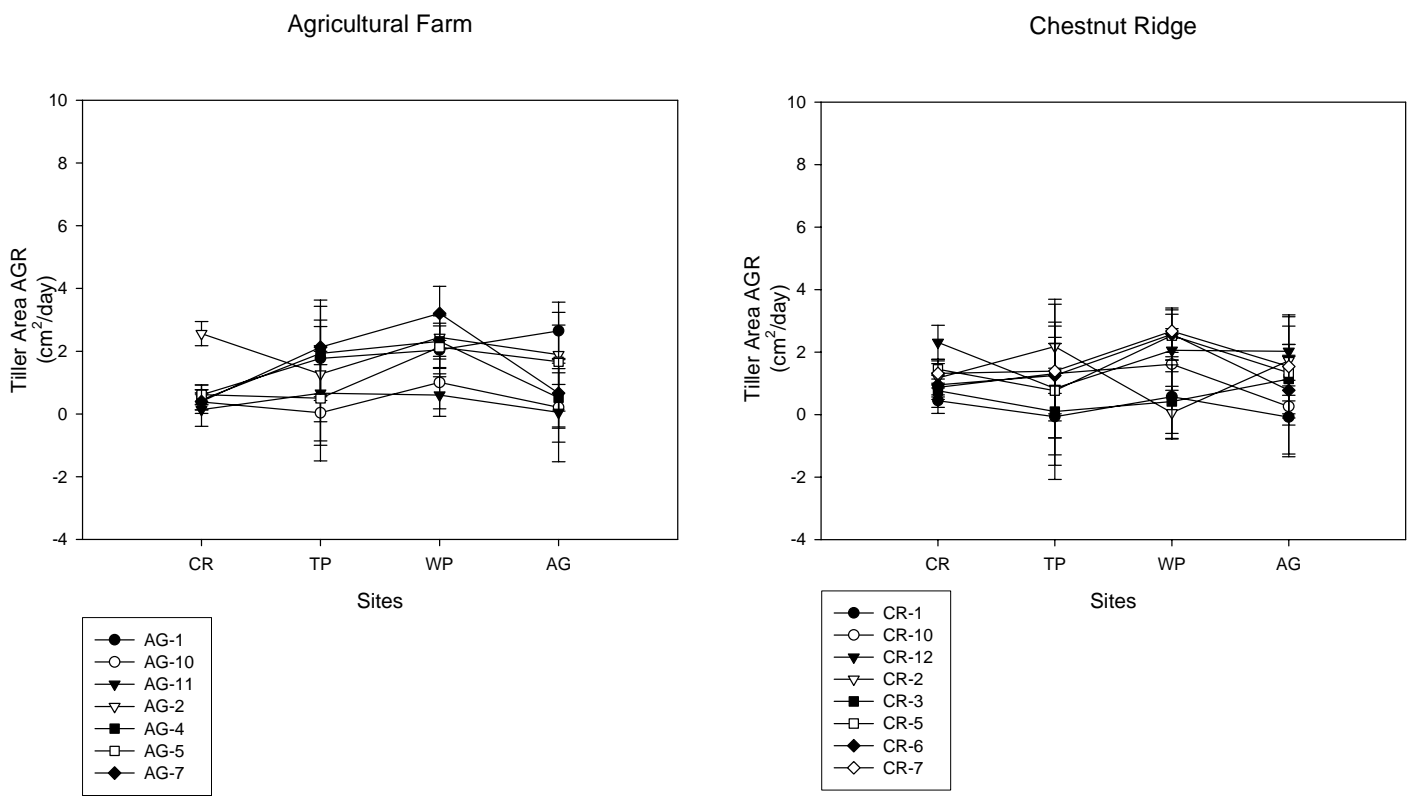

Trout Pond
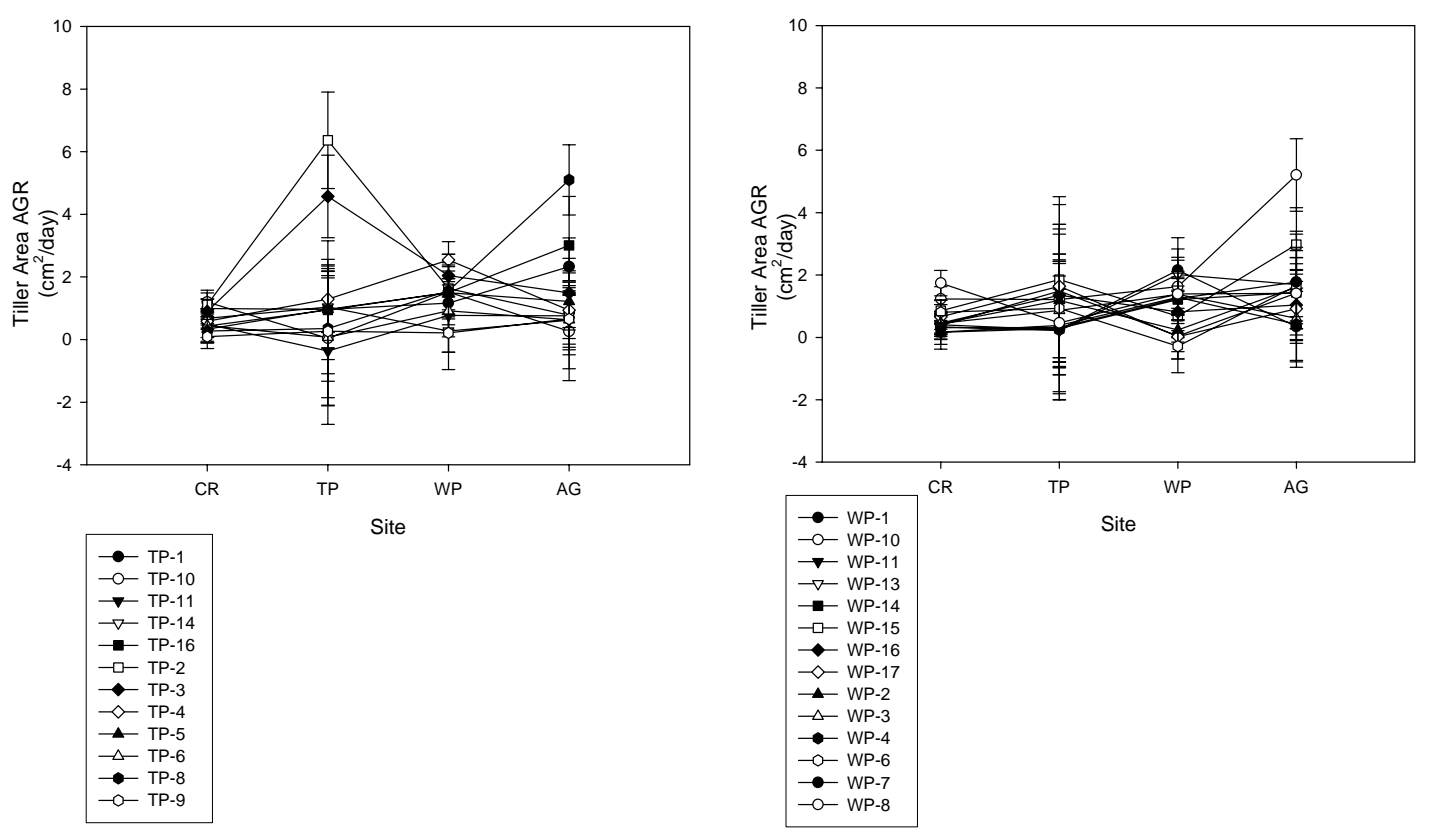
Figure 2.7: Genotype by environment (magnitude and equability) plot for biomass of genotypes from four field sites. $\mathbf{O}=$ Agricultural Farm $\mathrm{O}=$ Chestnut Ridge $\boldsymbol{\nabla}=$ Trout Pond $\nabla=$ White Park.

\section{$\mathrm{G} \times \mathrm{E}$ Analysis}

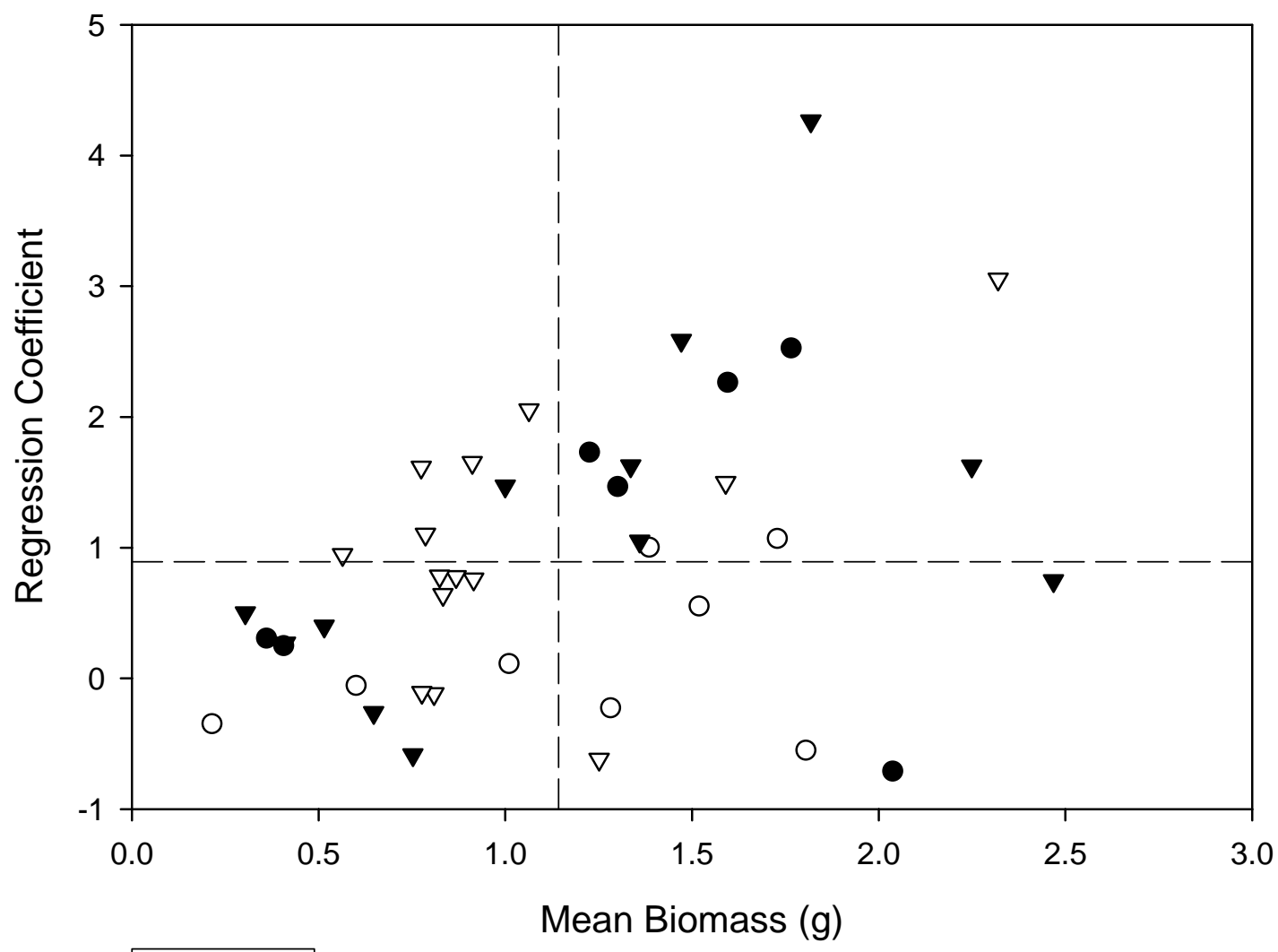

$$
\begin{array}{ll}
- & \text { AG } \\
\text { O } & \text { CR } \\
\nabla & \text { TP } \\
\nabla & \text { WP }
\end{array}
$$


Figure 2.8A-D: Tiller area relative growth rate $\left(\mathrm{cm}^{2} / \mathrm{cm}^{2} /\right.$ day) over the duration of the experiment of origin populations grown within each site. $\mathbf{O}=$ Agricultural Farm $\mathrm{O}=$ Chestnut Ridge $\boldsymbol{\nabla}=$ Trout Pond $\nabla=$ White Park.

A.

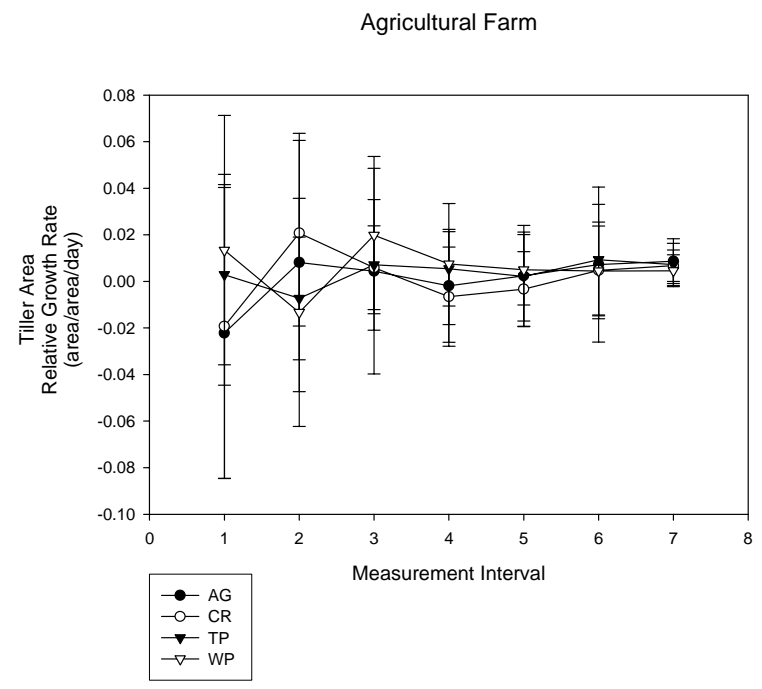

C.

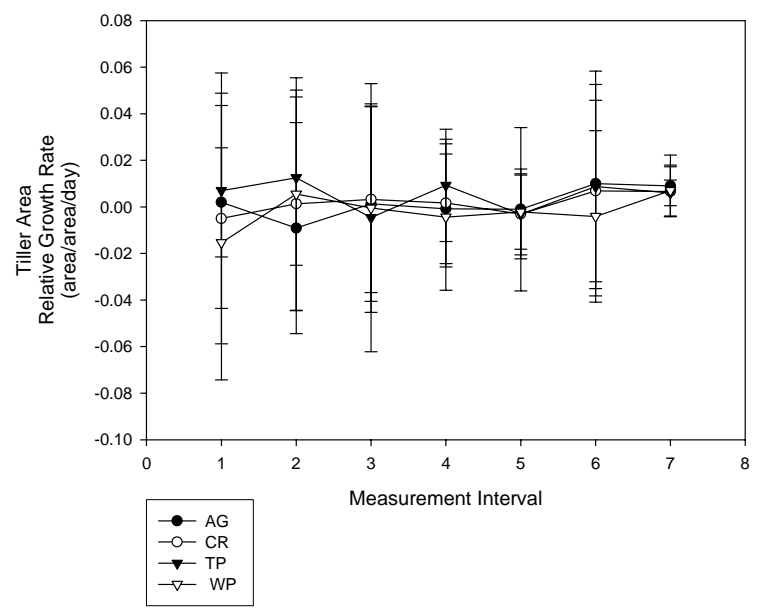

B.

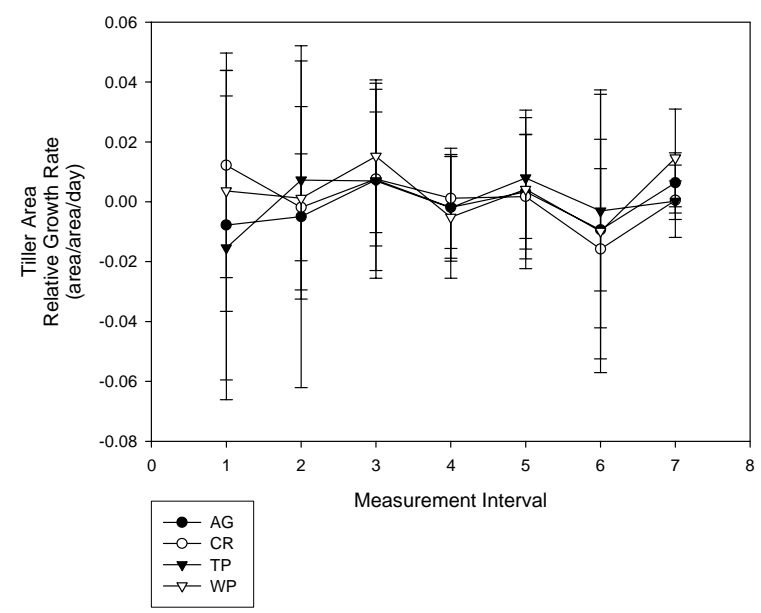

D.

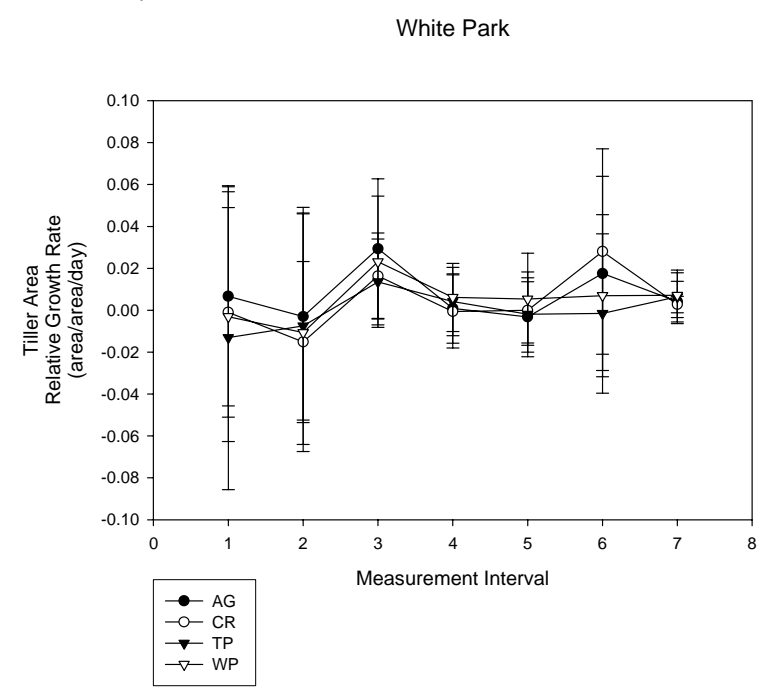


Figure 2.9: Tiller area absolute growth rate $\left(\mathrm{cm}^{2} /\right.$ day) of tillers grown in differing nitrogen transplant sites over the duration of the experiment.

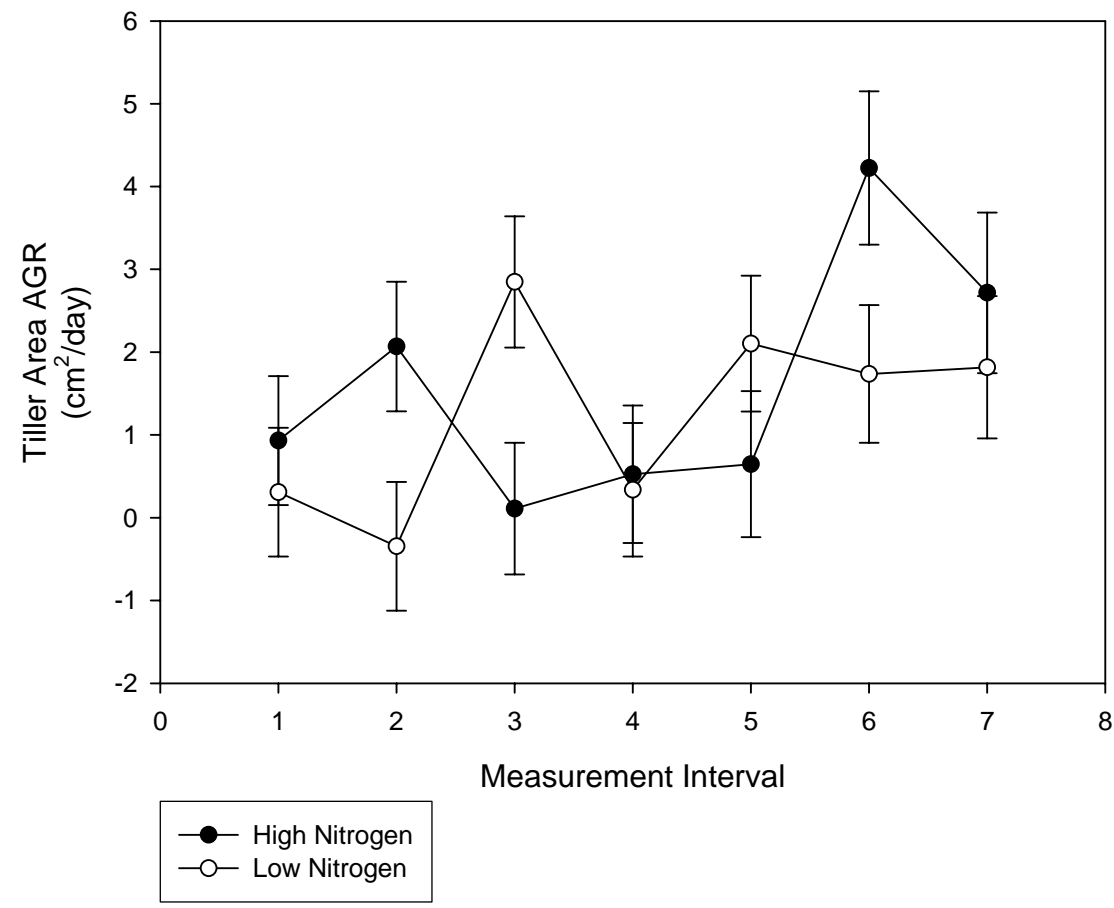

Figure 2.10: Tiller area relative growth rate $\left(\mathrm{cm}^{2} / \mathrm{cm}^{2} /\right.$ day) of tillers grown in differing nitrogen transplant sites over the duration of the experiment.

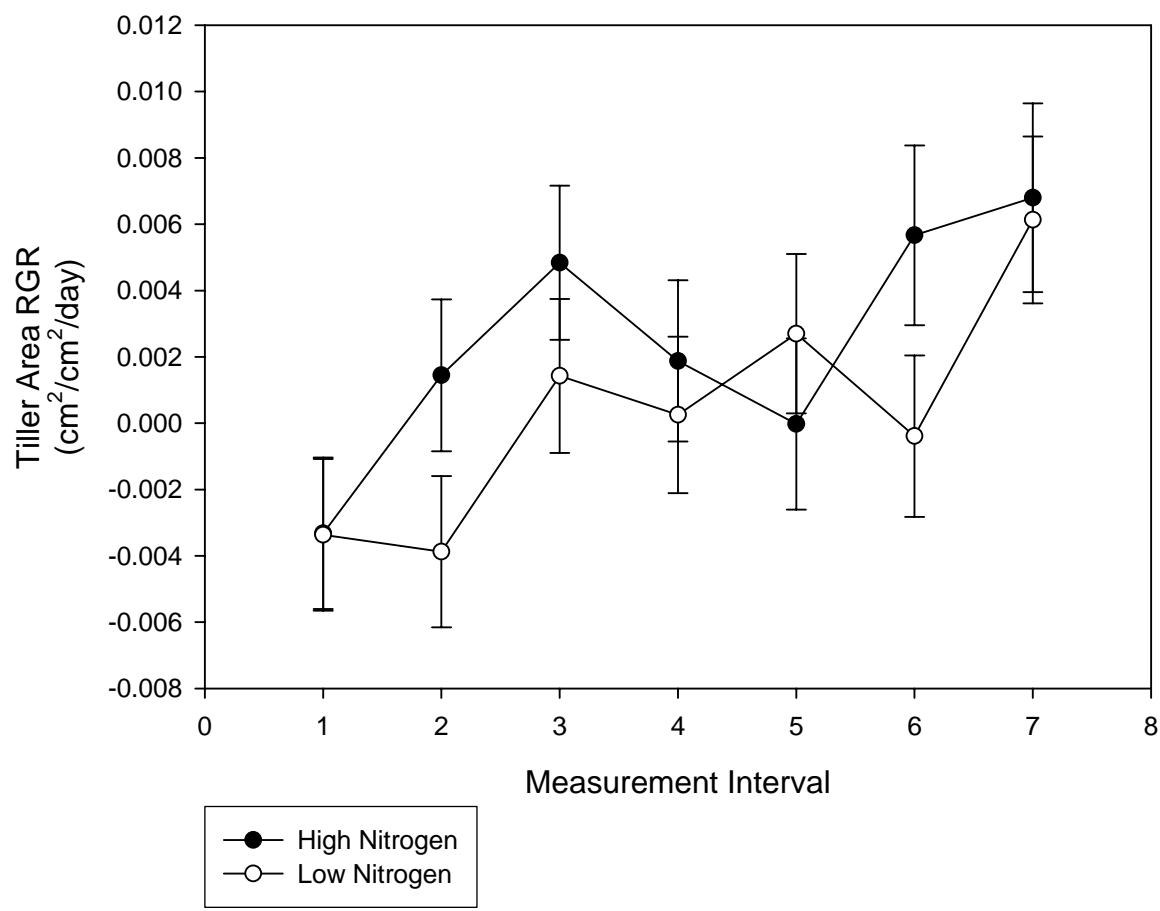


Figure 2.11: Final dry weight $(\mathrm{g})$ of tillers by origin field site. $A G=$ Agricultural Farm, $C R=$ Chestnut Ridge, $\mathrm{TP}=$ Trout Pond and $\mathrm{WP}=$ White Park.

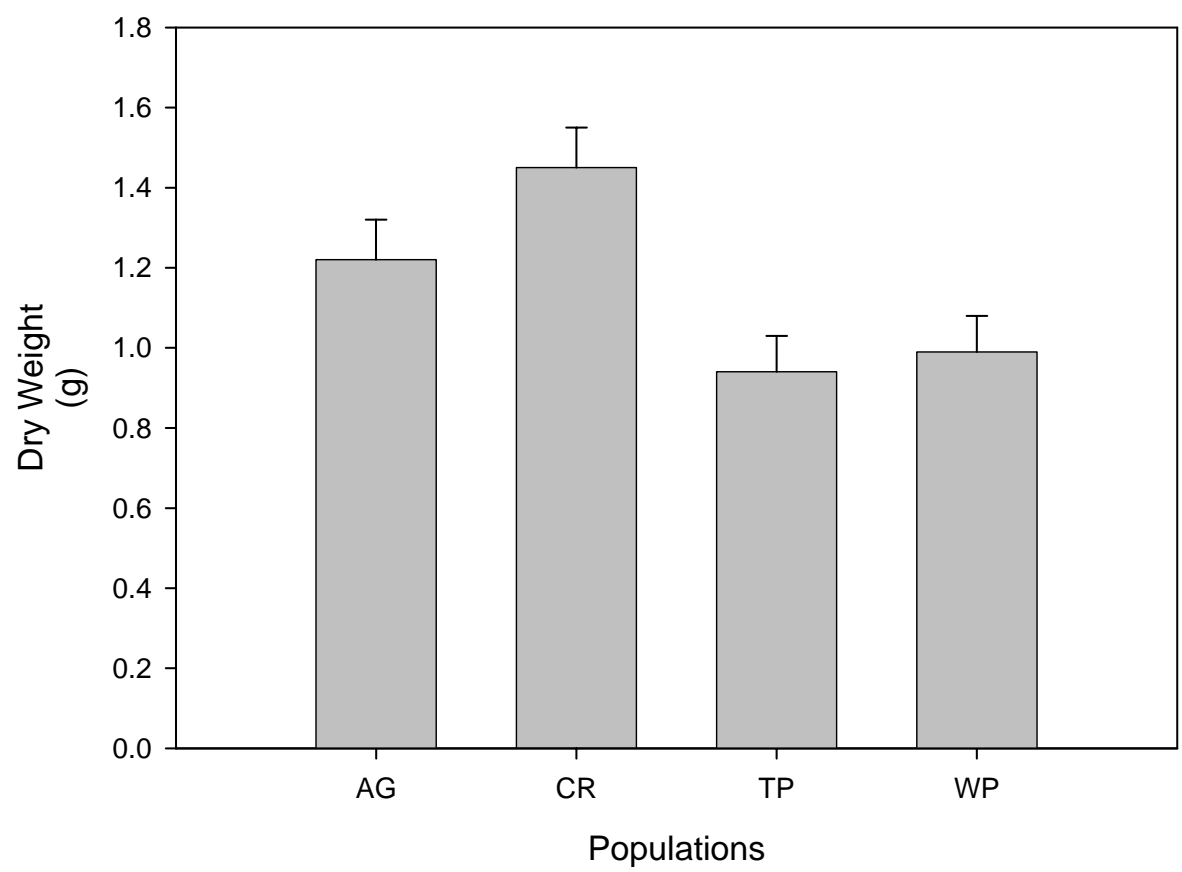

Figure 2.12: Final dry weight (g) of tillers by transplant field site. AG= Agricultural Farm, $\mathrm{CR}=$ Chestnut Ridge, $\mathrm{TP}=$ Trout Pond and WP=White Park.

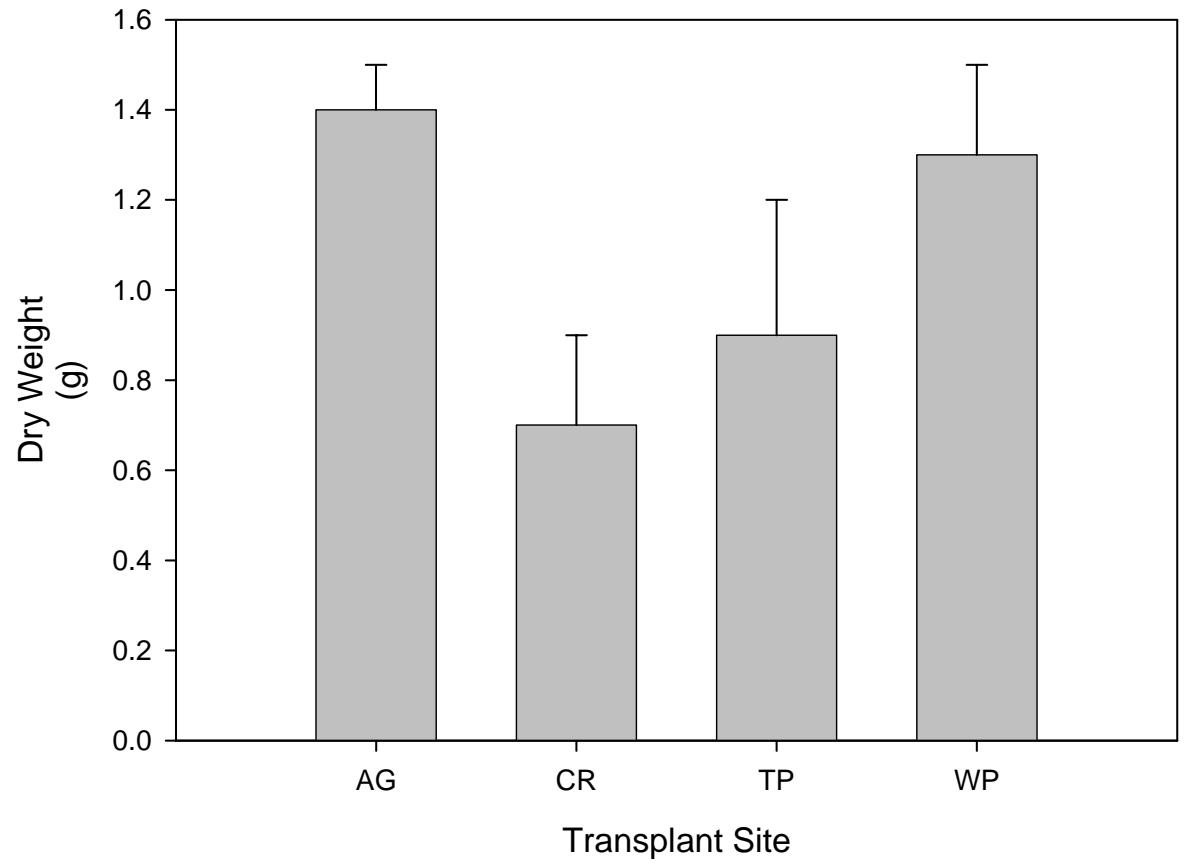


Figure 2.13: Final nitrogen concentration (mg/g) of tiller tissue from each transplant field site. $\mathrm{AG}=$ Agricultural Farm, $\mathrm{CR}=$ Chestnut Ridge, $\mathrm{TP}=$ Trout Pond and $\mathrm{WP}=$ White Park.

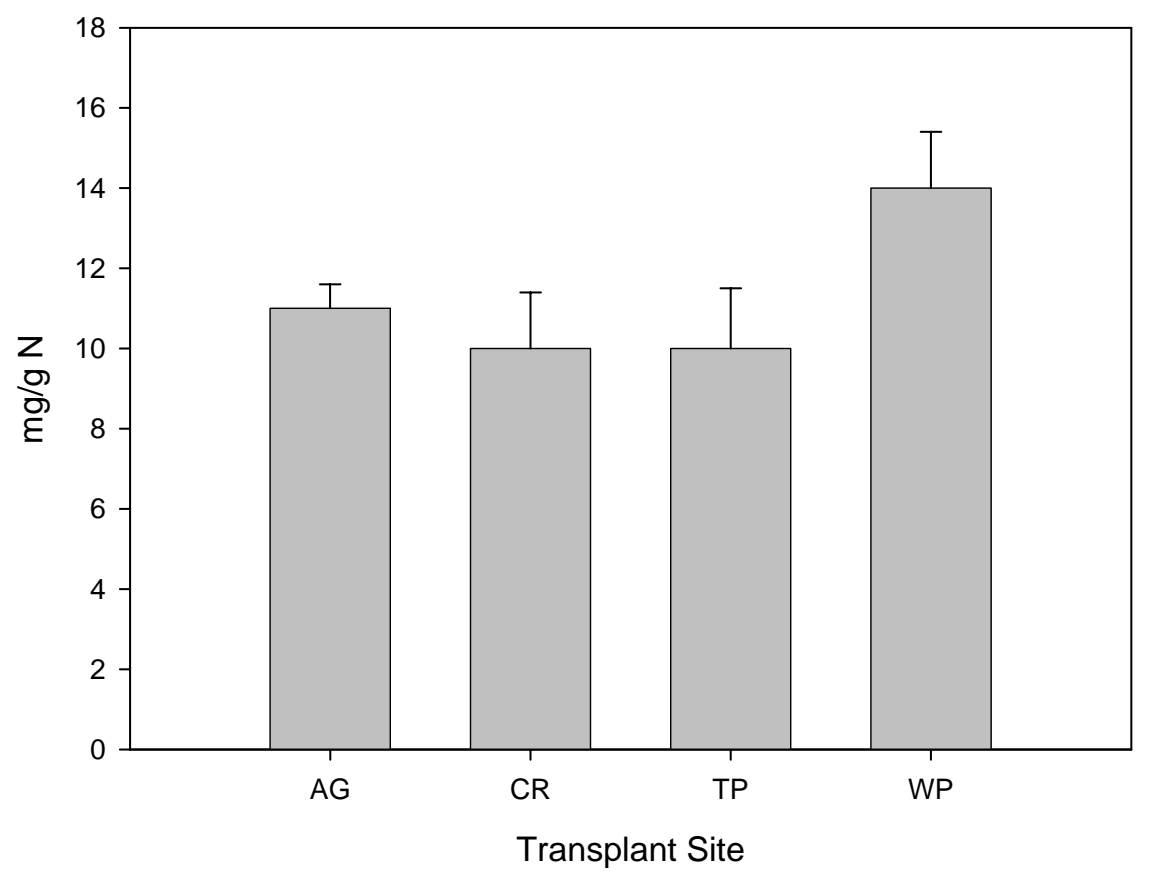

Figure 2.14: Final carbon:nitrogen ratio within tillers based on origin field site. AG= Agricultural Farm, $\mathrm{CR}=$ Chestnut Ridge, $\mathrm{TP}=$ Trout Pond and $\mathrm{WP}=$ White Park.

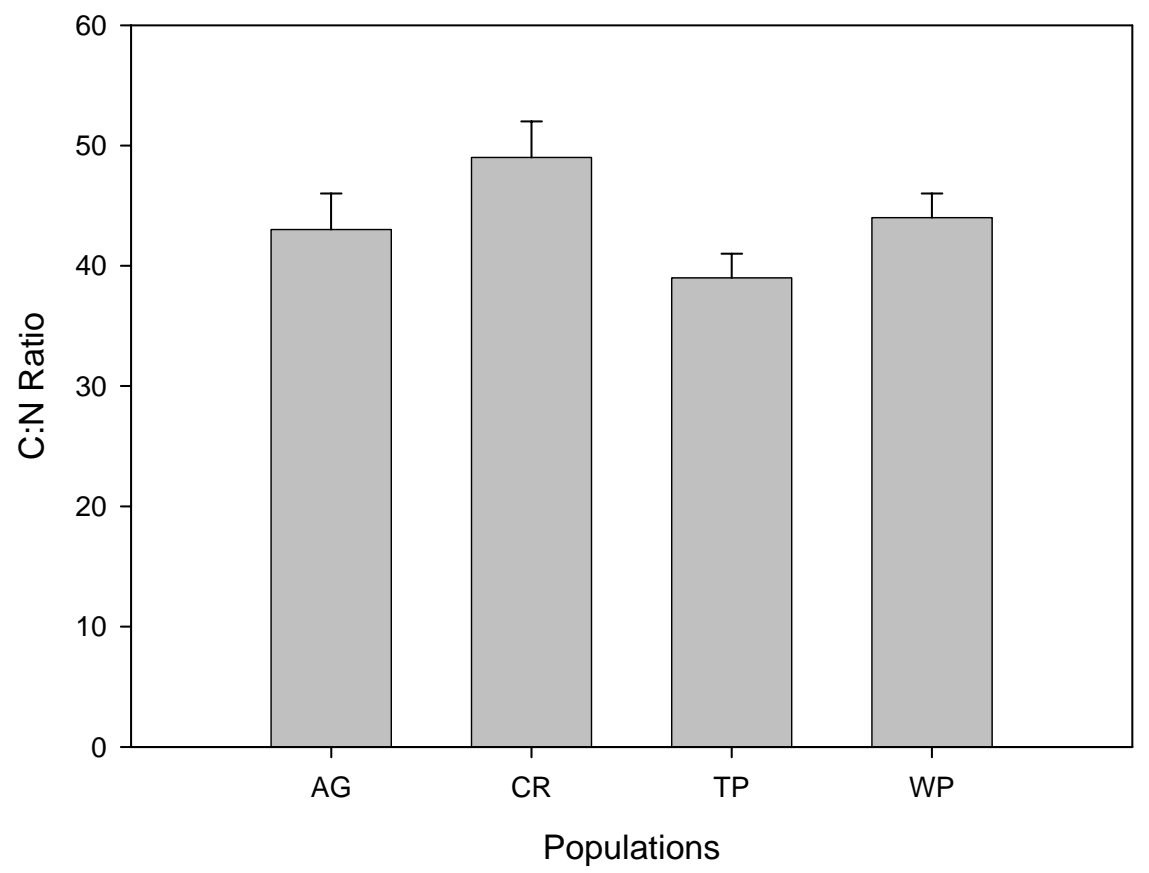


Figure 2.15: Final carbon:nitrogen ratio of tillers from each transplant field site. AG= Agricultural Farm, $\mathrm{CR}=$ Chestnut Ridge, $\mathrm{TP}=$ Trout Pond and $\mathrm{WP}=$ White Park.

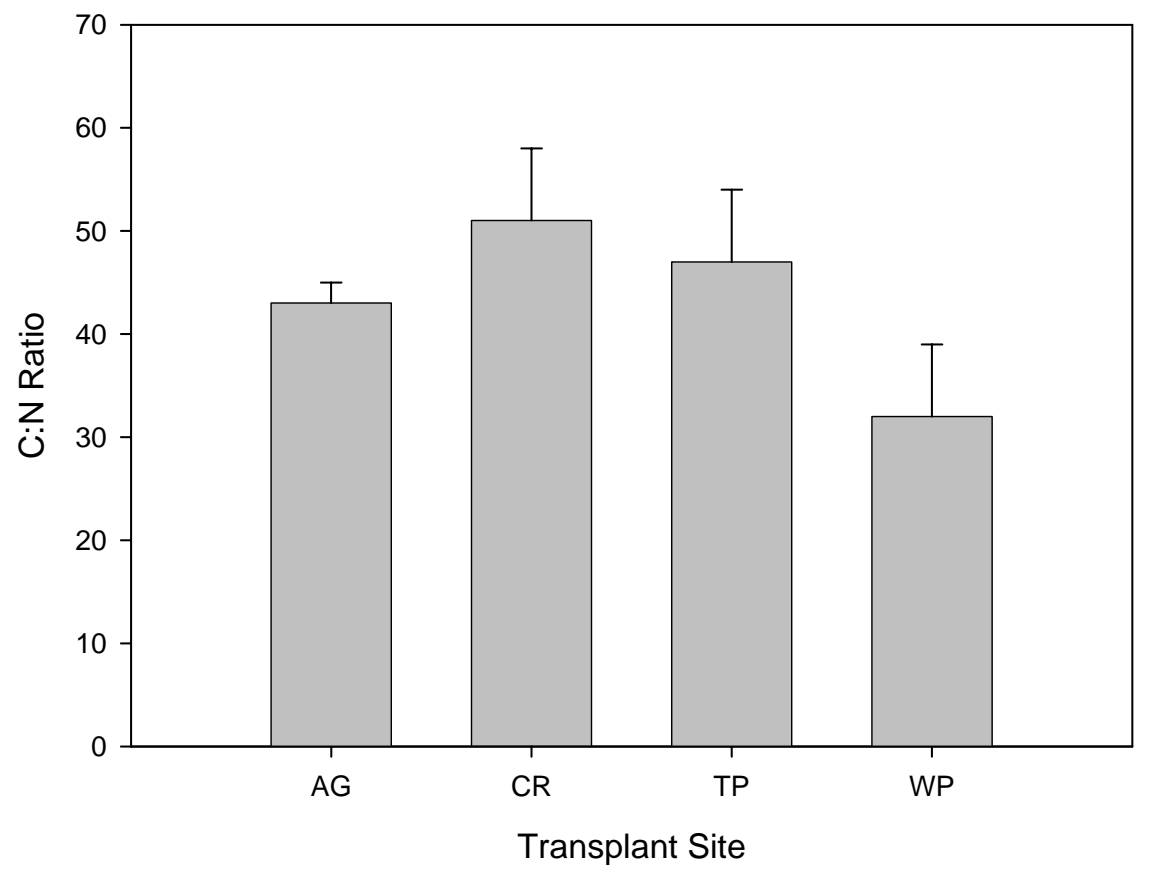

Figure 2.16: Mean carbon:nitrogen ratios of populations grown in differing nitrogen environments.

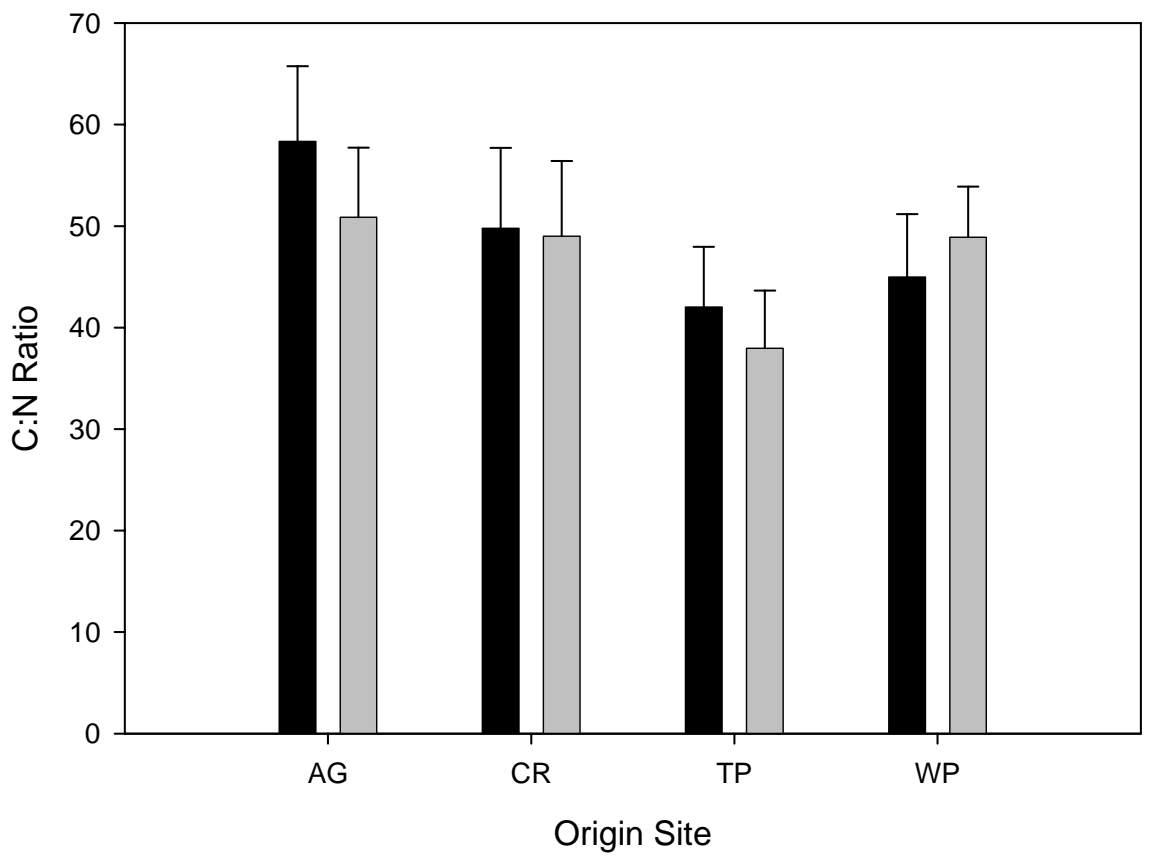




\section{Analysis II: Differential Ecotypic Response To Elevation and Nitrogen}

\section{Tiller Area}

Across all environments, log-transformed tiller area significantly differed between dates (Table 2.4; Julian date $\mathrm{p}<0.0001$ ). High-elevation populations produced more tiller area than low-elevation sites (Figure 2.17; Origin elevation $\mathrm{p}<0.0001$ ). Reciprocal transplants of populations based on elevation show that high-elevation populations had higher mean tiller area when transplanted into either high- or low-elevation sites (Figure 2.18; Transplant elevation*origin elevation $\mathrm{p}=0.0135$ ) and over time (Date*transplant elevation*origin elevation $\mathrm{p}=0.0089$ ). Although transplant elevation did not significantly directly affect tiller area, it did impact tiller area differently over time (Date*transplant elevation $\mathrm{p}<0.0001)$. Low-nitrogen populations appear to have a divergent response to elevation. Figure 2.19 shows higher mean tiller area in high elevations and a significantly lower area in low elevations (Origin nitrogen*origin elevation $\mathrm{p}<0.0001$ ). This relationship also holds with respect to elevation transplantation. Plants from low-elevation, low-nitrogen sites produced fewer mean number of tillers regardless transplant elevation (high or low) sites (Figure 2.20; Transplant elevation*origin nitrogen*origin elevation $\mathrm{p}=0.0041$ ).

Absolute growth rates (AGR) of tiller area differed significantly over time (Table 2.4; Measurement Interval $\mathrm{p}=0.0016$ ). Tiller area growth rates also significantly differed by transplant elevation over time (Measurement Interval*transplant elevation $\mathrm{p}=0.0036$ ). Here, plants grown in low-elevation sites had a higher mean growth rate over the course of the experiment. Low-elevation transplant sites had higher growth rates regardless of home site elevation (Figure 2.21; Transplant elevation*origin elevation $\mathrm{p}=0.0345$ ). This elevation interaction also varied over time (Measurement Interval*transplant elevation*origin elevation 
$\mathrm{p}=0.0366$ ). Higher AGR was observed in plants that were grown in low-elevation sites despite their origin elevation level.

Tiller area growth efficiency expectedly varied over time (Table 2.4; Measurement Interval $\mathrm{p}=0.0044)$. A greater efficiency in tiller area production was evident in populations that were transplanted back into their home site (Figure 2.22; Transplant elevation*origin elevation $\mathrm{p}=0.0337)$. In terms of site nutrient status, a significant divergence in tiller area growth efficiency is present in relation to elevation (Figure 2.23; Transplant nitrogen*transplant elevation*origin elevation $\mathrm{p}=0.0107)$. Populations transplanted to lowelevation sites tended to be more efficient at producing tiller area despite a population's origin or transplant nutrient status. However, populations transplanted into sites with low elevations and low nitrogen seemed to have the highest relative growth rates. This trend was also variable over time (Measurement Interval*transplant nitrogen*transplant elevation*origin nitrogen $\mathrm{p}=0.0275)$.

$\underline{\text { Biomass }}$

Significantly higher tiller biomass (Table 2.5) was observed in low-nitrogen populations from low elevations as well as high-nitrogen populations from high-elevation sites (Figure 2.24; Origin elevation*origin nitrogen $\mathrm{p}=0.0010$ ). When these populations were reciprocally transplanted, the high-elevation populations returned to high-nitrogen sites maintained their biomass accumulation (Figure 2.5; Transplant nitrogen*origin elevation $\mathrm{p}=0.0349$ ). High-elevation populations that were transplanted into low-nitrogen sites significantly increased their biomass production whereas low-elevation populations in lownitrogen sites declined. Overall, plants transplanted into high elevations had more biomass (Figure 2.26; Transplant elevation $\mathrm{p}<0.0001$ ). 


\section{$\underline{\text { Nutrient Composition }}$}

Tillers from plants grown at low elevations typically had a higher nitrogen concentration (Table 2.5; Figure 2.28; Transplant elevation $\mathrm{p}<0.0001$ ). The interaction of these two site variables shows that plants from populations transplanted to low elevation, nitrogen-poor sites accumulated more nitrogen in aboveground tissues (Figure 2.29; Transplant nitrogen*transplant elevation $\mathrm{p}=0.0002$ ). This trend appears not to be related to the plants' origin nutrient status (Figure 2.30; Transplant nitrogen*transplant elevation*origin nitrogen $\mathrm{p}=0.0342$ ). In terms of carbon accumulation, plants grown in lownitrogen conditions typically had higher carbon content (Table 2.5; Figure 2.27; Transplant nitrogen $\mathrm{p}=0.0012$ ). Plants grown in high-elevation (Figure 2.31) sites typically had a higher $\mathrm{C}: \mathrm{N}$ ratios (Table 2.5; Transplant elevation $\mathrm{p}<0.0001$ ) regardless of nitrogen level (Figure 2.32; Transplant nitrogen*transplant elevation $\mathrm{p}=0.0019)$. When this interaction is further decomposed, plants grown at high elevations tended to yield higher $\mathrm{C}: \mathrm{N}$ ratios within their home sites (Figure 2.33; Transplant nitrogen*transplant elevation*origin nitrogen p=0.0141). Transplant elevation also had a significant impact on $\mathrm{C}: \mathrm{N}$ ratios, regardless of nutrient status or elevation origin (Figure 2.33; transplant nitrogen*transplant elevation*origin elevation $\mathrm{p}=0.0140)$. 
Table 2.4: Analysis of variance for Tiller area, absolute $\left(\mathrm{cm}^{2} /\right.$ day) and relative $\left(\mathrm{cm}^{2} / \mathrm{cm}^{2} /\right.$ day $)$ growth rates. Type III mean squares are reported $(*=p<0.05)$. Note that Measurement Interval is reported as Julian Date for growth rates.

\begin{tabular}{|c|c|c|c|c|}
\hline Source & $\mathrm{DF}$ & $\begin{array}{l}\text { Tiller } \\
\text { Area }\end{array}$ & $\begin{array}{c}\text { Absolute } \\
\text { Growth Rate }\end{array}$ & $\begin{array}{c}\text { Relative } \\
\text { Growth Rate }\end{array}$ \\
\hline Julian Date (D) & 1 & 74.0868* & $1547.5144^{*}$ & $0.0108 *$ \\
\hline Transplant Nitrogen Level (TN) & 1 & 1.8608 & 0.0054 & 0.0009 \\
\hline Transplant Elevation (TE) & 1 & 0.1588 & 19.7996 & 0.0001 \\
\hline $\mathrm{TN} * \mathrm{TE}$ & 1 & 0.1573 & 40.9769 & 0.0005 \\
\hline Origin Nitrogen Level (ON) & 1 & 0.0003 & 3.9865 & 0.0007 \\
\hline Origin Elevation (OE) & 1 & $24.3568 *$ & 1.8664 & 0.0000 \\
\hline $\mathrm{ON}^{*} \mathrm{OE}$ & 1 & $44.6159 *$ & 10.9918 & 0.0005 \\
\hline $\mathrm{TN} * \mathrm{ON}$ & 1 & 0.3089 & 31.7558 & 0.0003 \\
\hline $\mathrm{TN} * \mathrm{OE}$ & 1 & 2.2002 & 54.9630 & 0.0027 \\
\hline $\mathrm{TE}^{*} \mathrm{ON}$ & 1 & 0.2745 & 7.2795 & 0.0000 \\
\hline $\mathrm{TE}^{*} \mathrm{OE}$ & 1 & $3.9584 *$ & $691.8584 *$ & $0.0060 *$ \\
\hline $\mathrm{TN}^{*} \mathrm{TE}^{*} \mathrm{ON} * \mathrm{OE}$ & 1 & 2.4757 & 2.1416 & 0.0008 \\
\hline $\mathrm{TN} * \mathrm{TE}^{*} \mathrm{ON}$ & 1 & 0.2302 & 318.7911 & $0.0086 *$ \\
\hline $\mathrm{TE}^{*} \mathrm{TN}^{*} \mathrm{OE}$ & 1 & 0.0102 & 122.0871 & 0.0003 \\
\hline $\mathrm{TN} * \mathrm{ON} * \mathrm{OE}$ & 1 & 1.3991 & 91.3360 & 0.0040 \\
\hline $\mathrm{TE}^{*} \mathrm{ON} * \mathrm{OE}$ & 1 & $5.3599 *$ & 78.7579 & 0.0001 \\
\hline $\mathrm{D} * \mathrm{TN}$ & 1 & 0.4982 & 3.6096 & 0.0009 \\
\hline D*TE & 1 & $13.3901 *$ & $1310.9503^{*}$ & 0.0035 \\
\hline $\mathrm{D} * \mathrm{TN} * \mathrm{TE}$ & 1 & 0.1597 & 420.2184 & 0.0020 \\
\hline $\mathrm{D}^{*} \mathrm{ON}$ & 1 & 0.0001 & 24.2297 & 0.0007 \\
\hline $\mathrm{D} * \mathrm{OE}$ & 1 & 0.4063 & 0.6734 & 0.0002 \\
\hline $\mathrm{D} * \mathrm{ON} * \mathrm{OE}$ & 1 & $4.4151 *$ & 104.3702 & 0.0003 \\
\hline $\mathrm{D} * \mathrm{TN} * \mathrm{ON}$ & 1 & 0.3350 & 226.1126 & 0.0001 \\
\hline $\mathrm{D} * \mathrm{TN} * \mathrm{OE}$ & 1 & 0.3298 & 7.7909 & 0.0006 \\
\hline $\mathrm{D} * \mathrm{TE} * \mathrm{ON}$ & 1 & 2.4480 & 14.8357 & 0.0004 \\
\hline $\mathrm{D} * \mathrm{TE} * \mathrm{OE}$ & 1 & $4.4417 *$ & $676.1948 *$ & 0.0027 \\
\hline $\mathrm{D} * \mathrm{TN}^{*} \mathrm{TE}^{*} \mathrm{ON} * \mathrm{OE}$ & 1 & 0.1448 & 433.8952 & 0.0002 \\
\hline $\mathrm{D}^{*} \mathrm{TN} * \mathrm{TE} * \mathrm{ON}$ & 1 & 0.6613 & 529.2677 & $0.0065 *$ \\
\hline $\mathrm{D} * \mathrm{TE}^{*} \mathrm{TN} * \mathrm{OE}$ & 1 & 0.1104 & 2.7945 & 0.0006 \\
\hline $\mathrm{D}^{*} \mathrm{TE} * \mathrm{ON} * \mathrm{OE}$ & 1 & 0.2285 & 247.1964 & 0.0004 \\
\hline $\mathrm{D} * \mathrm{TN} * \mathrm{ON} * \mathrm{OE}$ & 1 & 0.8558 & 2.7348 & 0.0025 \\
\hline
\end{tabular}


Figure 2.17: The effect of origin site elevation on tiller area $\left(\mathrm{cm}^{2}\right)$.

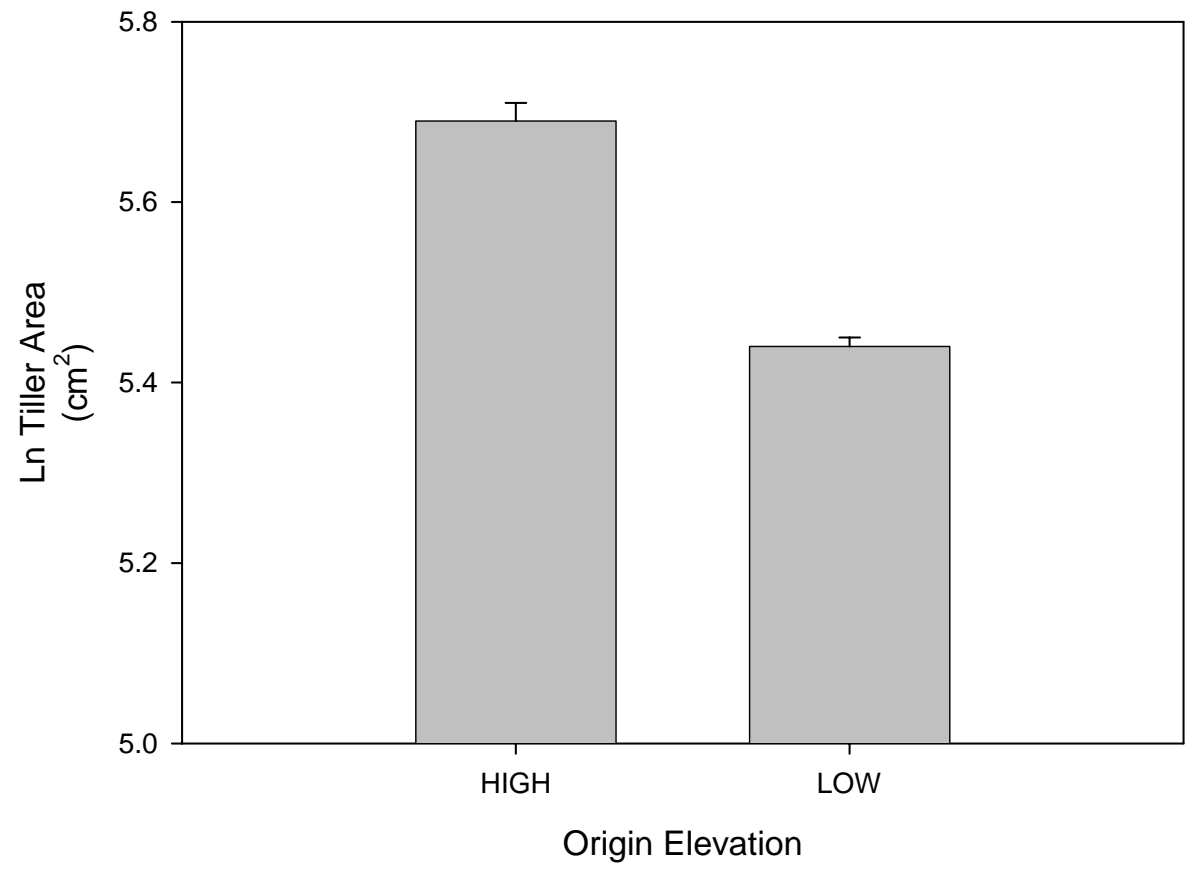

Figure 2.18: The interactive effect of transplant and origin site elevation on tiller area $\left(\mathrm{cm}^{2}\right)$. (H=High, L=Low)

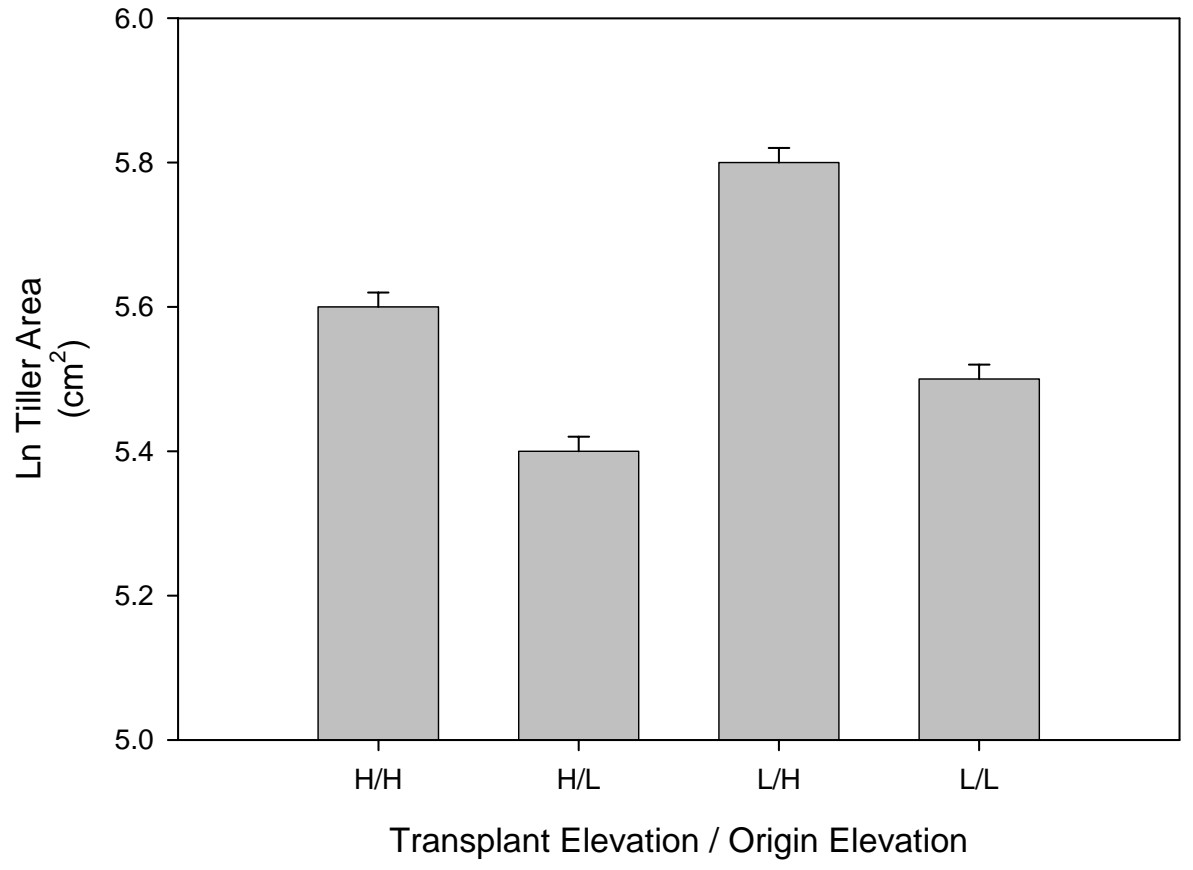


Figure 2.19: The interactive effect of origin site elevation and nutrient level on tiller area $\left(\mathrm{cm}^{2}\right)$. (H=High, L=Low)

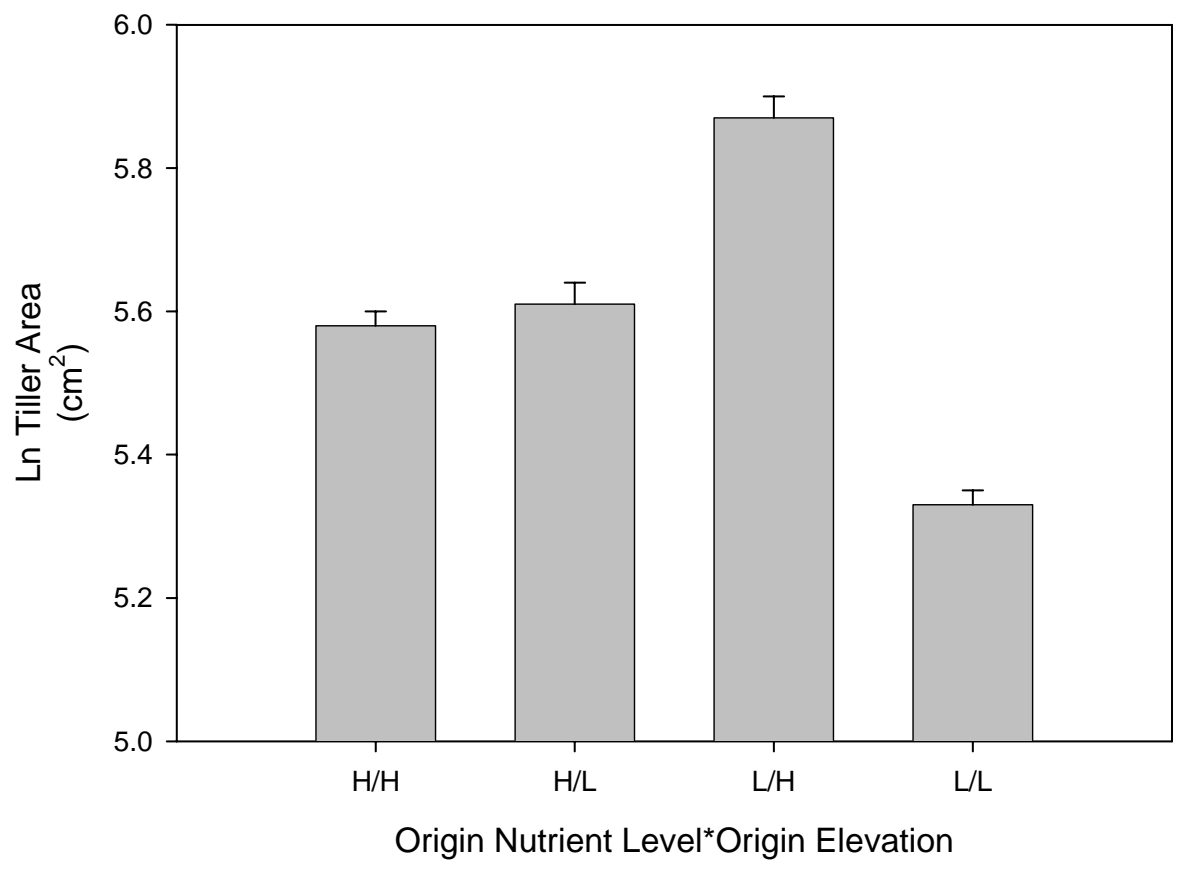

Figure 2.20: The interactive effect of transplant elevation, origin site nitrogen level and origin elevation on tiller area $\left(\mathrm{cm}^{2}\right)$. ( $\mathrm{H}=$ High, $\left.\mathrm{L}=\mathrm{Low}\right)$

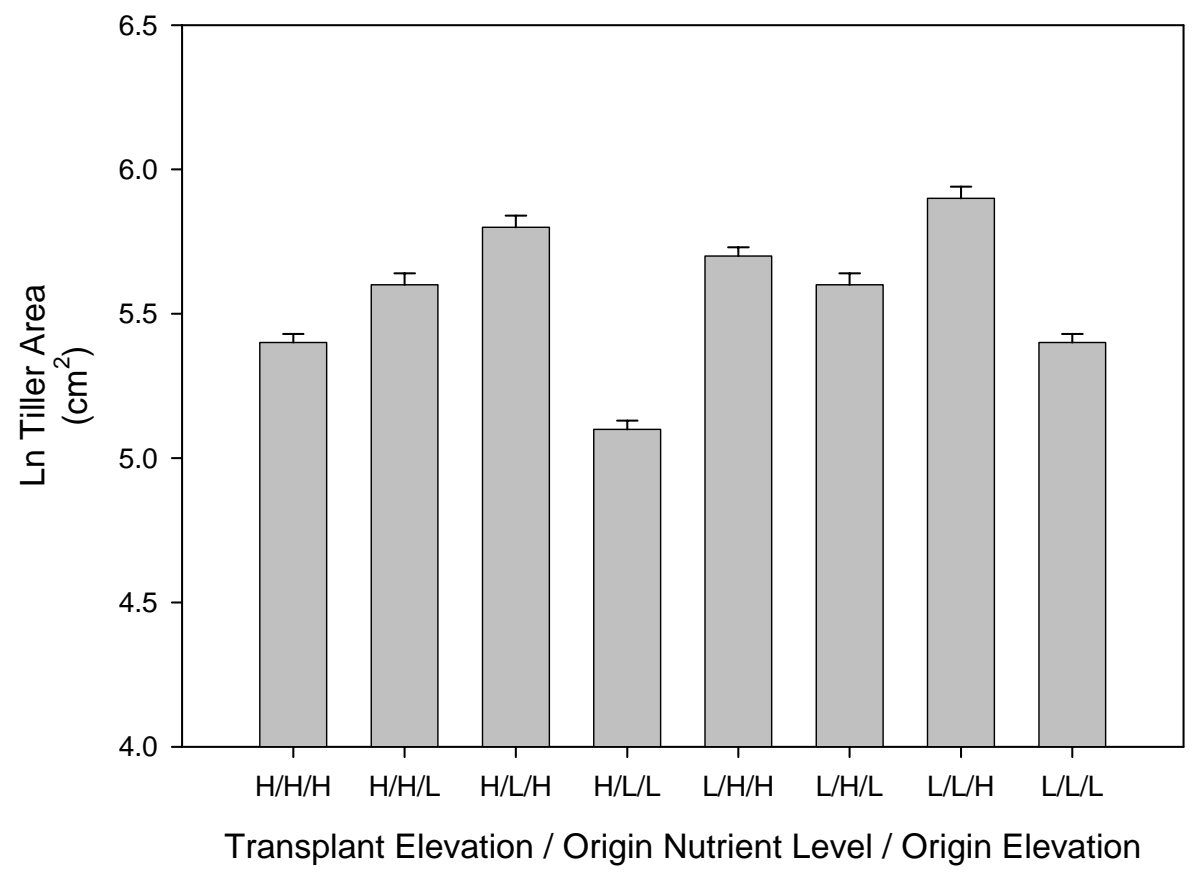


Figure 2.21: The interactive effect of transplant and origin site elevation on tiller area AGR $\left(\mathrm{cm}^{2} /\right.$ day $)$. (H=High, L=Low)

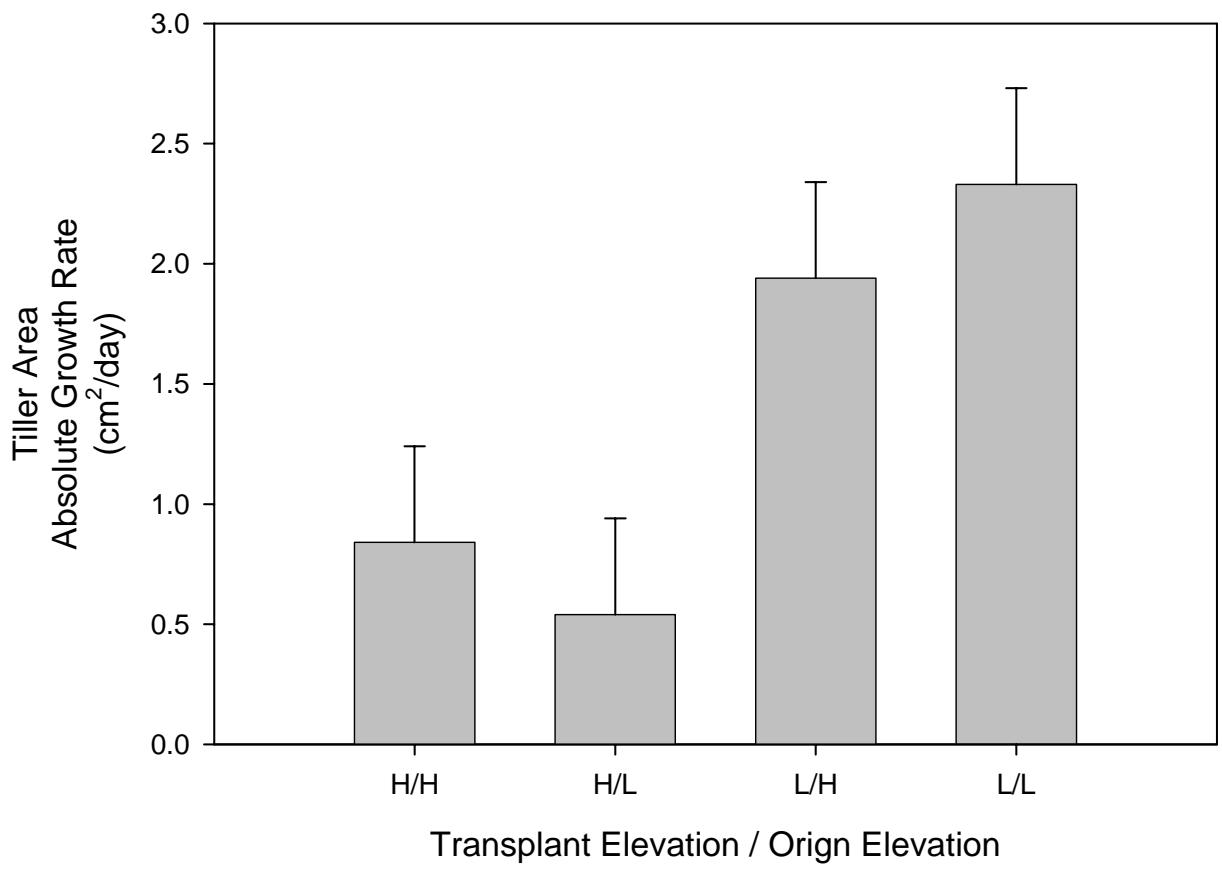

Figure 2.22: The interactive effect of transplant and origin site elevation on tiller area RGR $\left(\mathrm{cm}^{2} / \mathrm{cm}^{2} /\right.$ day). (H=High, L=Low)

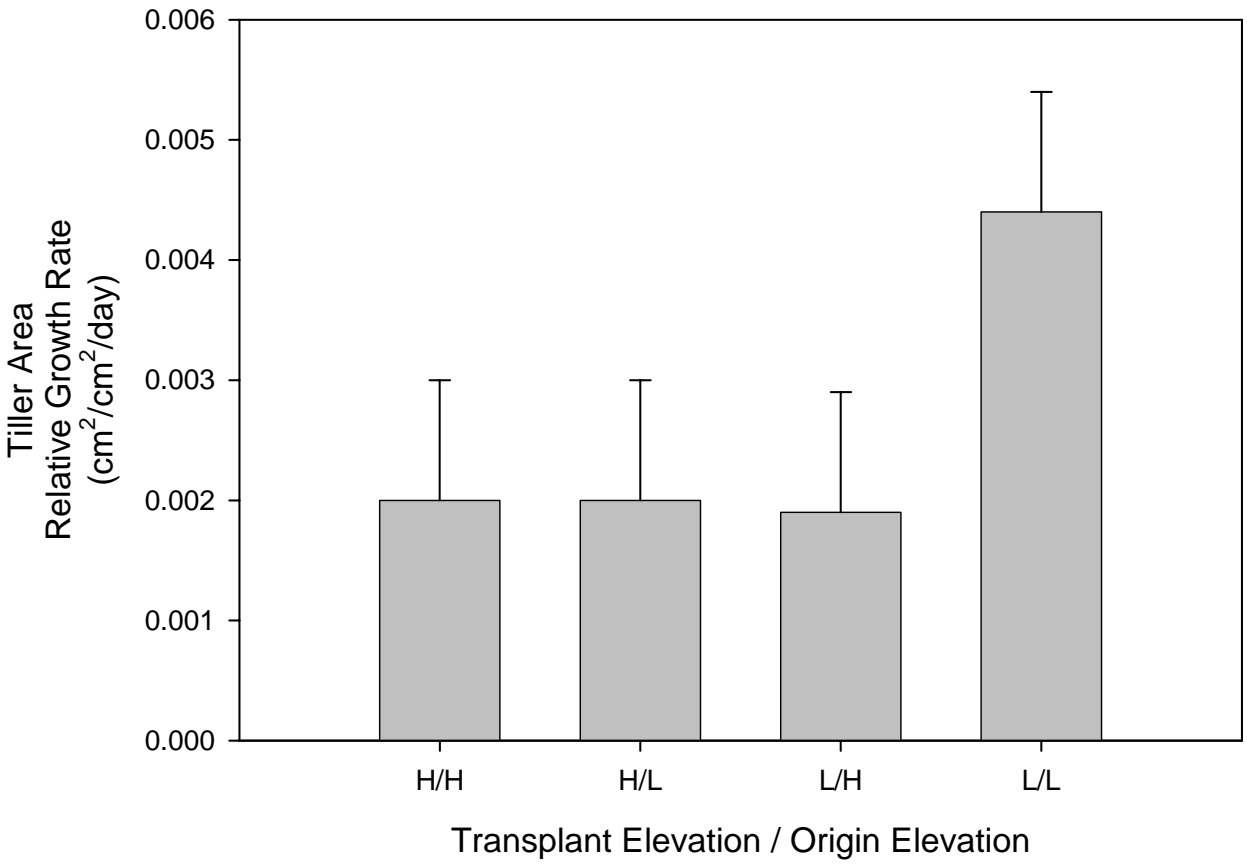


Figure 2.23: The interactive effect of transplant nitrogen and elevation and origin nitrogen level on tiller area RGR ( $\mathrm{cm}^{2} / \mathrm{cm}^{2} /$ day). (H=High, L=Low)

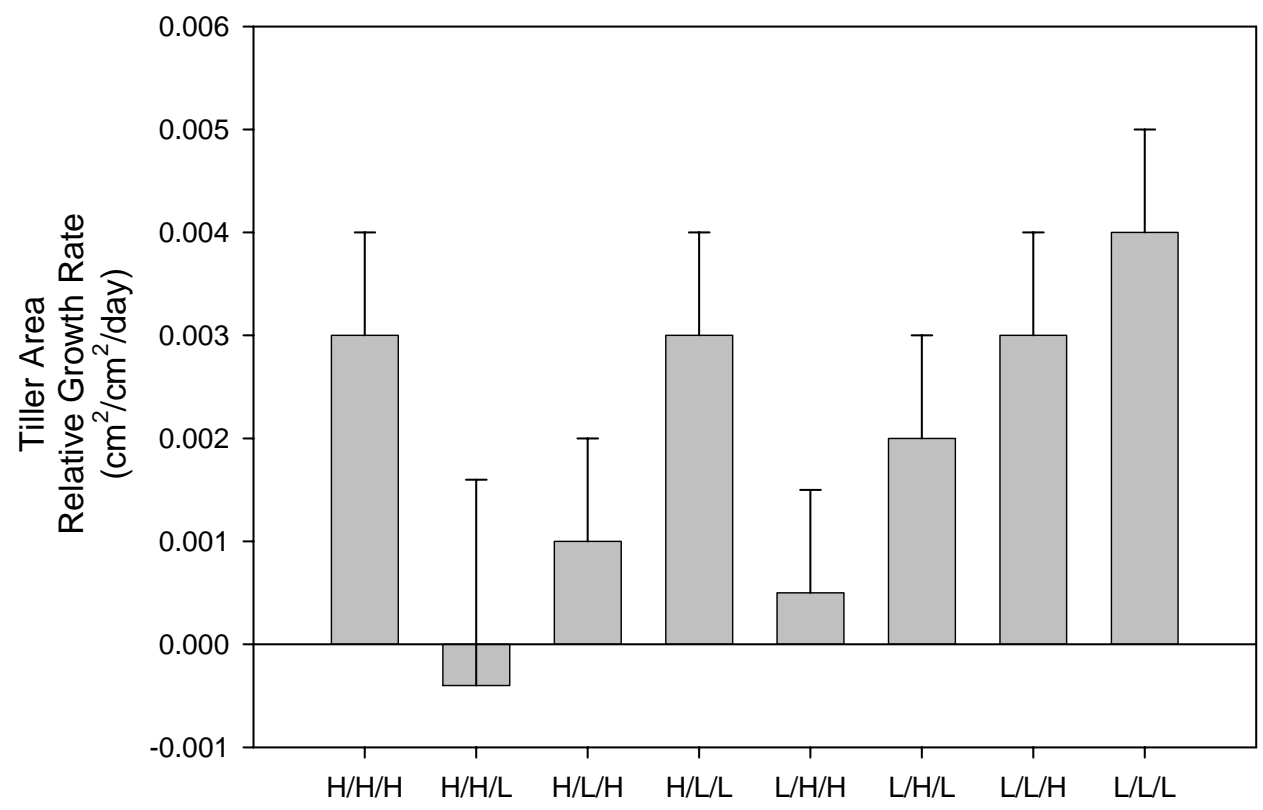

Transplant Nutrient Level / Transplant Elevation / Origin Nutirent Level 
Table 2.5: Analysis of variance for tiller biomass (g), carbon and nitrogen concentrations (mg/g) and carbon:nitrogen ratios. Type III mean squares are reported $(*=p<0.05)$.

\begin{tabular}{lccccc}
\hline \hline Source & DF & Biomass & $\begin{array}{c}\text { Carbon } \\
\text { Concentration }\end{array}$ & $\begin{array}{c}\text { Nitrogen } \\
\text { Concentration }\end{array}$ & C:N Ratio \\
\hline Transplant Nitrogen Level (TN) & 1 & 0.2446 & $32832.9250^{*}$ & $177.9724^{*}$ & 790.3610 \\
Transplant Elevation (TE) & 1 & $31.1156^{*}$ & 7834.6830 & $699.9089^{*}$ & $13516.3630^{*}$ \\
TN*TE & 1 & 0.9408 & 7236.7210 & $311.8944^{*}$ & $5841.0080^{*}$ \\
Origin Nitrogen (ON) & 1 & 1.1849 & 757.5330 & 0.6616 & 2022.0000 \\
Origin Elevation (OE) & 1 & 0.4447 & 118.7220 & 29.3499 & 3.7230 \\
ON*OE & 1 & $11.7830^{*}$ & 79.9180 & 12.6082 & 1732.5710 \\
TN*ON & 1 & 1.4378 & 1459.4780 & 2.6228 & 276.6590 \\
TN*OE & 1 & $4.7581^{*}$ & 2674.4690 & 50.1083 & 32.7930 \\
TE*ON & 1 & 0.1087 & 563.6650 & 4.2194 & 9.4360 \\
TE*OE & 1 & 0.3542 & 1279.1230 & 20.3564 & 808.5410 \\
TN*TE*ON*OE & 1 & 0.9942 & 270.2260 & 7.4656 & 589.2440 \\
TN*TE*ON & 1 & 1.7720 & 1403.4250 & $98.1714 *$ & $3624.4460 *$ \\
TE*TN*OE & 1 & 0.9028 & 4072.7780 & 60.4597 & $3627.4560 *$ \\
TN*ON*OE & 1 & 0.4071 & 1616.0590 & 5.6117 & 1.9550 \\
TE*ON*OE & 1 & 0.1456 & 1158.6070 & 7.2589 & 1956.8670 \\
\hline
\end{tabular}


Figure 2.24: The interactive effect of origin nitrogen level and elevation on tiller biomass (g). (H=High, L=Low)

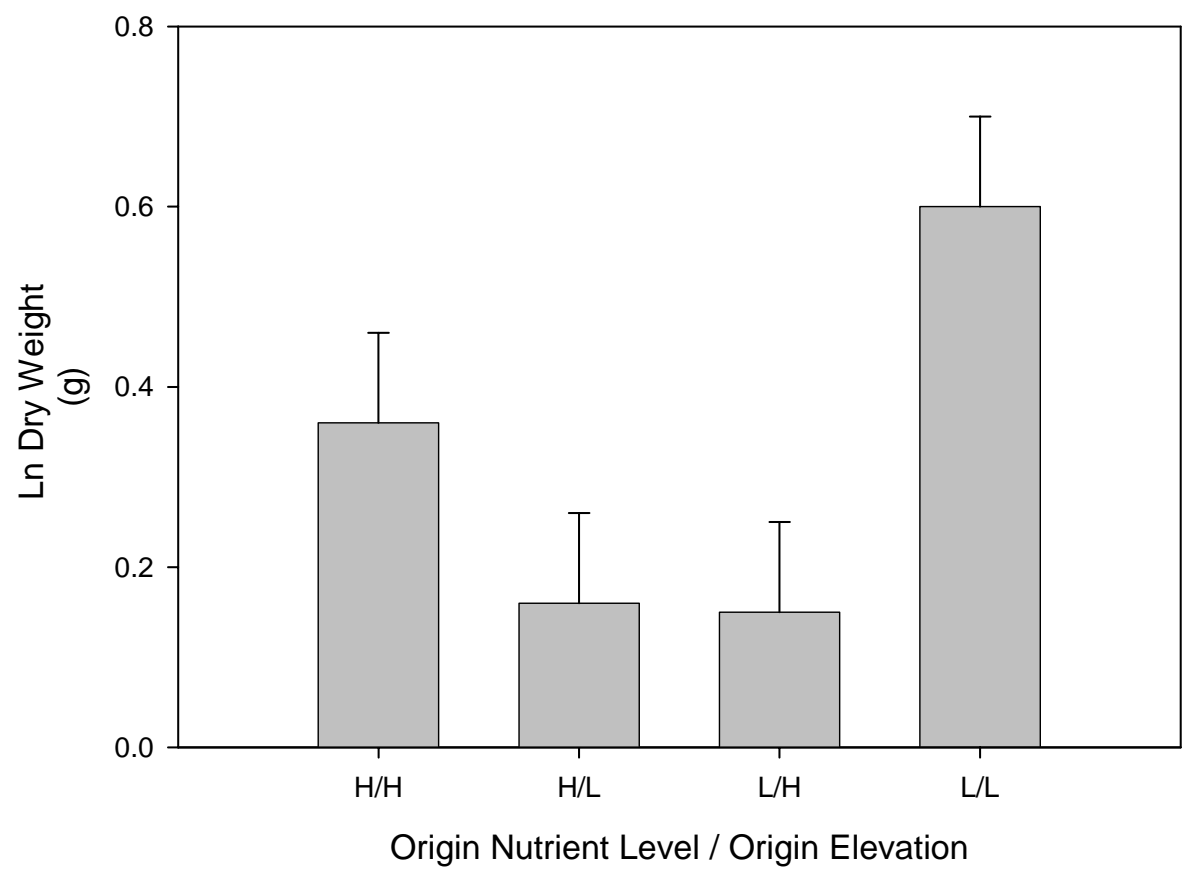

Figure 2.25: The interactive effect of transplant nitrogen level and site elevation on biomass (g). (H=High, L=Low)

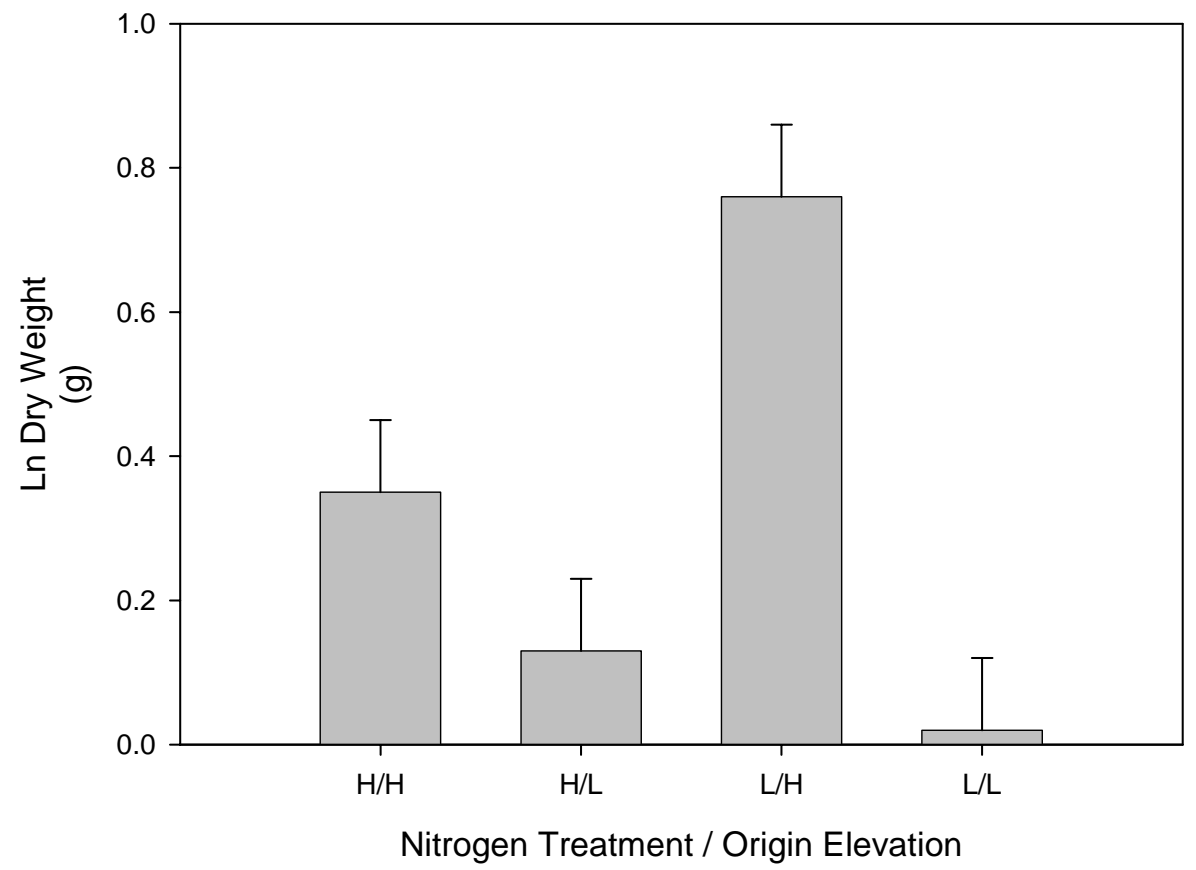


Figure 2.26: The effect of transplant site elevation on tiller biomass (g).

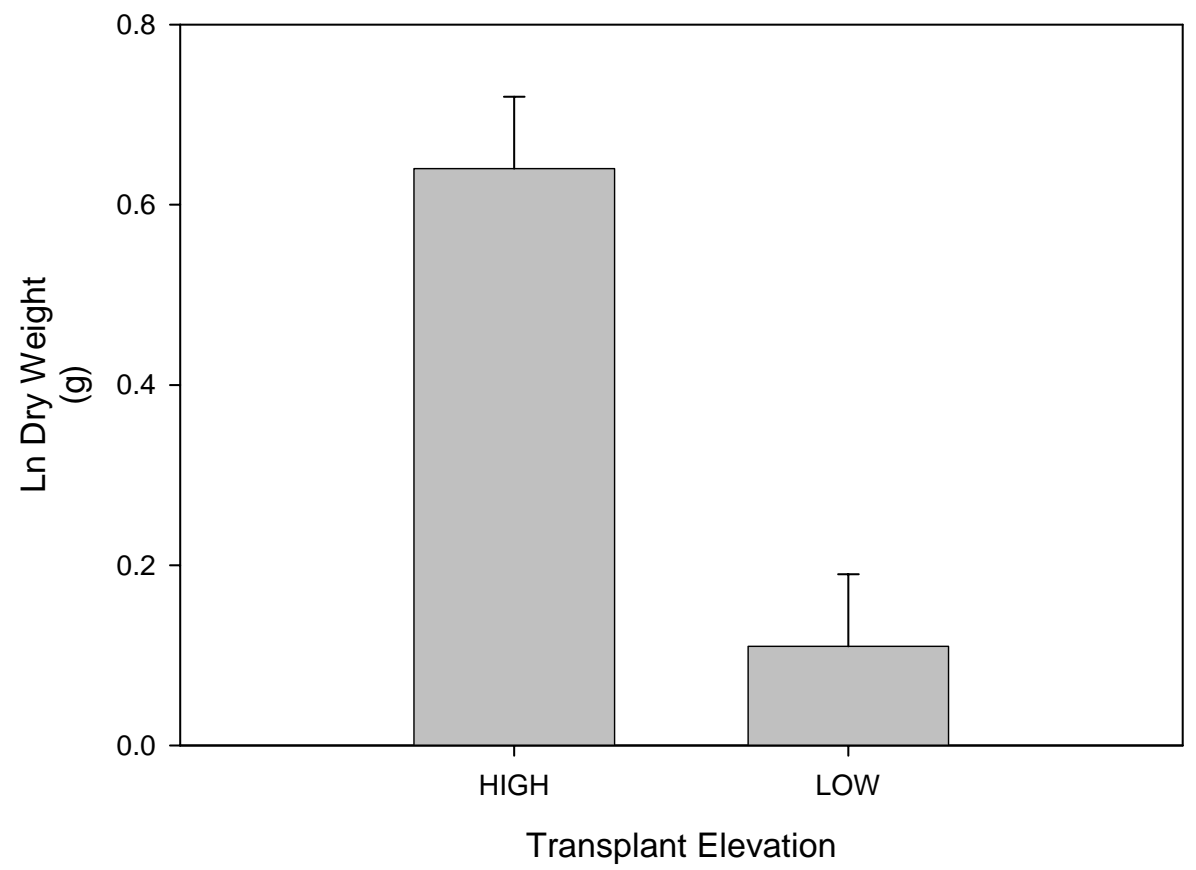

Figure 2.27: The effect of transplant nitrogen level on tiller carbon concentration (mg/g C).

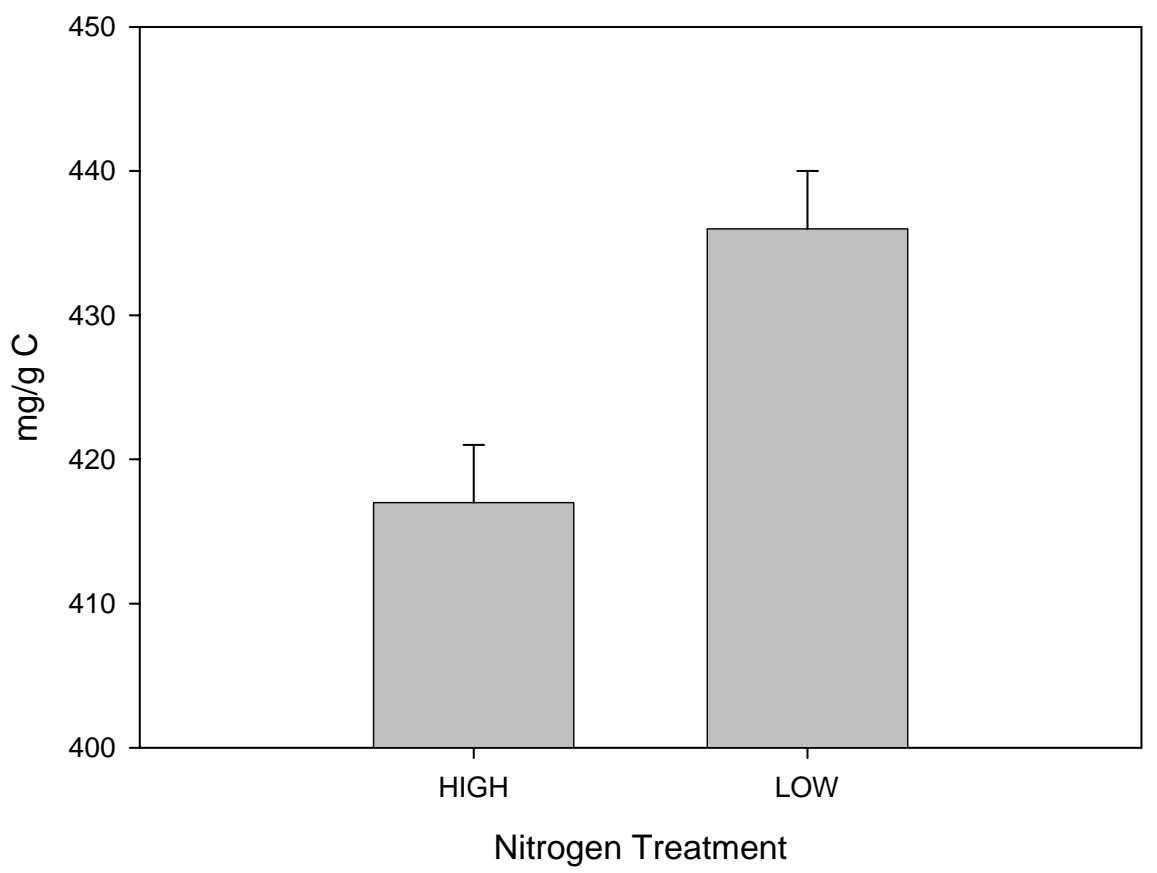


Figure 2.28: The effect of transplant elevation on tiller nitrogen concentration (mg/g N).

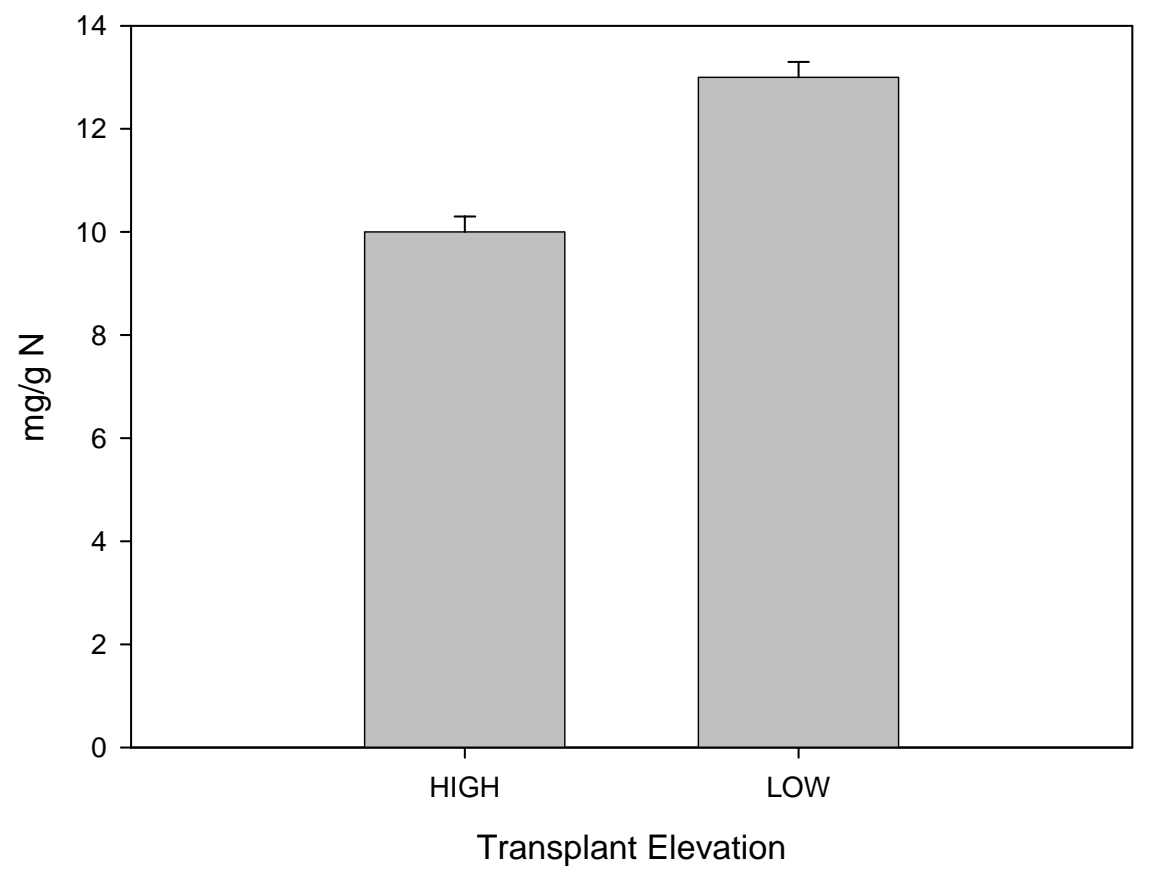

Figure 2.29: The interactive effect of transplant site nitrogen and elevation on tiller nitrogen concentration (mg/g N). (H=High, L=Low)

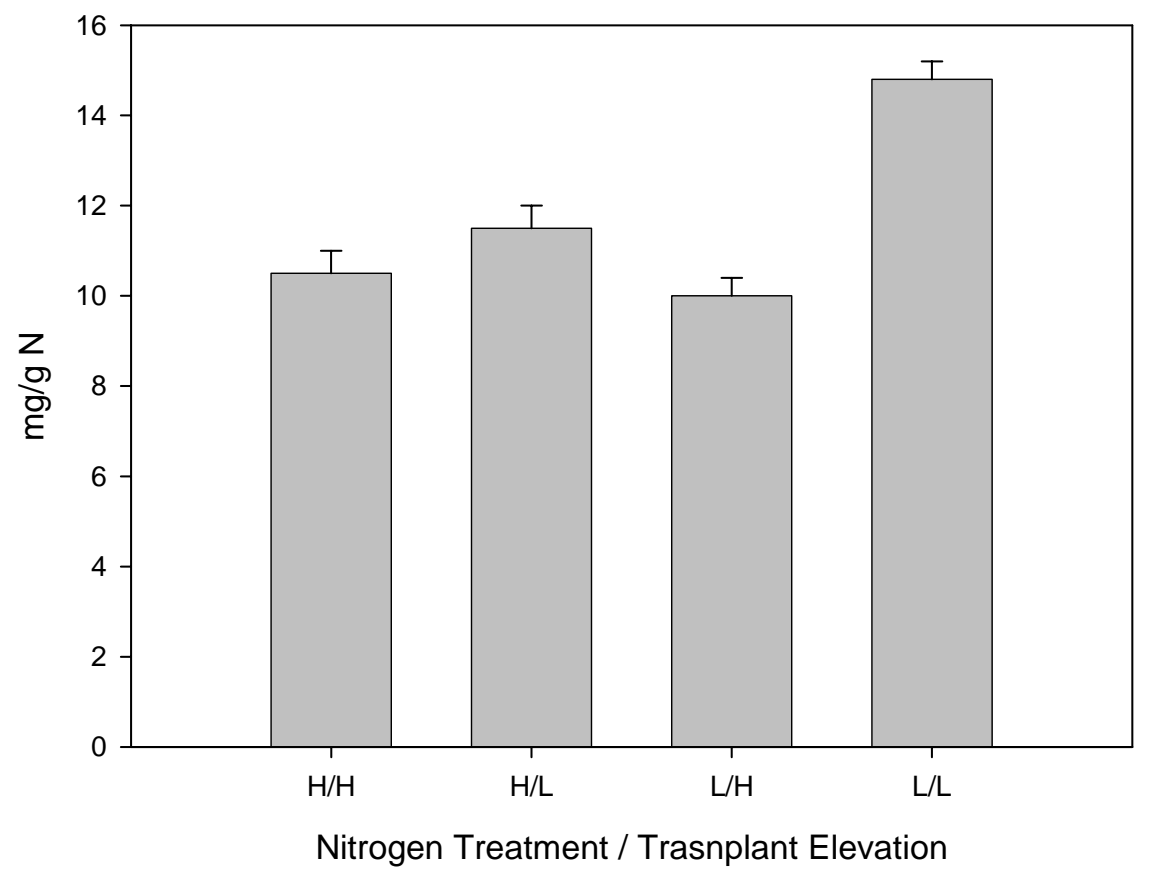


Figure 2.30: The interactive effect of transplant nitrogen level, elevation and origin nitrogen level on tiller nitrogen concentration (mg/g N). (H=High, L=Low)

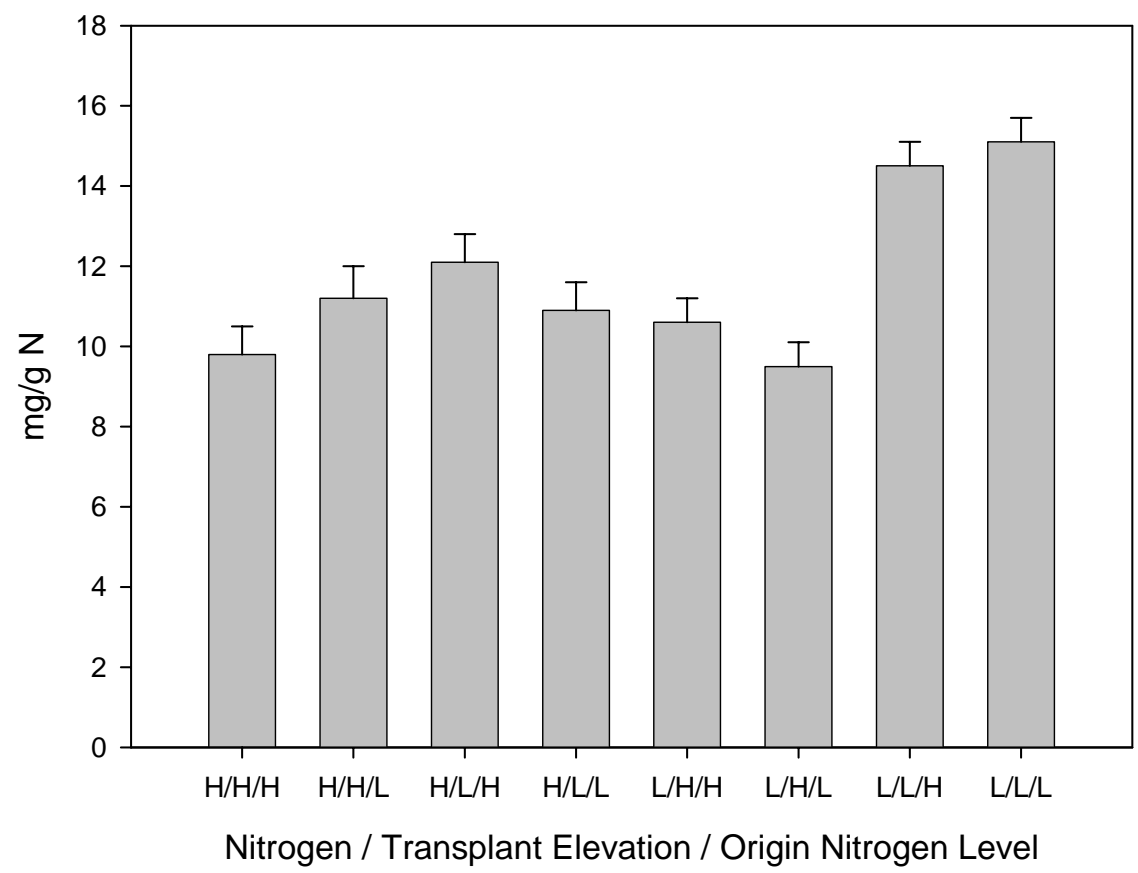

Figure 2.31: The effect of transplant site elevation on tiller $\mathrm{C}: \mathrm{N}$ ratio.

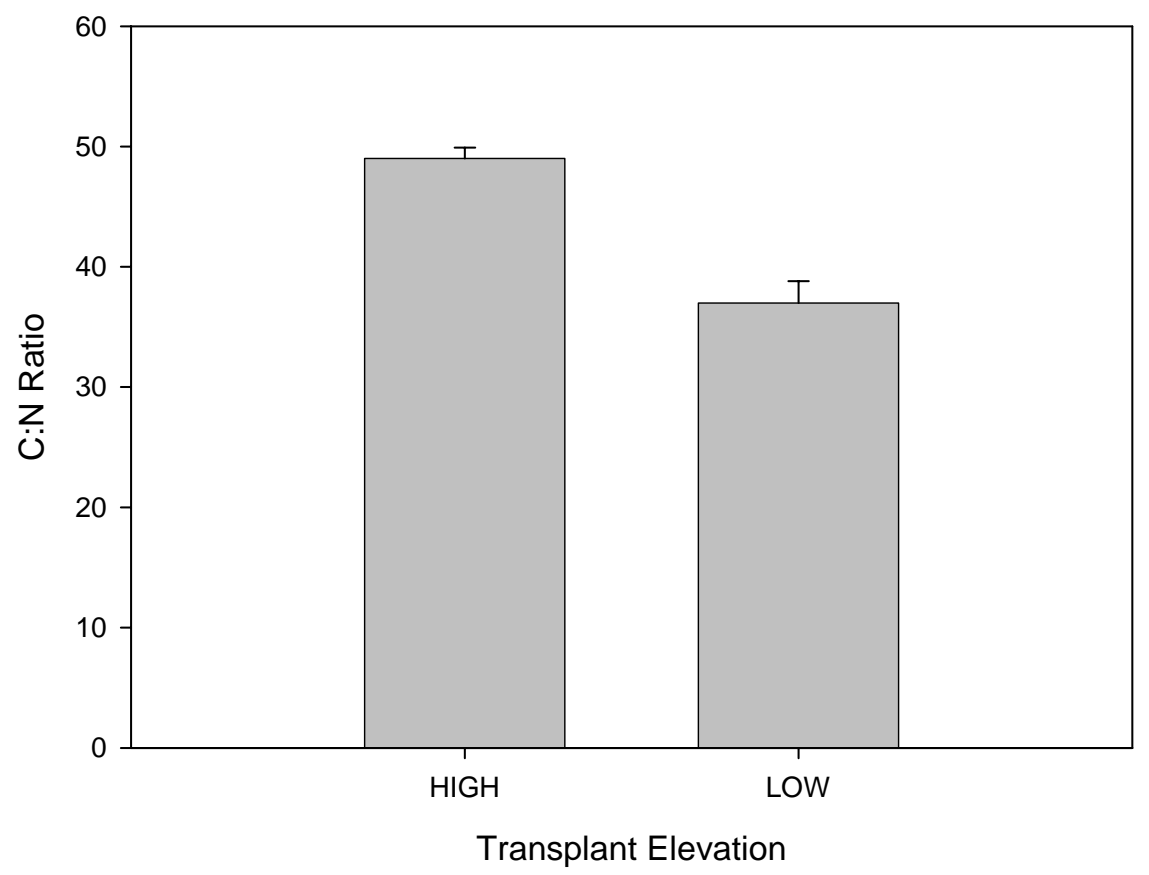


Figure 2.32: The interactive effect of transplant site elevation and nutrient level on tiller C:N ratio. (H=High, $\mathrm{L}=\mathrm{Low})$

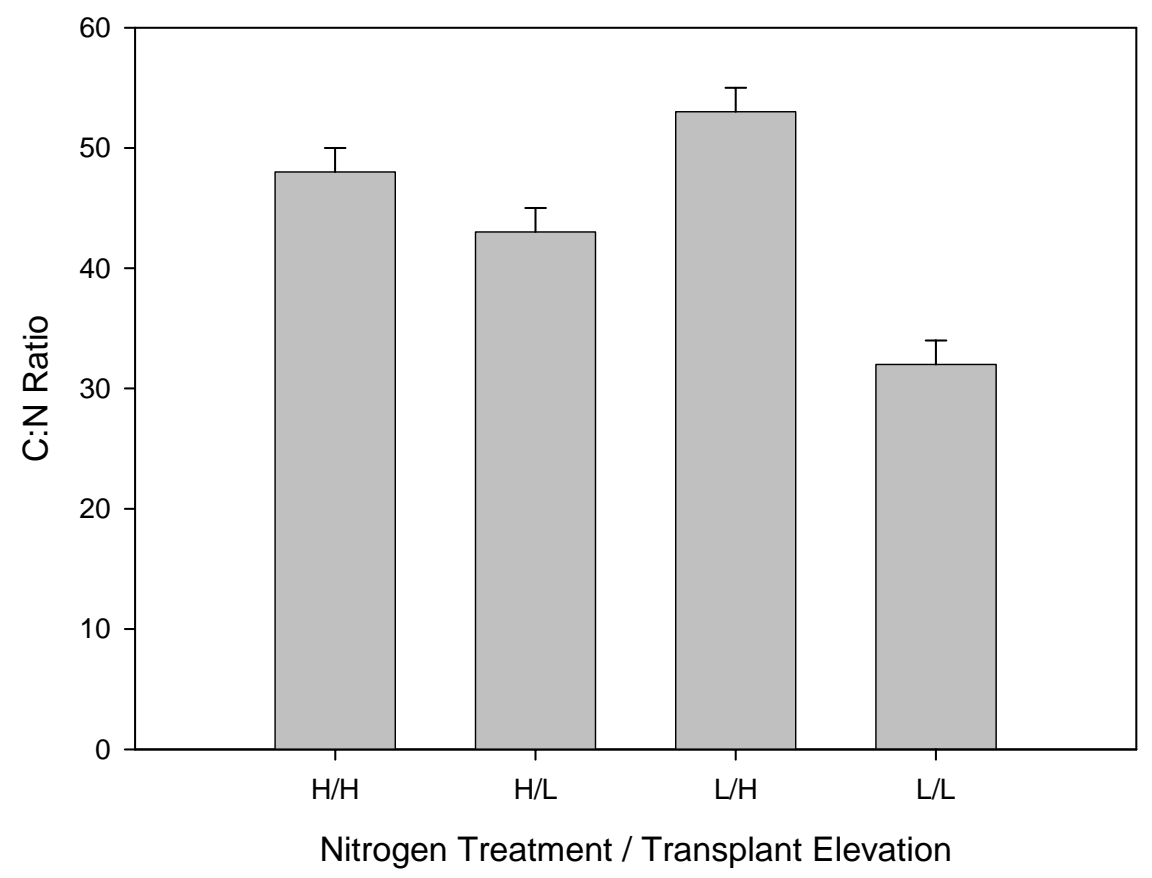

Figure 2.33: The interactive effect of transplant nitrogen level, elevation and origin nitrogen level on tiller C: $\mathrm{N}$ ratio. (H=High, $\mathrm{L}=\mathrm{Low}$ )

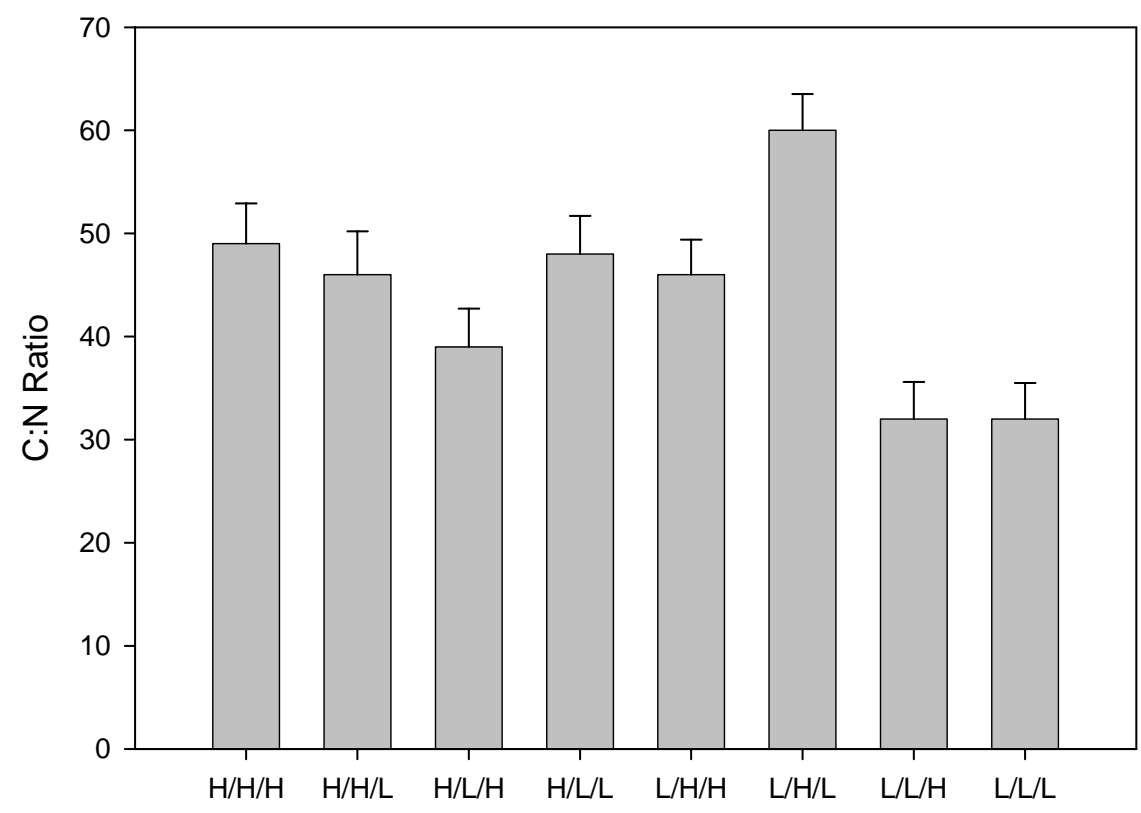

Nitrogen Treatment / Transplant Elevation / Origin Nitrogen Level 
Figure 2.34: The interactive effect of transplant elevation, nitrogen and origin elevation on tiller C:N ratio. ( $\mathrm{H}=\mathrm{High}, \mathrm{L}=\mathrm{Low})$

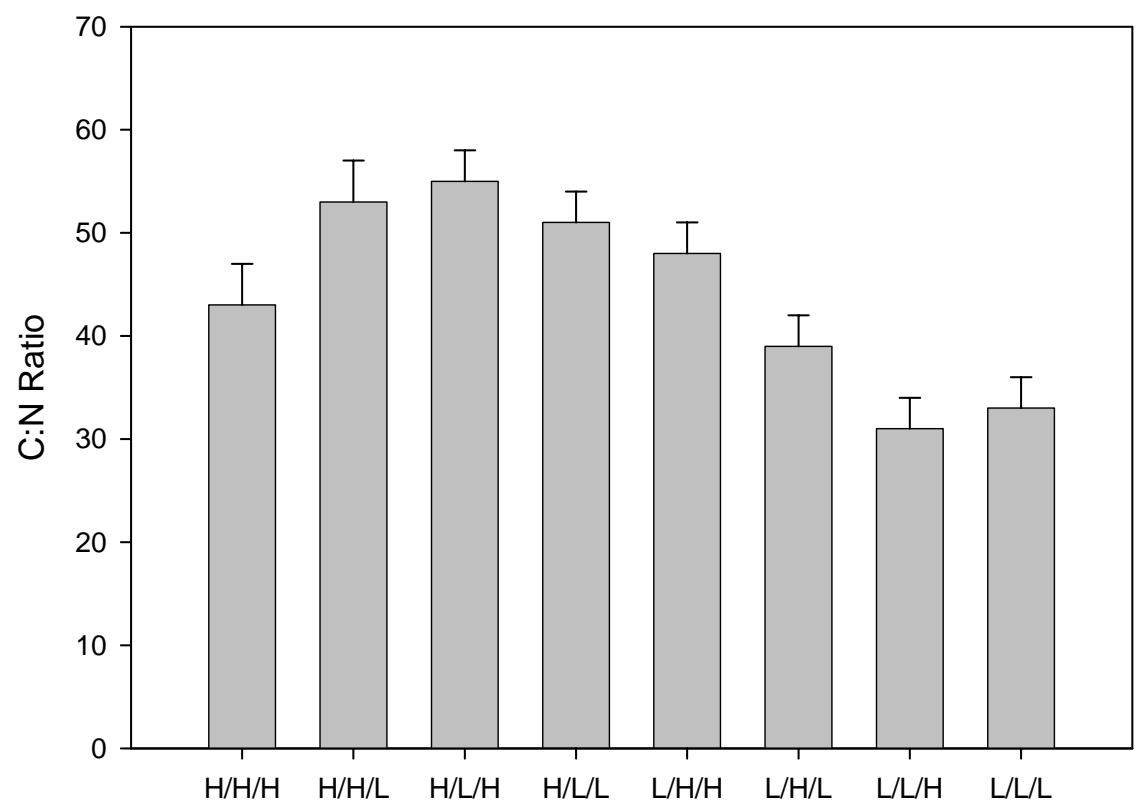

Transplant Elevation / Nitrogen Treatment / Origin Elevation 


\section{DISCUSSION}

Genotype and Population Responses

As seen in other species (Garbutt and Bazzaz 1987), the populations of J. effusus studied here contained both specialist and generalist genotypes, although the majority had a typical norm of reaction associated with a generalist response. Generalist ecotypes typically maintain more equable response across environments, producing a relatively low phenotypic variation. It is reasonable to assume that this is the result of significant physiological plasticity. This "jack-of-all trades; master of none" strategy is typically found in variable environments. The specialist approach has a relatively tightly constrained response to a very specific, typically long-term set of environmental conditions (Kassen 2002). Low tolerance to environmental change is due to antagonistic pleiotropy, which suggests that mutations or traits that help maximize fitness in one environment are not beneficial and may be harmful in other environments (Kassen 2002, Elena and Sanjuan 2003).

Selective pressures resulting from the environmental constraints at our field sites have produced both generalists and specialists. Genotypes from the Agricultural Farm and Chestnut Ridge field sites responded as generalists to the different nutrient levels among sites. White Park Genotypes responded as generalists except one, WP-10, which appeared to be a specialist in the environmental conditions (i.e. high nitrogen) found in the Agricultural Farm site. Three genotypes from the Trout Pond responded as specialists within highnutrient environments suggesting that environmental conditions at the Trout Pond have remained uniform long enough to select for more specialized genotypes. Generally, our data suggest that genotypes from low-nutrient sites responded more as generalists to nitrogen 
availability, whereas the majority of the specialists genotypes originated in high-nitrogen sites.

To understand better how the genotypes were responding to the environment, we examined the niche structure in response to nitrogen availability. This analysis gives measures of the relative niche breadth (equability) and magnitude of response between genotypes of interest. Garbutt and Zangerl (1983) proposed that highly equable responses would be correlated with a lower magnitude of response because of a physiological tradeoff (Garbutt and Bazzaz 1987). Our data suggest that Chestnut Ridge genotypes were more uniform and had a larger niche breadth than other genotypes. White Park genotypes were smaller than average, implying a generalist approach to occupying its niche, based on my assumption that high-resource specialists would maximize growth. However, one White Park genotype was a specialist with respect to the performance of genotypes from the Agricultural Farm site.

Magnitude of response and equability were positively correlated among genotypes from high-nitrogen sites (Trout Pond and Ag Farm), supporting Garbutt and Zangerl’s (1983) contention of a possible tradeoff between equability and magnitude of response. This tradeoff has ecologically important implications on the potential plasticity of a genotype across a resource gradient. Highly equable genotypes could fill broader range of niches using a generalist approach, whereas genotypes with high magnitude would specialize within a resource environment. As a result, the niche for a given genotype could be controlled by resource availability and resulting tradeoffs between resource acquisition and use efficiency.

In this study, J. effusus growth varied in response to the nitrogen level within the transplant site. Generally, plants originating from high-nitrogen populations that were 
transplanted into high-nitrogen sites maintained growth and production of tiller area observed similar to their home site. Agricultural Farm and White Park populations had higher mean tiller area over time, suggesting differences in growth based on elevation. I attribute low performance and growth early in the growing season to transplant shock.

We believe that a "home site advantage" relationship exists in populations within our experiment. As a result of higher resource acquisition, ecotypes from high-nitrogen sites exhibit the most fitness for other high-nitrogen environments. This partially supports our idea of a negative correlation between resource use and acquisition. However, tiller area production was high in some low-nitrogen sites (i.e. Chestnut Ridge), suggesting that another suite of genetic characters were being enacted upon. Home-site advantages have developed to maximize the fitness of the genotype to specific environmental conditions. It is important to point out that, a population's growth greatly decreases when faced with new nutrient condition compared to home or similar-status sites. Pigliucci (2001) suggests that resource limitations might result in magnified phenotypic differences. Previous environmental changes (i.e. local air pollution, increased $\mathrm{CO}_{2}$ levels, heavy metals) may have elicited adaptations within affected species, and, when faced with a relatively new change, populations could rely on this memory or previous experiences in order to survive (Ernst 1993). Since this field study lasted one growing season we cannot infer long-term plastic responses within our study populations. However, significant changes in the growth patterns of $J$. effusus were observed within weeks from the initial transplant shock. We hypothesize that foreign genotypes could potentially shift their phenotypic expression to meet the needs of the new environmental conditions in successive growing seasons. Overall, it is important to understand that genotypes and their environment interact uniquely and that this interaction 
results in a wide variety of potential phenotypic outcomes (Sultan and Bazzaz 1993). This wide breadth of variability results in the maintenance of genetic diversity within the populations.

Biomass allocations were highest in the populations originating from Chestnut Ridge site. This increased allocation is unexpected since this is a low-nitrogen site. Plants transplanted to the Agricultural Farm and White Park exhibited greater biomass production than in other sites. Both of these sites are at a lower elevation and implies a potential interactions of elevation upon populations. Plants transplanted to high-elevation sites (Trout Pond and Chestnut Ridge) had 20 \% higher C:N ratios, suggesting that individuals in these locations were becoming more efficient in nitrogen utilization.

\section{Elevation Response}

I expected plant populations from cooler environments to be shorter with reduced growth and expressing increased resource-use efficiency (Chapin and Chapin 1981). Therefore, it is logical to assume that, when transplanted to lower elevations where environmental characteristics are more favorable for growth and development, this transplant effect would stimulate a population's growth potential. The results of this study appear to support the findings of Chapin and Chapin (1981). Interestingly, some of the general assumptions of nitrogen-elevation model were not completely supported. Most notably, tiller biomass and nitrogen accumulation were in opposite directions to that expected by the model, suggesting the multifaceted role of elevation was underestimated within our model assumptions.

\section{Ecotype Response}


We hypothesized that inherent negative correlations exist between resource utilization and acquisition, resulting in individuals that have become strongly adapted to their specific home environmental conditions (relative elevation and nitrogen) and that cannot rapidly respond to the differing environmental conditions. This study showed a strong overall trend for high-elevation populations growing in low-nitrogen environments to have higher tiller area and growth rates. This is counter to the model proposed by Garbutt and McGraw (see Chapter 1). Their model suggests that plants from low-resource environments should have considerably lower AGR's than those from high-resource environments. Fundamentally, individuals from low-resource environments should have evolved attributes to increase resource use efficiency. In other words, populations from this environment invest in optimal or efficient usage of a low-supply resource (i.e. nitrogen). This conservative allocation to biomass helps ensure the survival and persistence of plants in resource-limited environment. Ecotypes from high-resource environments make gross resource investments into biomass. This increased allocation to biomass helps overcome competition.

The plasticity of $J$. effusus appears to be most affected by differences in elevation rather than nitrogen availability. It is unusual that plant populations at high elevation produced the most biomass at low- rather than high-nitrogen conditions. This might imply that plastic shifts occur much more slowly with nitrogen rather than factors associated with elevation. Although nitrogen indeed is an important controlling factor on the plasticity of $J$. effusus, its effect is far outweighed by elevation. This shift is unusual because these plants should not be carbon-limited, but might reflect carbon stress due to transplanting and adjusting to new environmental conditions. Dueck (et al. 1991) found that moderate increases in nitrogen supply could result in increased frost sensitivity in plants. This suggests 
that plants accustomed to high-nitrogen soils might be more sensitive to nitrogen acquisition and, therefore, have lower growth rates when transplanted to high-elevation sites. As a result, ecotypes might switch from nitrogen acquisition and accumulation to carbon storage for over-wintering or a reproductive outburst (Pianka 1994). This interaction can only be confirmed by a whole-plant examination (above and belowground) in field conditions. Response of populations to these environmental conditions is dependent on the physiological potential of all genotypes of a population to react to these temporal and spatial patterns of change (Ernst 1993, Fowden et al. 1993, Via et al. 1995, Bazzaz 1996, Gedroc et al. 1996, Bell and Sultan 1999).

Although differences exist between the proposed model and the results of this study, we believe our model is still useful as a guide to growth responses within the context of limiting resources. It is important to note that we assumed that nutrient availability would be the main factor acting upon genotypes within these populations. In our findings, the influence of elevation as a selective pressure on genotypes seemed more important. Since distribution of nutrients and other essential environmental characteristics are heterogeneous across a landscape, a separate model is needed to predict spatial distribution of individual ecotypes.

\section{$\underline{\text { Applications }}$}

The results from this study have implications that go beyond a basic understanding of ecological genetics and phenotypic plasticity. By applying information on home site advantage nitrogen and elevation interactions on the physiology of plant systems, environmental managers can begin to develop techniques for selection of genotypes for nitrogen remediation. Selection of genotypes that naturally (or artificially) grow in elevated 
nitrogen runoff at specific elevations result in phenotypes that maximize their fitness and growth rates within these conditions. Introduction of these special populations into constructed wetlands or buffer strips could lead to increased extraction of nitrogen and therefore a decreased impact upon the watershed.

The overall results of this study partially support the hypothesized negative correlation between RUE and RAR as predicted in the Garbutt and McGraw Model (Chapter 1). However, this study provides evidence that elevation has an important role in the growth and development of our study populations. When grown in high elevation, J. effusus increased aboveground growth regardless of nitrogen status. Although results of this study support our negative correlation hypothesis with respect to nitrogen, physiological responses to differences in elevation is apparently not governed by the same sets of genes as nitrogen response. To understand this phenomenon in terms of entire plant growth and life history strategy better, I also must quantify belowground growth. 


\section{REFERENCES}

Archibold, O.W. 1995. Ecology of World Vegetation. Chapman and Hall Press, New York.

Bazzaz, F.A. 1996. Plants in a changing environment. Cambridge University Press, Cambridge.

Bazzaz, F.A. and J.L. Harper. 1977. Demopgraphic analysis of the growth of Linum usitatissimum. New Phytologist 78:193-208.

Bell, D.L. and S.E. Sultan. 1999. Dynamic phenotypic plasticity for root growth in Polygonum: a comparative study. American Journal of Botany 86: 807-819.

Bennington, C.C. and J.B. McGraw. 1995. Natural selection and ecotypic differentiation in Impatiens pallida. Ecological Monographs 65:303-323.

Bennington, C.C. and J.B. McGraw. 1996. Environmental-dependence of quantitative genetic parameters in Impatiens pallida. Evolution 50: 1083-1097.

Bertness, M.D. and A.M. Ellison. 1987. Determinants of pattern in a New England salt marsh community. Ecological Monographs 57:129-147.

Brewer, S.J. and M.D. Bertness. 1996. Disturbance and intraspecific variation in the clonal morphology of salt marsh perennials. Oikos 77:107-116.

Brewer, S.J., T. Rand, J.M. Levine, and M.D. Bertness. 1998. Biomass allocation, clonal dispersal, and competitive success in three salt marsh plants. Oikos 82: 347-353.

Briggs D. and S.M. Walters. 1984. Plant Variation and Evolution. Cambridge University Press, London, England.

Chapin, F.S. III and M.C. Chapin. 1981. Ecotypic differentiation of growth processes in Carex aquatilis along latitudinal and local gradients. Ecology 62:1000-1009.

Chesapeake Bay Foundation. 2001. Chesapeake Bay Program: State of the Bay Report. Annapolis, Maryland.

Clausen, J., D.D. Keck and W.M. Hiesey. 1940. Experimental studies on the nature of species I: Effect of varied environments on western North American plants. Carnegie Institution of Washington Publication 581.

Demchik, M. and K. Garbutt. 1999. Growth of woolgrass in acid mine drainage. Journal of Environmental Quality 28:243-249. 
Dueck, T.A., F. Dorel, R. Ter Horst and L.J. Van der Eerden. 1991. Effects of ammonia and sulpher dioxide on the frost sensitivity of Pinus sylvestris. Water, Air, Soil Pollution 54:35-49.

Elena, S. and R. Sanjuan. 2003. Climb every mountain?. Science 302:2074-2075.

Ernest, S.K. and J.H. Brown. 2001. Homeostasis and compensation: The role of species and resources in ecosystem stability. Ecology 82:2118-2132.

Ernst, W.H.O. 1993. Population dynamics, evolution and environment: Adaptations to environmental stress. IN L. Fowden, T. Mansfield, and J. Stoddart [eds], Plant Adaptation to Environmental Stress, pp. 19-44. Chapman and Hall, New York.

Fisher, R.A. 1920. Some remarks on the methods formulated in a recent article on "the quantitative analysis of plant growth?”. Annuals of Applied Biology 7:376.

Fowden, L., T. Mansfield and J. Stoddart. 1993. Plant Adaptation to Environmental Stress. Chapman and Hall, New York, New York.

Garbutt, K. and F.A. Bazzaz. 1987. Populations niche structure: Differential response of Abutilon theophrasti progeny to resource gradients. Oecologia 72:291-296.

Garbutt, K. and A.R. Zangerl. 1983. Application of genotype-environmental interaction analysis to niche quantification. Ecology 64:1292-1296.

Gedroc, J.J., K.D.M. McConnaughay and J.S. Coleman. 1996. Plasticity in root/shoot partitioning: optimal, ontogenetic, or both? Functional Ecology 10:44-50.

Grime, J.P. 1979. Plant strategies and vegetation processes. Wiley and Sons, New York.

Grime, J.P., J.C. Crick, and J.E. Rincon. 1986. The ecological significance of plasticity. IN : D.H. Jennings and A.J. Trewavas [eds.], Plasticity in Plants, pp 5-29. Pindar Scarborough, North Yorkshire.

Grime, J.P. 1994. The role of plasticity in exploiting environmental heterogeneity. IN M.M. Caldwell and R.W. Pearcy [eds.], Exploitation of Environmental Heterogeneity by Plants, pg 1-21. Academic press, New York, NY.

Harper, J.L. 1977. Population Biology of Plants. Academic press. New York.

Hutchings, M.J., E.A John and D.K. Wijesinghe. 2003. Toward understanding the consequences of soil heterogeneity for plant populations and communities. Ecology 84:2322-2334.

Johnson, C.M., P.R. Stout, T.C. Broyer and A.B. Carlton. 1957. Comparative chlorine requirements of different plant species. Plant and Soil 8:337-353. 
Lewontin, R.C. 1978. Adaptation. Scientific American 239:213-230.

Lortie, C.J. and L.W. Aarssen. 1996. The specialization hypothesis for phenotypic plasticity in plants. International Journal for Plant Science 157: 484-487.

Kassen, R. 2002. The experimental evolution of specialists, generalist, and the maintenance of diversity. Journal of Evolutionary Biology 15:173-190.

Marschner, H. 1995. Mineral Nutrition of Higher Plants. Academic Press, New York.

McGraw, J.B. 1987. Experimental ecology of Dryas octopetala ecotypes IV: Field photosynthesis of reciprocal transplants. Holarctic Ecology 10:308-311.

McGraw, J.B. and K. Garbutt. 1990. Demographic growth analysis. Ecology 71:11991204.

Mencuccini, M, P. Piussi and A.Z. Sulli. 1995. Thirty years of seed production in a subalpine Norway spruce forest: Patterns of temporal and spatial variation. Forest Ecology and Management 76:109-125.

Mooney, H.A., R.W. Pearcy and J. Ehleringer. 1987. Plant physiological ecology today. Bioscience 37:18-20.

Nault, A. and D. Gagnon. 1988. Seasonal biomass and nutrient allocation patterns in wild leek (Allium tricoccum Ait.), a spring geophyte. Bulletin of the Torrey Botanical Club 115: 45-54.

Pianka, E.R. 1994. Evolutionary Ecology. Harper Collins Publishing, New York.

Pigliucci, M. 2001. Phenotypic Plasticity: Beyond Nature and Nurture. John Hopkins University Press. Baltimore, Maryland.

Santamaria, L., J. Figuerola, J.J. Pilon, M. Mjelde, A.J. Green, T. De Boer, R.A. King and R.J. Gornall. 2003. Plant performance across latitude: The role of plasticity and local adaptation in an aquatic habitat. Ecology 84:2454-2461.

SAS. 1994. SAS/JMP User’s Guide. Release 3.01 Edition. SAS Institute, Cary, NC.

Sultan, SE. 1987. Evolutionary implications of phenotypic plasticity in plants. Evolutionary Biology 21:127-176.

Sultan, S.E. and F.A. Bazzaz. 1993. Phenotypic plasticity in Polygonum persicaria II. Norms of reaction to soil moisture and the maintenance of genetic diversity. Evolution 47:1032-1049. 
Via, S, R. Gomulkiewicz, G. De Jong, S.M. Schlicting, and P.H.Van Tienderen. 1995. Adaptive phenotypic plasticity: consensus and controversy. Trends in Ecology and Evolution 10:212-217.

Walter, H. 1973. Vegetation on the Earth in relation to climate and the eco-physiological conditions. English Universities Press, London, UK. 
CHAPTER 3

CHANGES IN JUNCUS EFFUSUS L. ROOT MORPHOLOGY IN RELATION TO NITROGEN AVAILABILITY 


\section{INTRODUCTION}

Historically, plant roots have been the least-studied and often-ignored aspect of plant biology. Ironically, this forgotten portion is likely the most essential component of the entire plant biological system. Root systems are comprised of a congregate of several individual components that together constitute what Waisel et al. (2002) appropriately called the functional "Hidden Half” of plants. Plant roots perform numerous biologically significant tasks including nutrient uptake, carbon compound release for mycorrhizal interactions, structural support, and carbohydrate storage (Bohm 1979, Feldamn 1984, Wilcox 1968). It is estimated that roots can contribute $40-85 \%$ of net primary productivity in some ecosystems (Fogel 1985, Fitter 1987).

The inherent opaque nature of soil and the vast network of roots that are deployed into the rhizosphere make quantification extremely difficult (Fitter and Stickland 1992, Nielsen et al 1997). Over the past decade, advances in technology have permitted a better understanding of the importance of roots to overall plant growth and development. Rhizotron tubes (Day et al. 1996), ground penetrating radar (Butnor et al. 2003) and glass plate rhizotrons techniques (Gross et al. 1992) have allowed excellent, if limited, quantification of root growth and development.

Plant roots have some of the most adaptive characteristics of any plant organ. Since the primary functional task of roots is the uptake of nutrients and water, roots have a number of genetic adaptations to meet the challenges of the ever-changing and non-uniform nature of the rhizosphere. (Berntson and Woodward 1992, Berntson 1994, Lynch and Van Beem 1994, Casper et al. 2003). When considering the role roots play in plant survival within diverse environments, we must assume that plant roots have devised multiple and complex adaptive 
strategies to maintain fitness in soil, an often highly populated matrix of roots, microbes, insects, etc. (Eissenstat and Caldwell 1989, Jackson and Caldwell 1989, Lariguauderie and Richards 1994, Bell and Sultan 1999). Many studies have shown plants to have the inherent plasticity to shift root morphology in response to changes in the rhizosphere (Drew et al. 1973, Grime et al. 1986, Fitter 1987, Fitter and Stickland 1991, Zobel, 1991). Pregitzer (2003) noted that it is feasible for differing functionality to exist within a root system. If this assumption were true, all aspects of root morphology (i.e. lifespan, physiology, etc.) would become dependent on the acquired resource. This idea has strong implications for root plasticity in a heterogeneous environment. The effectiveness of this selective pressure to produce a specific and effective adaptation depends on three aspects of interactions between genotype and environment. These include functionality of adaptive plasticity (environmental tolerance), diversity of norms of reaction in a population, and distribution of variability within the environment (Levins 1968, Sultan 1987, Sultan and Bazzaz 1993).

Soil nutrient status provides a powerful selective force on plant populations. Genetic variation seems to exist within species for the ability to utilize, or at least tolerate, high levels of nutrients. Garbutt and McGraw (chapter 1) postulated that individuals in a population do not have the ability to maintain fitness when subjected to rapidly changing nutrient availabilities. The inherent negative correlation between efficiency of resource utilization (RUE) and effectiveness of resource acquisition (RAR) prevents the unique physiological traits of both strategies from being simultaneously expressed. As a result, increased resource use efficiency increases an individual's fitness in low-resource environments. Conversely, high resource acquisition rates are associated with high resource availability. Physiological characteristics of RUE include conservative growth rates with lower amounts of biomass 
containing increased tissue quality. Plants from high-resource environments are characterized by high growth rates that result in abundant low tissue quality biomass. The plants' "perception" of response to a changing environment results in two opposing strategies: one becomes conservative with its resources to ensure its place in the environment whereas the other enters into a competitive race to prevent other (potentially better-adapted) species from gaining a foothold on its environment.

These opposing strategies have developed in plant populations that have persisted in relatively homogeneous environments. The long-term expression of these traits has resulted in a life history form, or an “ecotype”, for each respective site (Darwin 1859, Turesson 1922, 1930, Bennington and McGraw 1995). Although selective pressures have forced these populations to express a specific growth form continually, the potential for genetic variation remains in the gene pool (Bennington and McGraw 1996). If environmental conditions change, the standing population has the potential to shift the expression of its phenotype to meet its changing environment. Past studies suggested that organisms within stressful or unfavorable environments tend to have increased environmental variance and decreased heritability (Blum 1988, Bennington and McGraw 1996).

Despite the elusive nature of the plant root, roots provide opportunities to explore the critical phenomena of plasticity in life histories. Changes that occur in developing root systems are a function not only of the environment, but also of the genetics of the system. This interactive ability has evolved over the past 400 million years of natural selection and has made the root system the most plastic of all plant structures (Fitter 1987). In addition, plant roots are the most dynamic plant organs when faced with changes in environmental conditions. The resulting ability to exploit resources in the environment is a direct function 
of the genotype $\mathrm{x}$ environment interaction and a plants phenotypic plasticity. For example, Jackson et al. (1990) found that root systems have an exceptionally high rate of plasticity in response to phosphorus fertilization. This morphological plasticity implies a critical connection between nutrient uptake capacity and mineral nutrient capture (especially in the short-term fertilization pulses).

The goal of this study was to determine changes in root morphology related to the life history and application of nitrogen in the rhizosphere. I measured responses to simulated nitrogen environments to determine if the physiological RUE and RAR traits are negatively correlated within root systems. Due to the inherent negative correlation between these two traits, we believe that plant root systems will not be able to respond rapidly to the same resource in opposing nitrogen availability environments.

Juncus effusus L. (common rush) was the model organism for this study due to its abundant representation in most aquatic and wetland environments. The potential for $J$. effusus to reproduce asexually (via vegetative propagation) makes this species and ideal candidate to examine the effects of variable nutrient environments in relation to different genotypes because treatments can be applied to multiple members of the same genetic structure. 


\section{METHODS AND MATERIALS}

\section{$\underline{\text { Plant Source }}$}

I collected Juncus effusus L. plants from two high-nutrient sites (WVU Agricultural and Animal Science Farm and Trout Pond) and two low-nutrient locations (Chestnut Ridge Park Pond and White Park) in Monongalia County, WV. Sites were identified by standard total soil carbon:nitrogen content analysis by the WVU Department of Biology (Chapter 2; Figure 2.2). Each site was also identified by elevation; high (Trout Pond and Chestnut Ridge) and low (Agricultural Farm and White Park). Four tillers were collected from each of five widely spaced clumps of $J$. effusus at each site. Given the phalanx growth pattern of this species, I assumed that each clump was the offspring of a single seed and, hence, each tiller represented a single genotype. All plants were propagated vegetatively through a hydroponics technique using 0.25 strength Johnson’s stock nutrient solution (Johnson et al. 1957).

\section{Experimental Set-up}

Forty glass plate mini-rhizotrons were built from pieces of 0.25 inch $(0.64 \mathrm{~cm})$ plate glass that measured 8.5 inches $(21.59 \mathrm{~cm})$ wide by 22 inches $(55.88 \mathrm{~cm})$ long. Four U-bolts secured all a U-shaped length of 1 inch $(2.54 \mathrm{~cm})$ diameter black vacuum tubing with an internal wire support between two glass plates. (Figure 3.1). I filled each mini-rhizotron with pro-mix potting soil (without nitrogen) and planted them with a corresponding genotype of $J$. effusus. Twenty rhizotrons were treated with a 0.25 strength Johnson's stock nutrient solution containing nitrogen, while the second group received the same stock solution without nitrogen. 
Experimental treatments began on February 26, 2002 in environmental growth chambers and later in a greenhouse (Morgantown, WV) at an angle of $30^{\circ}$ from vertical. Changes in root development and morphology were tracked by taking a digital root images. These images were acquired approximately every three to four days with a 3.3 mega pixel Olympus C-3040 Zoom Camedia digital camera. I also measured changes in tiller morphology (total tiller number, highest tiller height, and tiller area). On May 1, 2002, I harvested all plants rinsed soil particles from the roots, and acquired final root images with a Microtek ScanMaker 9600 XL flatbed scanner.

\section{Sample Preparation}

After harvesting the plants, I separated the tillers from the roots and dried them in individually labeled paper bags with a mechanical convection oven at $70^{\circ} \mathrm{C}$. I weighed each sample for total biomass and ground them using a UDY Cyclone Sample Mill (Fort Collins, CO) with a $20 \mathrm{~mm}$ filter screen. I analyzed the processed samples for total carbon-nitrogen using the Carlo Erba CHNS model NA 1500 Analyzer (Carlo Erba, Milan, Italy) with an Acetanilide standard.

\section{Data Analysis}

I used the MacRHIZO Pro version 3.10b (Régent Instruments, Québec, Canada) software package to analyze the rhizotron images and determine multiple aspects of root morphology: length, diameter, surface area, total volume, total number of tips, forks and crossings, etc. I compared above- and belowground data to morphological growth and developmental data collected from the rhizotron images and analyzed the data for elevation and nitrogen effects. 
To provide a complete understanding of changes in growth over time in each microenvironmental setting, I used two measures of grow rate. I calculated absolute growth rate (AGR) as follows:

$$
\text { Absolute Growth Rate }=\frac{x_{2}-x_{1}}{t_{2}-t_{1}}
$$

where $\mathrm{x}$ is the size of a plant component at time t (Demchik and Garbutt 1999; McGraw and Garbutt 1990). I also used relative growth rate (RGR) as an estimate of the changes in the efficiency of $J$. effusus to the given treatments. This index was calculated by the following equation:

$$
\text { Relative Growth Rate }=\frac{\ln x_{2}-\ln x_{1}}{t_{2}-t_{1}}
$$

where $x$ is size of component at time $t$. (McGraw and Garbutt 1990). I used SPSS version 11.5 (SPSS, Chicago, IL) for my statistical analysis. 
Figure 3.1: Minirhizotron design for root morphology observation.

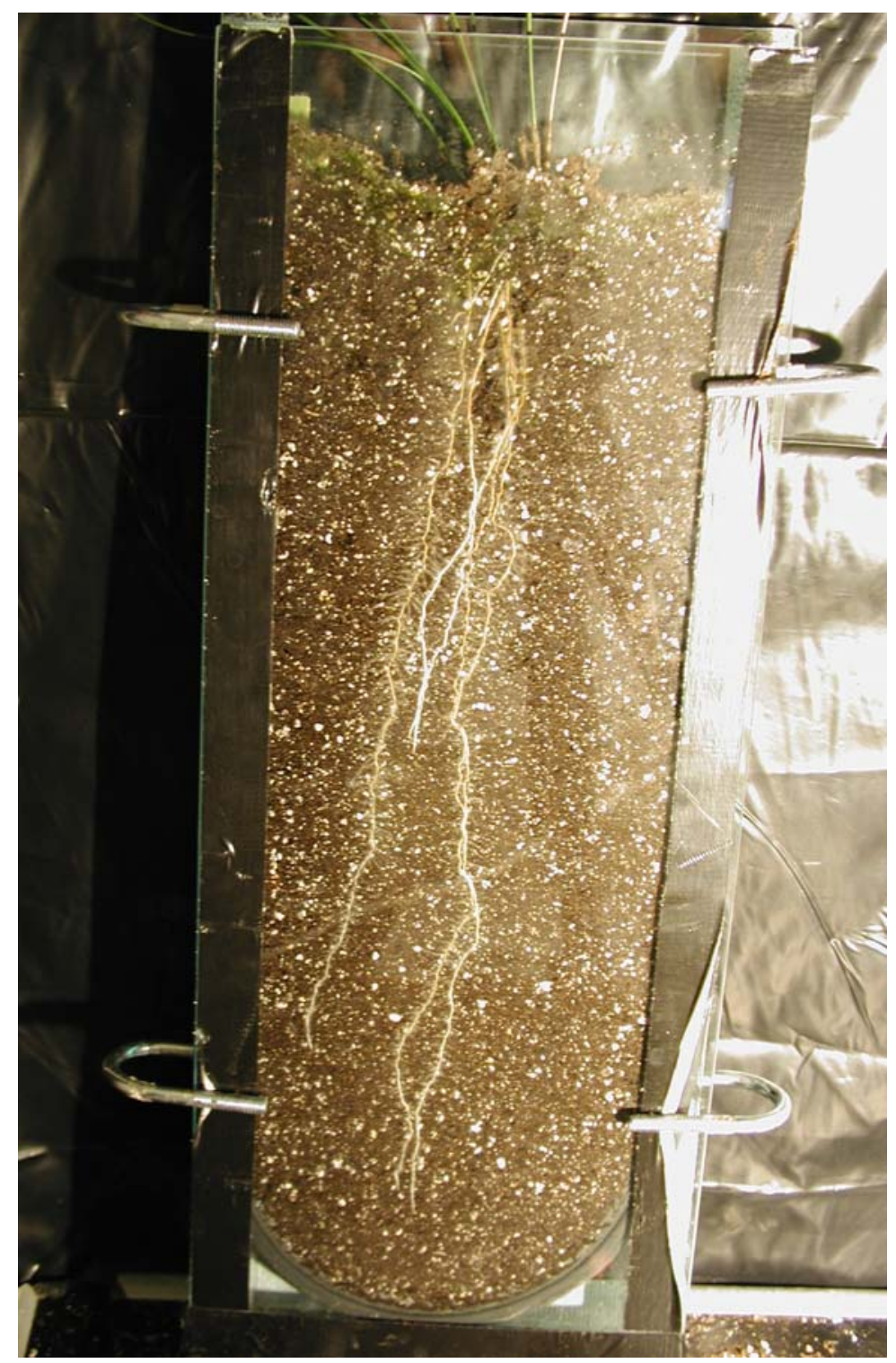




\section{RESULTS}

\section{Tiller Area}

Tiller area (Table 3.1) varied significantly over time (Date $\mathrm{p}=0.0128)$. Tiller area was greatest in both high-nitrogen and high-elevation populations (Figure 3.2; Origin nitrogen $\mathrm{p}<0.0001$; Origin elevation $\mathrm{p}=0.0091$ ). Aboveground area was higher within high-nitrogen populations grown in high elevations (Origin elevation*origin nitrogen $\mathrm{p}<0.0001$ ). Plants originating from high-nitrogen, high-elevation sites produced more tiller area when treated with high-nitrogen treatments (Figure 3.3; Transplant nitrogen*origin elevation*origin nitrogen $\mathrm{p}=0.0091$ ). However, plants originating from low-nitrogen, high-elevation populations produced less tiller area when subjected to high-nitrogen treatments. There were no significant treatment effects on AGR or RGR over the course of the experiment.

\section{$\underline{\text { Root Length }}$}

There were significant variations between dates in root length (Table 3.2; Date $\mathrm{p}<0.0001$ ). Root length was significantly longer in high-nitrogen populations (Figure 3.4; Origin nitrogen $\mathrm{p}=0.0092$ ). High-elevation populations also had a higher mean root length compared to low-elevation sites (Figure 3.5; Origin elevation $\mathrm{p}=0.0004$ ).

\section{$\underline{\text { Root Surface Area }}$}

Root surface area measurements varied significantly over time (Table 3.2; Date $\mathrm{p}<0.0001$ ). Root surface area was significantly higher in high-elevation populations (Origin elevation $\mathrm{p}=0.0035)$. Mean root surface area was highest in high-nitrogen populations from high elevations (Figure 3.6; Origin nitrogen*origin elevation $\mathrm{p}=0.0269$ ). Growth rates (AGR) of root surface area also varied over time (Table 3.3; Measurement Interval 
$\mathrm{p}<0.0001)$. In addition, there were significant variations over time for the both nitrogen populations among the different origin elevations (Measurement Interval*origin nitrogen*origin elevation $\mathrm{p}=0.0120$ ). Growth efficiency measurements only varied over time (Table 3.3; Measurement Interval p=0.0117).

\section{$\underline{\text { Root Diameter }}$}

Significant differences in root diameter were observed over time (Table 3.2; Date $\mathrm{p}<0.0001$ ). Diameters were higher in low-nitrogen populations compared to high-nitrogen sites $(p=0.0391)$. Plants from low-nitrogen populations at low elevations produced larger root diameters (Figure 3.7; Origin nitrogen*origin elevation $\mathrm{p}=0.0001$ ). There were no significant differences in absolute growth rates (AGR) among treatments (Table 3.3). Although, the efficiency (RGR) of root diameter production varied over time for nitrogen populations in differing nitrogen treatments, no definitive trend for this interaction was evident.

\section{$\underline{\text { Root Tips }}$}

The production of root tips varied over time (Table 3.2; Date <0.0001). Highnitrogen populations had the most root tips (Figure 3.8; Origin nitrogen $\mathrm{p}=0.0007$ ). The same trend was seen in high-elevation populations (Figure 3.9; Origin elevation $\mathrm{p}<0.0001$ ). High-elevation populations produced more root tips over time than low-elevation populations (Figure 3.10; Date*origin elevation $\mathrm{p}=0.0367$ ). Nevertheless, there was a noticeable drop at the fifth measurement due to transfer from the environmental growth chambers to the greenhouse. Absolute growth rate of root tips (Table 3.3) was significantly different over time (Measurement Interval $\mathrm{p}<0.0001$ ). Although significant, the interaction of differing 
nitrogen populations and elevations over time did not reveal a deterministic pattern (Measurement Interval*origin nitrogen*origin elevation $\mathrm{p}=0.00160$ ).

\section{$\underline{\text { Biomass }}$}

Biomass was only significantly different based on the origin nitrogen level of the populations (Table 3.4). Tiller biomass (Origin nitrogen $\mathrm{p}=0.0141$ ) and whole-plant dry biomass $(p=0.0296)$ was highest in populations from high-nitrogen sites (Figures 3.11 and 3.12 respectively). Root biomass did not significantly differ among nitrogen treatments. Root:shoot ratios (Table 3.4, Figure 3.17) were significantly higher in plants treated with nitrogen (Treatment Nitrogen $\mathrm{p}=0.0350$ ).

\section{Nutrient Composition}

Nitrogen analysis of tiller and root tissues did not reveal significant accumulation differences. Carbon accumulation was also not significantly different between treatments in both the above- and belowground components. Neither tiller or whole plant tissue analysis yielded significantly different C:N ratios between treatments (Table 3.4). However, root tissues appeared to have a significant difference in C:N ratios. Plants from low elevations had a higher mean $\mathrm{C}: \mathrm{N}$ ratio when compared to plants that originated from high-elevation sites such as the Trout Pond or Chestnut Ridge Park (Figure 3.13; Origin elevation $\mathrm{p}=0.0034$ ). Root C:N ratios were affected by nitrogen treatments (Treatment nitrogen $\mathrm{p}=0.0068)$. Roots that were treated with a high-nitrogen Johnson's solution yielded higher carbon to nitrogen ratios (Figure 3.14). In terms of root:shoot ratios, nitrogen concentration was highest (Origin nitrogen $\mathrm{p}=0.0440$ ) in plants originating from low-nitrogen environments 
(Figure 3.15). Furthermore, root:shoot C:N ratios are highest in plants originating from lownitrogen populations (Figures 3.16 and 3.17; Table 3.4, Origin nitrogen $\mathrm{p}=0.0370$ ). 
Table 3.1: Repeated measures analysis of variance for tiller area $\left(\mathrm{cm}^{2}\right)$. Type III mean squares are reported $(*=p<0.05)$.

\begin{tabular}{|c|c|c|}
\hline Source & DF & Tiller Area \\
\hline Date (D) & 10 & $724028.80 *$ \\
\hline Treatment Nitrogen (TN) & 1 & 19174.25 \\
\hline Origin Nitrogen (ON) & 1 & $1673388.44^{*}$ \\
\hline Origin Elevation (OE) & 1 & $246828.71 *$ \\
\hline $\mathrm{D} * \mathrm{TN}$ & 10 & 62182.58 \\
\hline $\mathrm{D}^{*} \mathrm{ON}$ & 10 & 68378.33 \\
\hline $\mathrm{TN} * \mathrm{ON}$ & 1 & 4614.35 \\
\hline $\mathrm{D} * \mathrm{TN} * \mathrm{ON}$ & 10 & 88175.38 \\
\hline $\mathrm{D} * \mathrm{OE}$ & 10 & 48799.44 \\
\hline $\mathrm{TN} * \mathrm{OE}$ & 1 & 9596.64 \\
\hline $\mathrm{D} * \mathrm{TN} * \mathrm{OE}$ & 10 & 18532.62 \\
\hline $\mathrm{ON} * \mathrm{OE}$ & 1 & 822804.30* \\
\hline $\mathrm{D}^{*} \mathrm{ON} * \mathrm{OE}$ & 10 & 53832.99 \\
\hline $\mathrm{TN} * \mathrm{ON} * \mathrm{OE}$ & 1 & $216569.41 *$ \\
\hline $\mathrm{D} * \mathrm{TN} * \mathrm{ON} * \mathrm{OE}$ & 10 & 51923.29 \\
\hline
\end{tabular}

Table 3.2: Repeated measures analysis of root length $(\mathrm{cm})$, surface area $\left.\mathrm{cm}^{2}\right)$, diameter $(\mathrm{cm})$ and number of root tips. Type III mean squares are reported $(*=p<0.05)$.

\begin{tabular}{|c|c|c|c|c|c|}
\hline Source & DF & $\begin{array}{c}\text { Root } \\
\text { Length }\end{array}$ & $\begin{array}{c}\text { Surface } \\
\text { Area }\end{array}$ & $\begin{array}{c}\text { Root } \\
\text { Diameter }\end{array}$ & $\begin{array}{l}\text { Root } \\
\text { Tips }\end{array}$ \\
\hline Date (D) & 9 & $5059662.32 *$ & $2350455.92 *$ & $0.17 *$ & $13394180.10 *$ \\
\hline Treatment Nitrogen (TN) & 1 & 9027.16 & 7618.95 & 0.00 & 10.00 \\
\hline Origin Nitrogen (ON) & 1 & 231853.05* & 62868.63 & $0.01 *$ & 746905.89 \\
\hline Origin Elevation (OE) & 1 & $437634.72 *$ & $151250.34 *$ & 0.00 & 1527975.09* \\
\hline $\mathrm{D} * \mathrm{TN}$ & 9 & 55406.58 & 31214.08 & 0.01 & 61739.24 \\
\hline $\mathrm{D} * \mathrm{ON}$ & 9 & 123616.19 & 41261.82 & 0.01 & 377886.28 \\
\hline $\mathrm{TN} * \mathrm{ON}$ & 1 & 11871.85 & 2076.75 & 0.00 & 2816.18 \\
\hline $\mathrm{D} * \mathrm{TN} * \mathrm{ON}$ & 9 & 43273.65 & 23704.93 & 0.01 & 168696.99 \\
\hline $\mathrm{D}^{*} \mathrm{OE}$ & 9 & 342541.86 & 164047.16 & 0.01 & $1157192.74 *$ \\
\hline $\mathrm{TN} * \mathrm{OE}$ & 1 & 83.46 & 368.01 & 0.00 & 1645.35 \\
\hline $\mathrm{D} * \mathrm{TN} * \mathrm{OE}$ & 9 & 112245.00 & 50209.65 & 0.00 & 185517.48 \\
\hline $\mathrm{ON} * \mathrm{OE}$ & 1 & 88448.36 & $86259.16^{*}$ & $0.02 *$ & 29782.19 \\
\hline $\mathrm{D} * \mathrm{ON} * \mathrm{OE}$ & 9 & 69653.56 & 32519.13 & 0.01 & 349904.76 \\
\hline $\mathrm{TN} * \mathrm{ON} * \mathrm{OE}$ & 1 & 18682.79 & 17970.36 & 0.00 & 88545.40 \\
\hline D*TN*ON*OE & 9 & 34159.94 & 14231.08 & 0.01 & 107793.59 \\
\hline
\end{tabular}


Table 3.3: Analysis of variance of absolute and relative growth rates for root surface area $\left(\mathrm{cm}^{2} /\right.$ day; $\mathrm{cm}^{2} / \mathrm{cm}^{2} /$ day), diameter ( $\mathrm{cm} / \mathrm{cm} /$ day) and number of root tips. Type III mean squares are reported $(*=p<0.05)$.

\begin{tabular}{|c|c|c|c|c|c|}
\hline Source & DF & $\begin{array}{l}\text { Root Surface } \\
\text { Area Absolute } \\
\text { Growth Rate } \\
\end{array}$ & $\begin{array}{c}\text { Root Surface } \\
\text { Area Relative } \\
\text { Growth Rate }\end{array}$ & $\begin{array}{c}\text { Root Diameter } \\
\text { Relative } \\
\text { Growth Rate } \\
\end{array}$ & $\begin{array}{c}\text { Root Tips } \\
\text { Absolute } \\
\text { Growth Rate }\end{array}$ \\
\hline Measurement Interval (D) & 8 & $13416.027 *$ & $0.598 *$ & $0.307 *$ & 87268.578* \\
\hline Treatment Nitrogen (TN) & 1 & 62.983 & 0.008 & 0.000 & 383.982 \\
\hline Origin Nitrogen (TN) & 1 & 6.578 & 0.001 & 0.003 & 346.931 \\
\hline Origin Elevation (OE) & 1 & 26.568 & 0.005 & 0.001 & 367.715 \\
\hline $\mathrm{D} * \mathrm{TN}$ & 8 & 1544.921 & 0.231 & 0.032 & 3123.283 \\
\hline $\mathrm{D} * \mathrm{ON}$ & 8 & 2461.099 & 0.064 & 0.028 & 16326.199 \\
\hline $\mathrm{TN} * \mathrm{ON}$ & 1 & 6.878 & 0.000 & 0.002 & 603.712 \\
\hline $\mathrm{D} * \mathrm{TN} * \mathrm{ON}$ & 8 & 922.803 & 0.234 & $0.040 *$ & 10194.615 \\
\hline $\mathrm{D} * \mathrm{OE}$ & 8 & 1503.371 & 0.074 & 0.023 & 18658.423 \\
\hline $\mathrm{TN} * \mathrm{OE}$ & 1 & 66.301 & 0.000 & 0.000 & 1361.028 \\
\hline $\mathrm{D} * \mathrm{TN} * \mathrm{OE}$ & 8 & 1264.449 & 0.090 & 0.006 & 9954.332 \\
\hline $\mathrm{ON} * \mathrm{OE}$ & 1 & 33.135 & 0.009 & 0.000 & 4350.390 \\
\hline $\mathrm{D} * \mathrm{ON} * \mathrm{OE}$ & 8 & $5077.187^{*}$ & 0.159 & 0.004 & $34760.812 *$ \\
\hline $\mathrm{TN}^{*} \mathrm{ON} * \mathrm{OE}$ & 1 & 73.385 & 0.001 & 0.000 & 227.415 \\
\hline $\mathrm{D} * \mathrm{TN} * \mathrm{ON} * \mathrm{OE}$ & 8 & 3748.160 & 0.218 & 0.009 & 15371.575 \\
\hline
\end{tabular}

Table 3.4: Analysis of variance of tiller and whole plant biomass (g), root carbon: nitrogen ratios, and root:shoot biomass (g), nitrogen concentrations (mg/g) and carbon:nitrogen ratios.. Type III mean squares are reported $(*=p<0.05)$.

\begin{tabular}{lccccccc}
\hline \hline Source & $\begin{array}{c}\text { Tiller } \\
\text { DF Biomass }\end{array}$ & $\begin{array}{c}\text { Total } \\
\text { Biomass }\end{array}$ & $\begin{array}{c}\text { Root } \\
\text { C:N }\end{array}$ & $\begin{array}{c}\text { Root:Shoot } \\
\text { Biomass }\end{array}$ & $\begin{array}{c}\text { Root:shoot } \\
\text { Nitrogen }\end{array}$ & $\begin{array}{c}\text { Root:Shoot } \\
\text { C:N }\end{array}$ \\
\hline $\begin{array}{l}\text { Treatment Nitrogen } \\
\text { (TN) }\end{array}$ & 1 & 0.00 & 0.00 & $534.89^{*}$ & $1.196^{*}$ & 0.194 & 0.307 \\
$\begin{array}{l}\text { Origin Nitrogen } \\
\text { (ON) }\end{array}$ & 1 & $0.69 *$ & $1.99 *$ & 8.77 & 0.222 & $0.261^{*}$ & $0.435^{*}$ \\
$\begin{array}{l}\text { Origin Elevation } \\
\text { (OE) }\end{array}$ & 1 & 0.00 & 0.03 & $446.21^{*}$ & 0.321 & 0.195 & 0.296 \\
TN*ON & 1 & 0.06 & 0.14 & 174.29 & 0.006 & 0.176 & 0.287 \\
TN*OE & 1 & 0.02 & 0.11 & 108.18 & 0.019 & 0.002 & 0.003 \\
ON*OE & 1 & 0.13 & 0.67 & 73.62 & 0.104 & 0.086 & 0.088 \\
TN*ON*OE & 1 & 0.13 & 0.36 & 7.15 & 0.006 & 0.001 & 0.049 \\
\hline
\end{tabular}


Figure 3.2: The effects of elevation on tiller area $\left(\mathrm{cm}^{3}\right)$ from differing nitrogen populations.

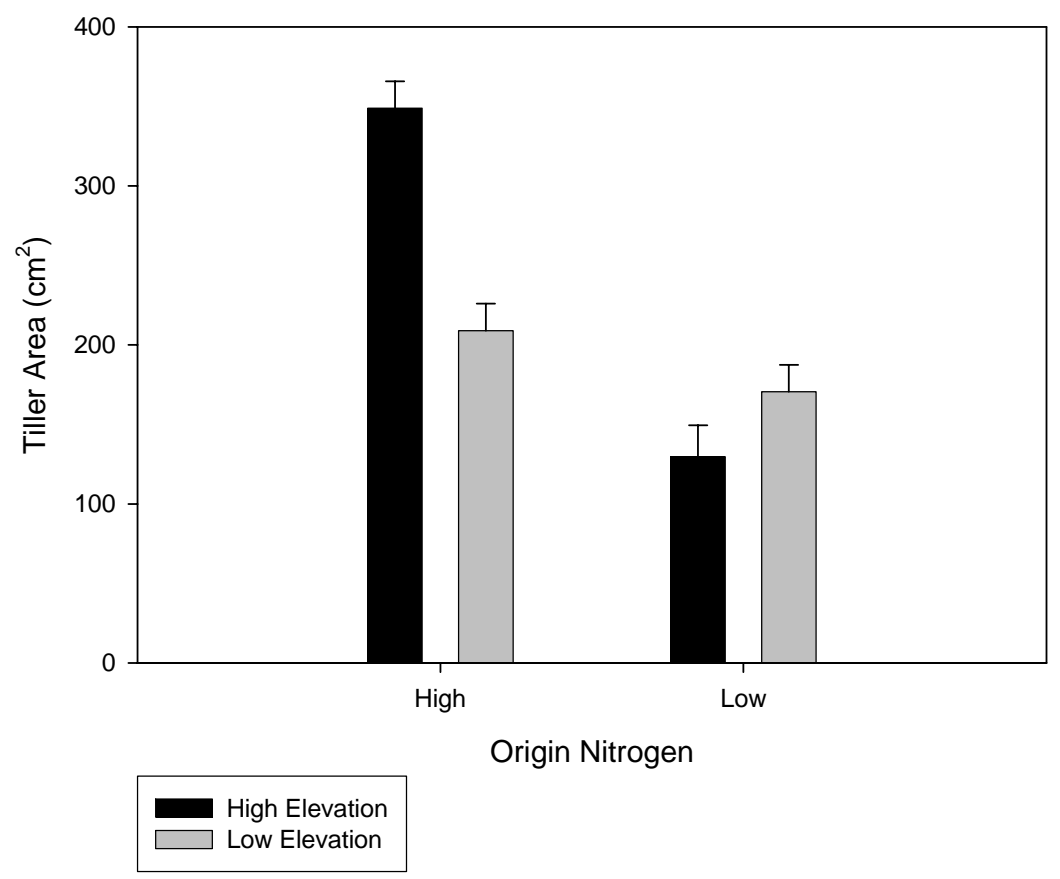


Figure 3.3: The effect of high-and low-nitrogen treatments on tiller area $\left(\mathrm{cm}^{3}\right)$ from differing nutrient and elevation populations.

High Transplant Nitrogen
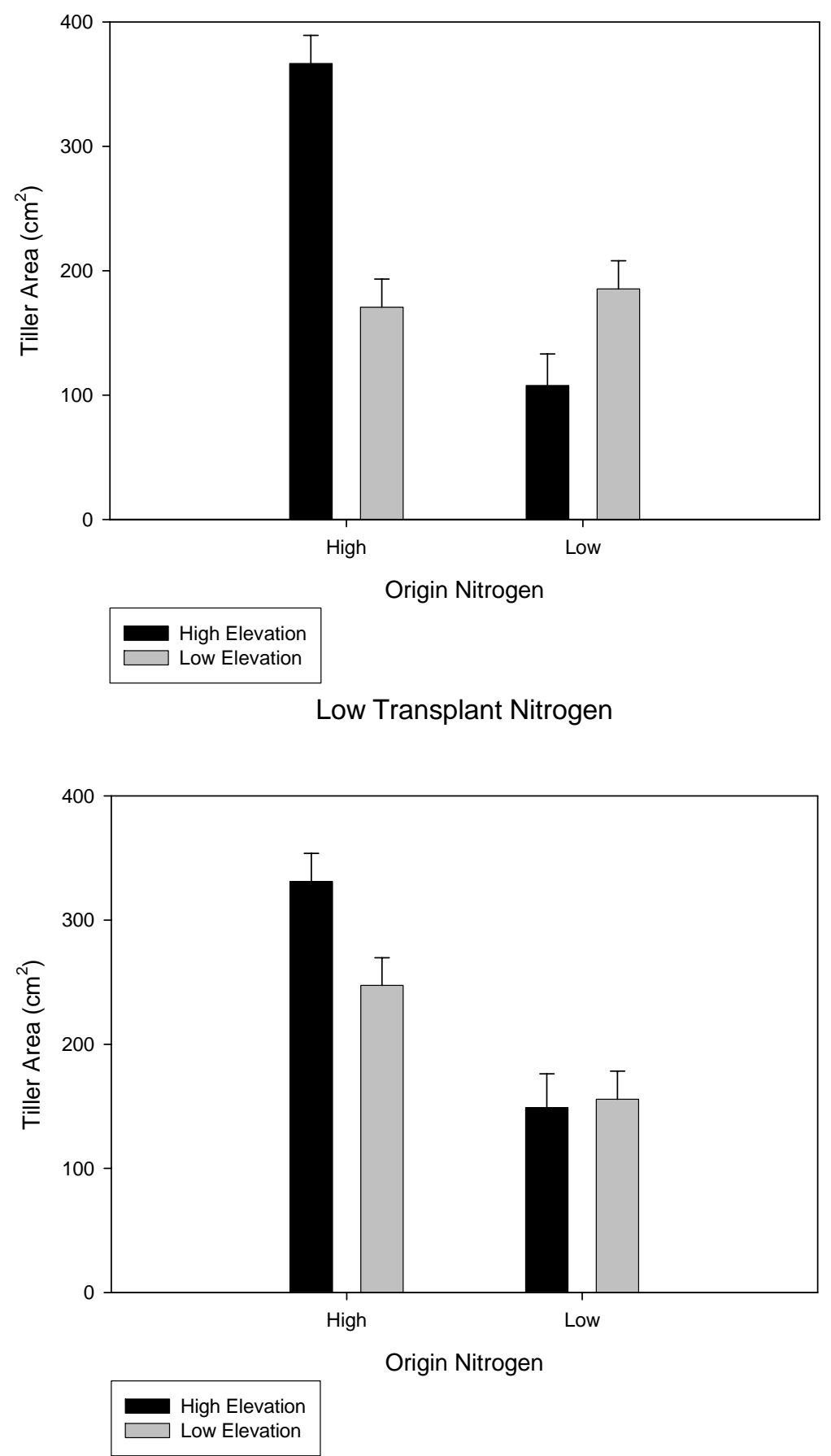
Figure 3.4: Differences in root length $(\mathrm{cm})$ between differing nitrogen populations.

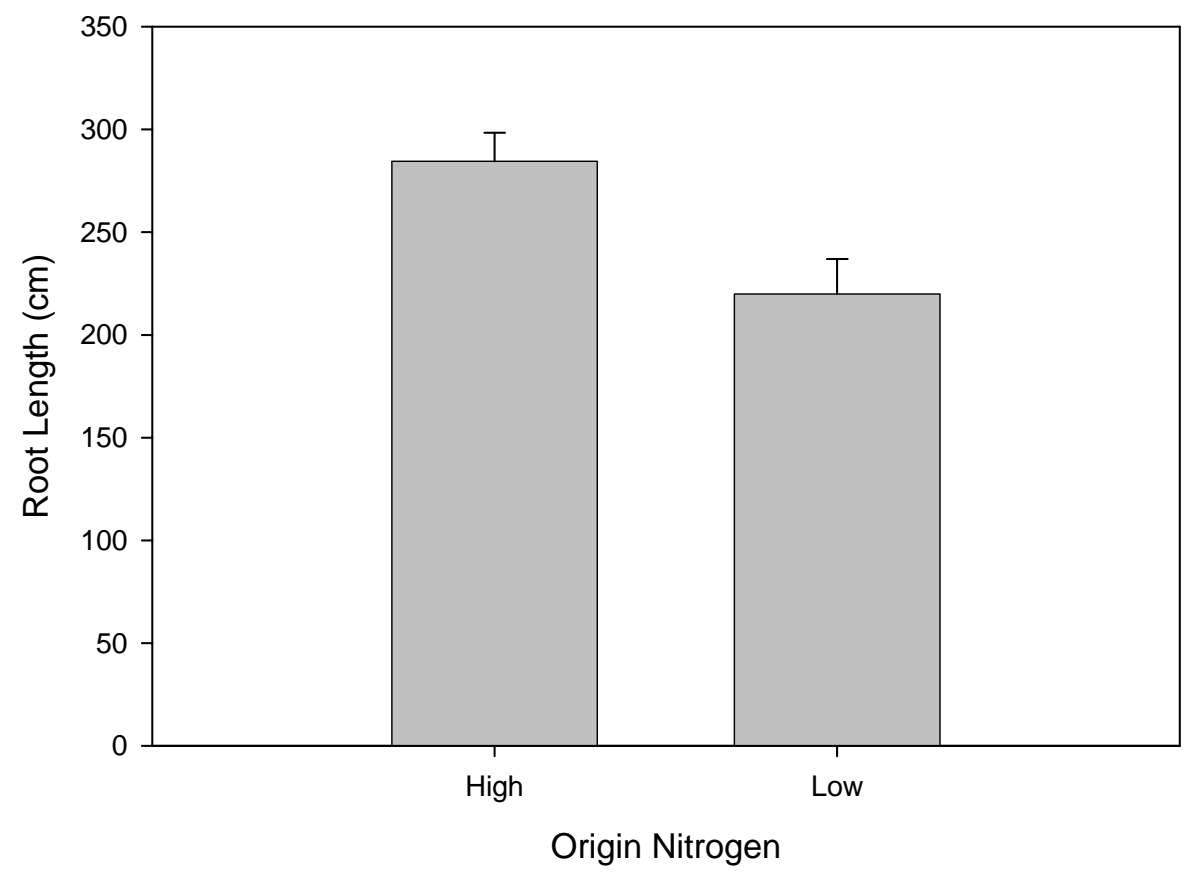

Figure 3.5: The effect of elevation on root length (cm).

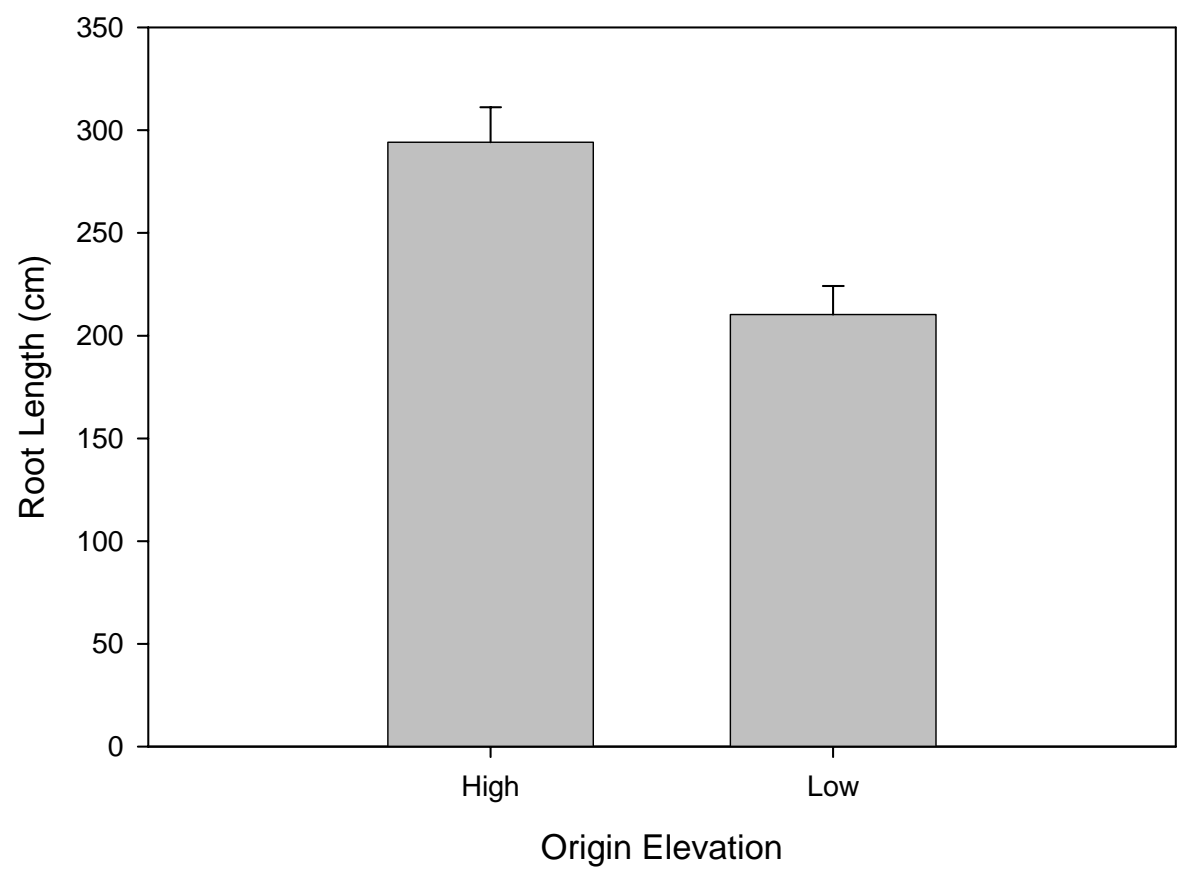


Figure 3.6: The effects of elevation on root surface area $\left(\mathrm{cm}^{3}\right)$ in two nitrogen populations.

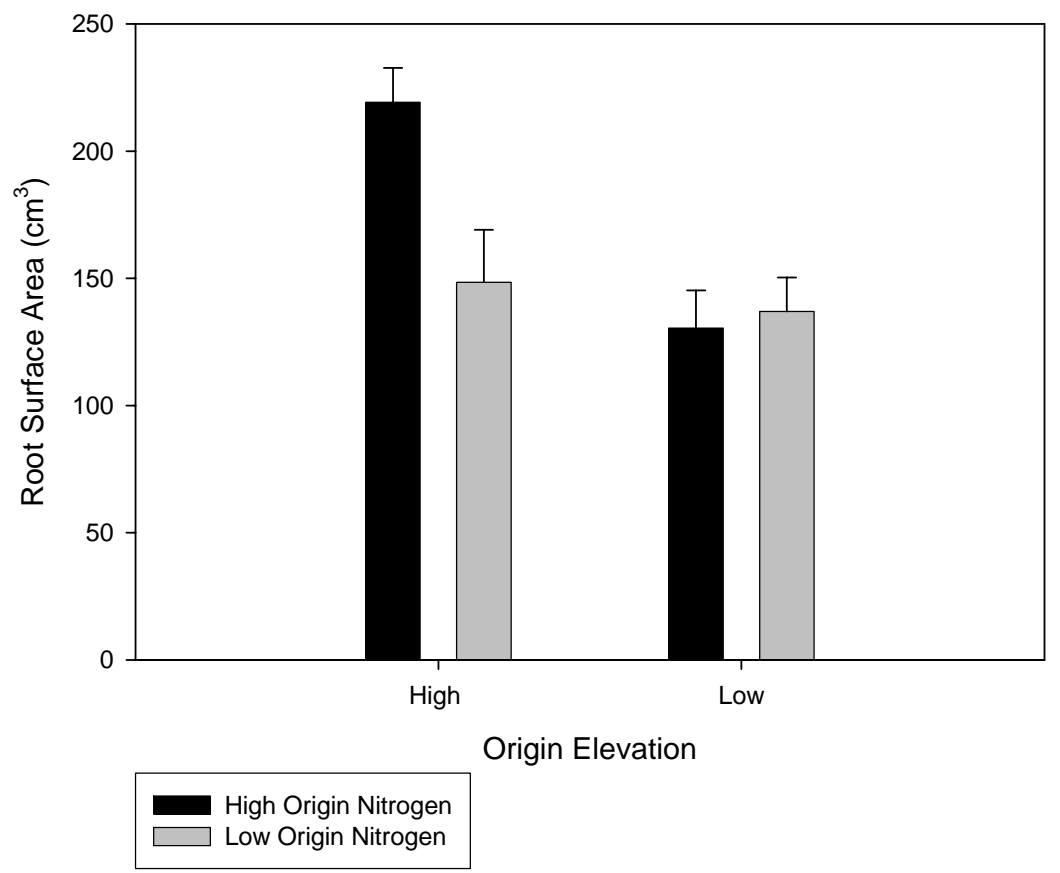

Figure 3.7: The effects of elevation on root diameter $(\mathrm{cm})$ in differing nitrogen populations.

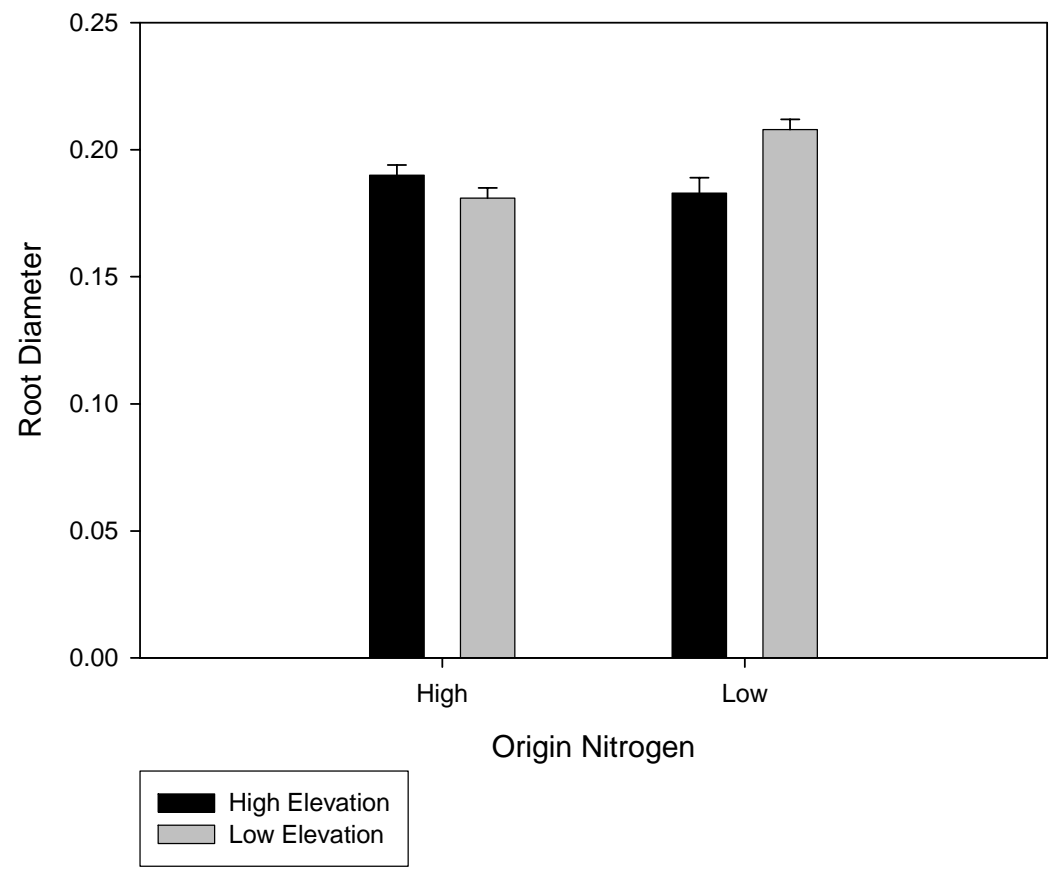


Figure 3.8: Differences in mean number of root tips in two nitrogen populations.

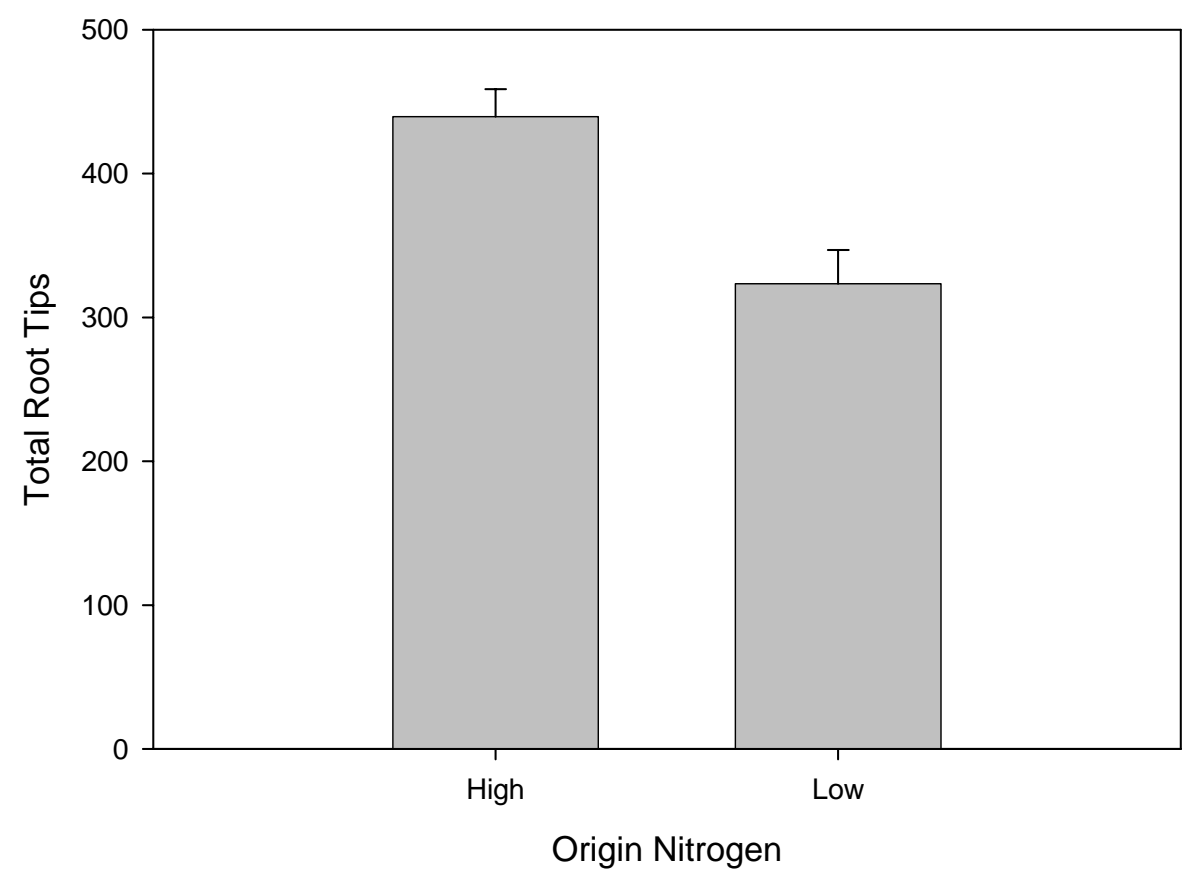

Figure 3.9: The mean number of root tips in opposing elevations.

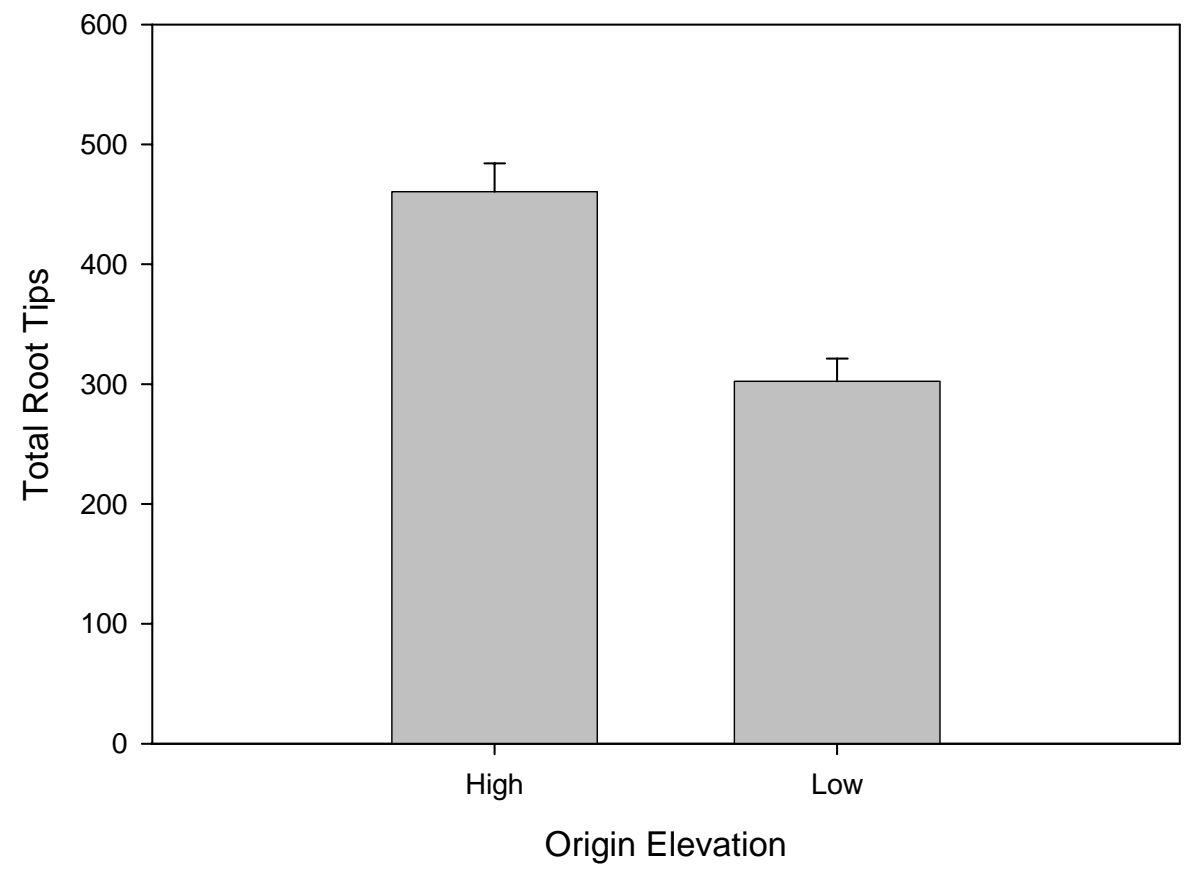


Figure 3.10: The effect of elevation on the mean number of root tips over time.

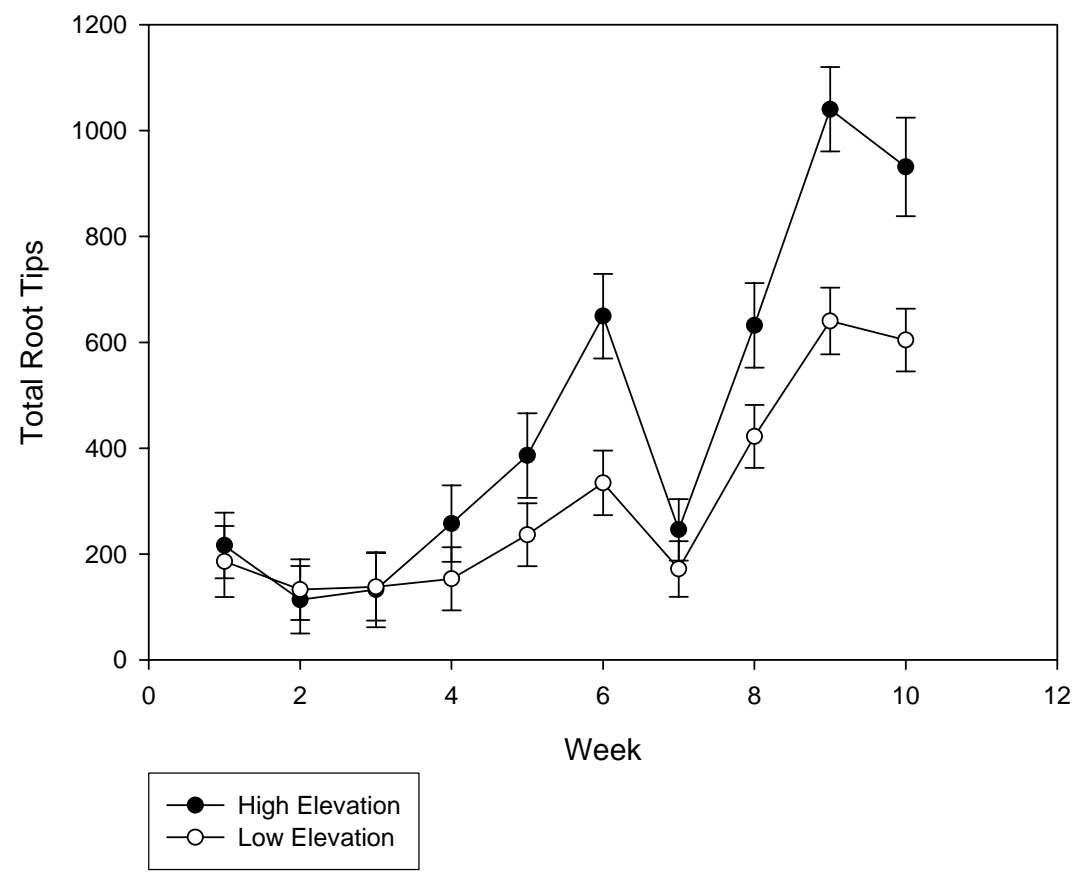

Figure 3.11: Differences in tiller biomass (g) between two nitrogen populations

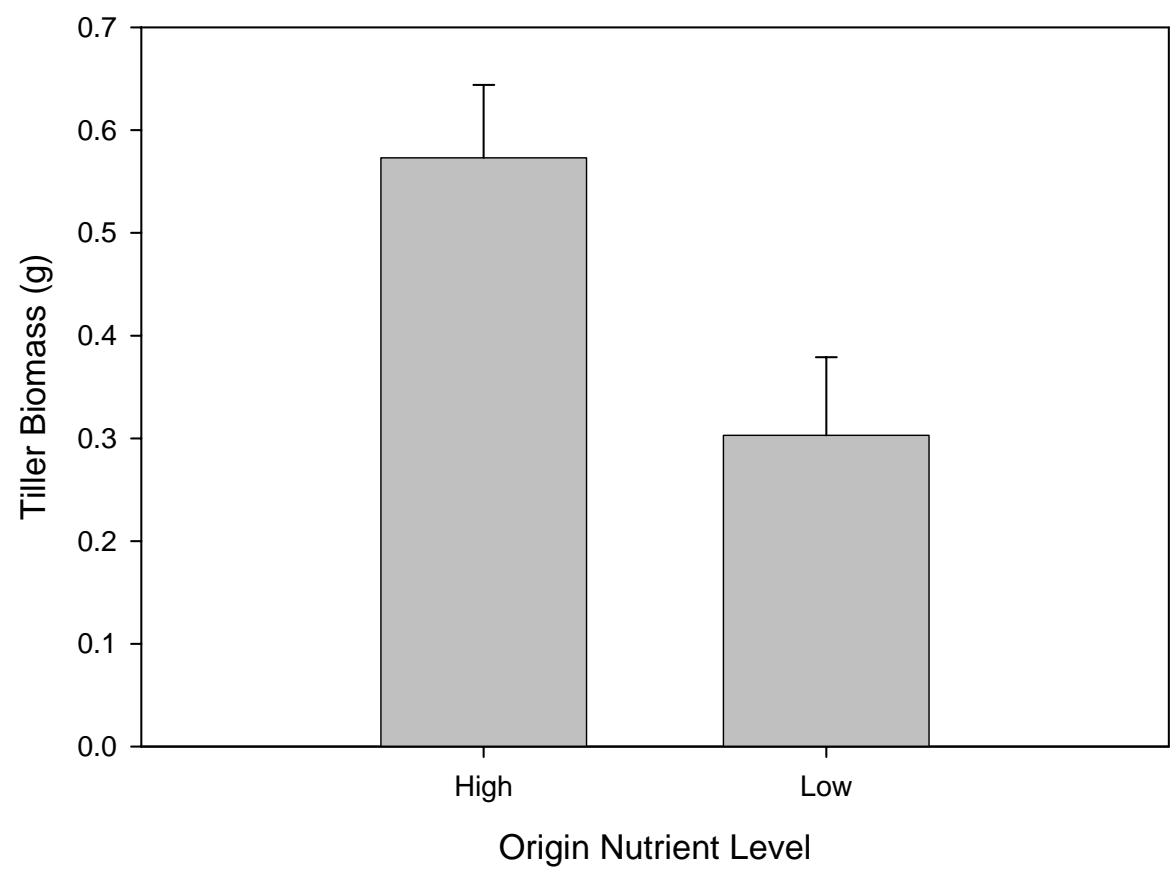


Figure 3.12: Differences in whole plant biomass between two nitrogen populations

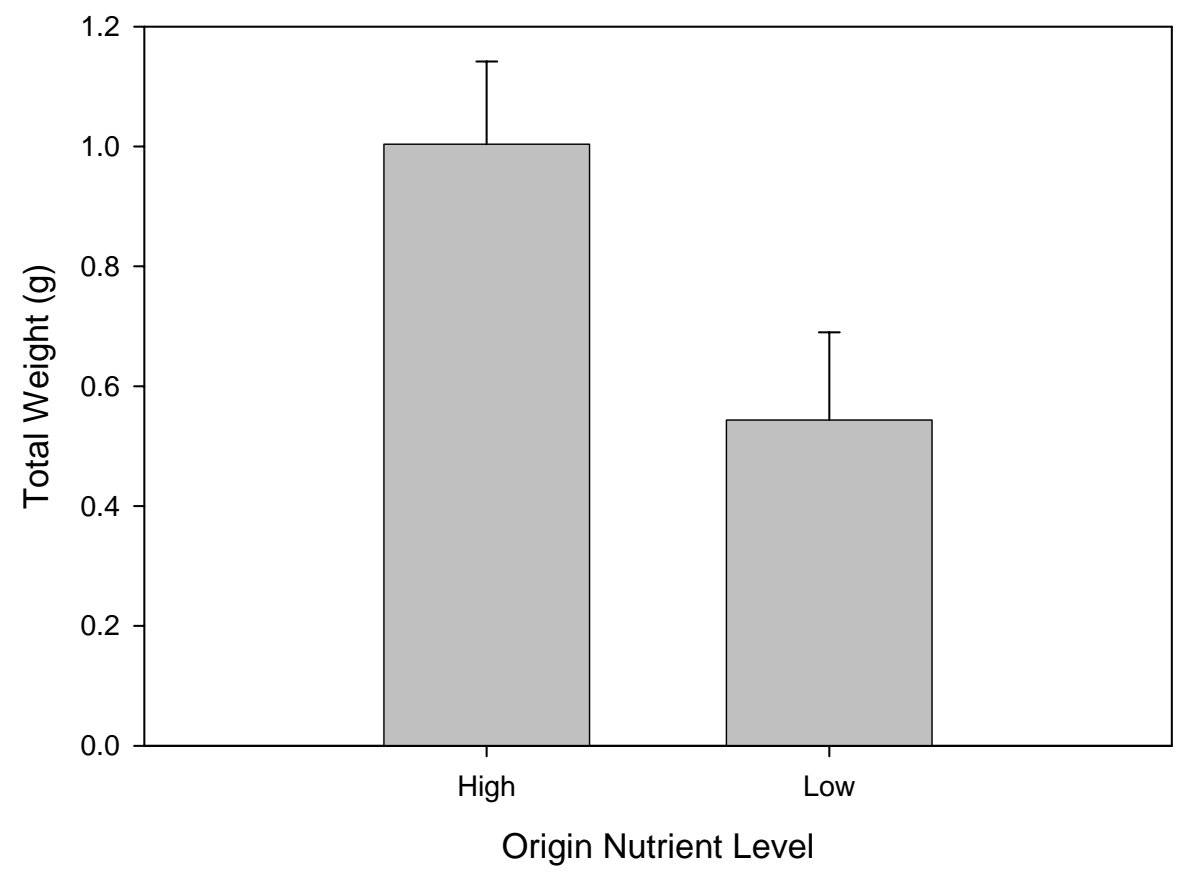

Figure 3.13: The effect of elevation on root C:N ratios.

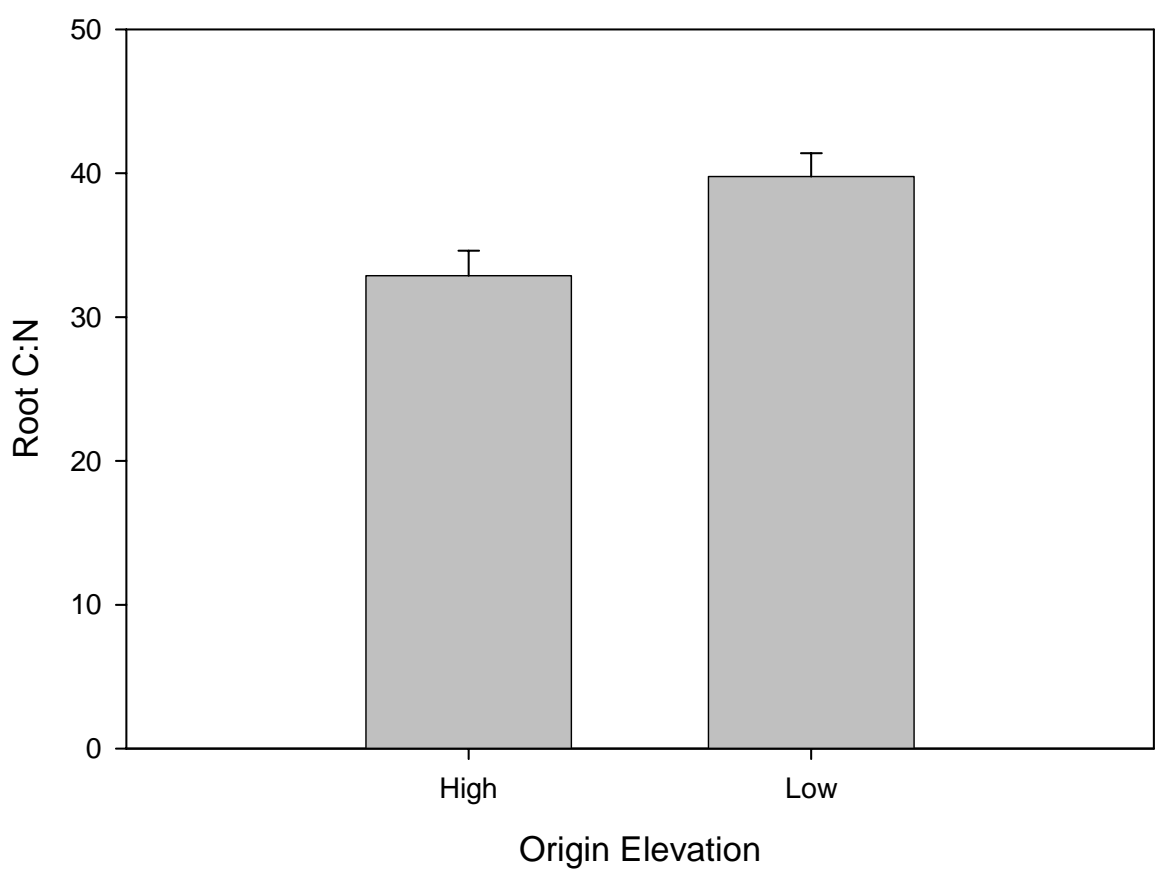


Figure 3.14: The effect of nitrogen on root C:N ratios.

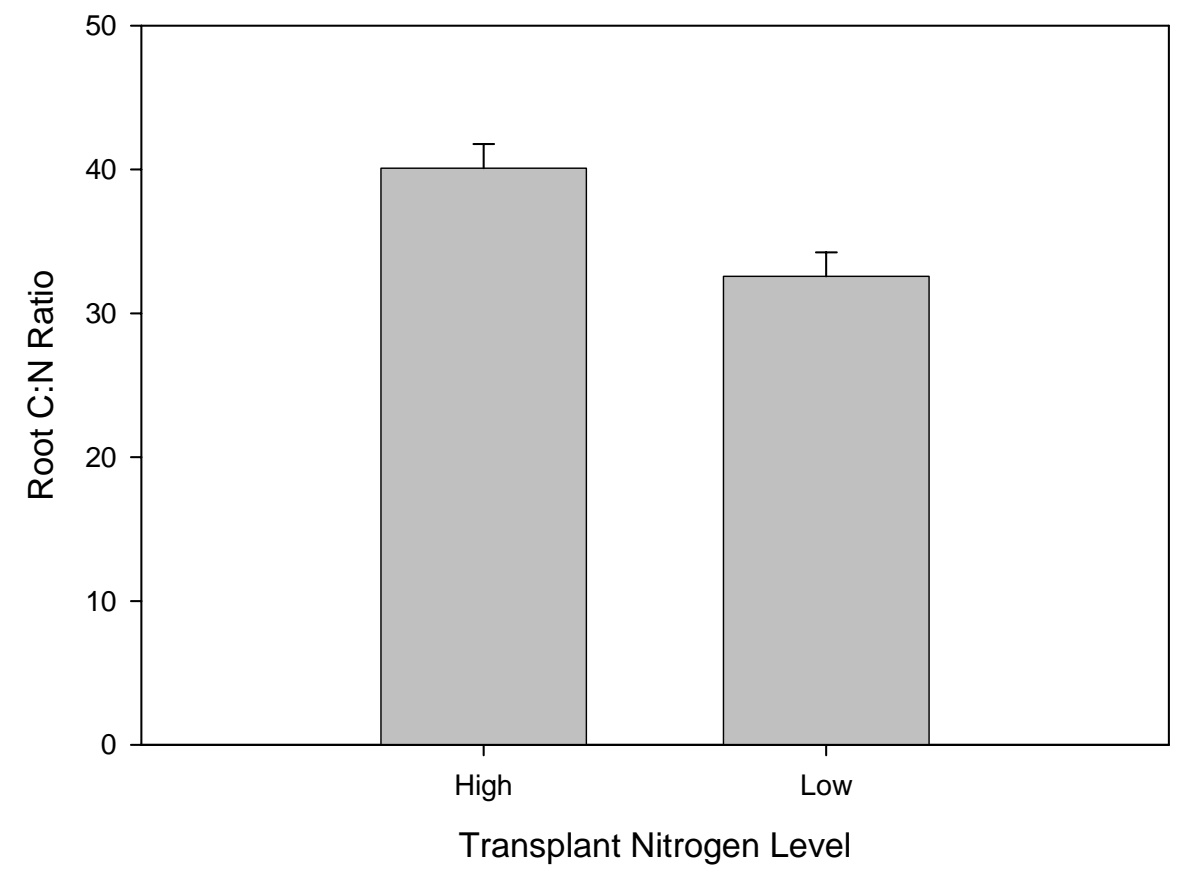

Figure 3.15: The effect of nitrogen on root:shoot weight.

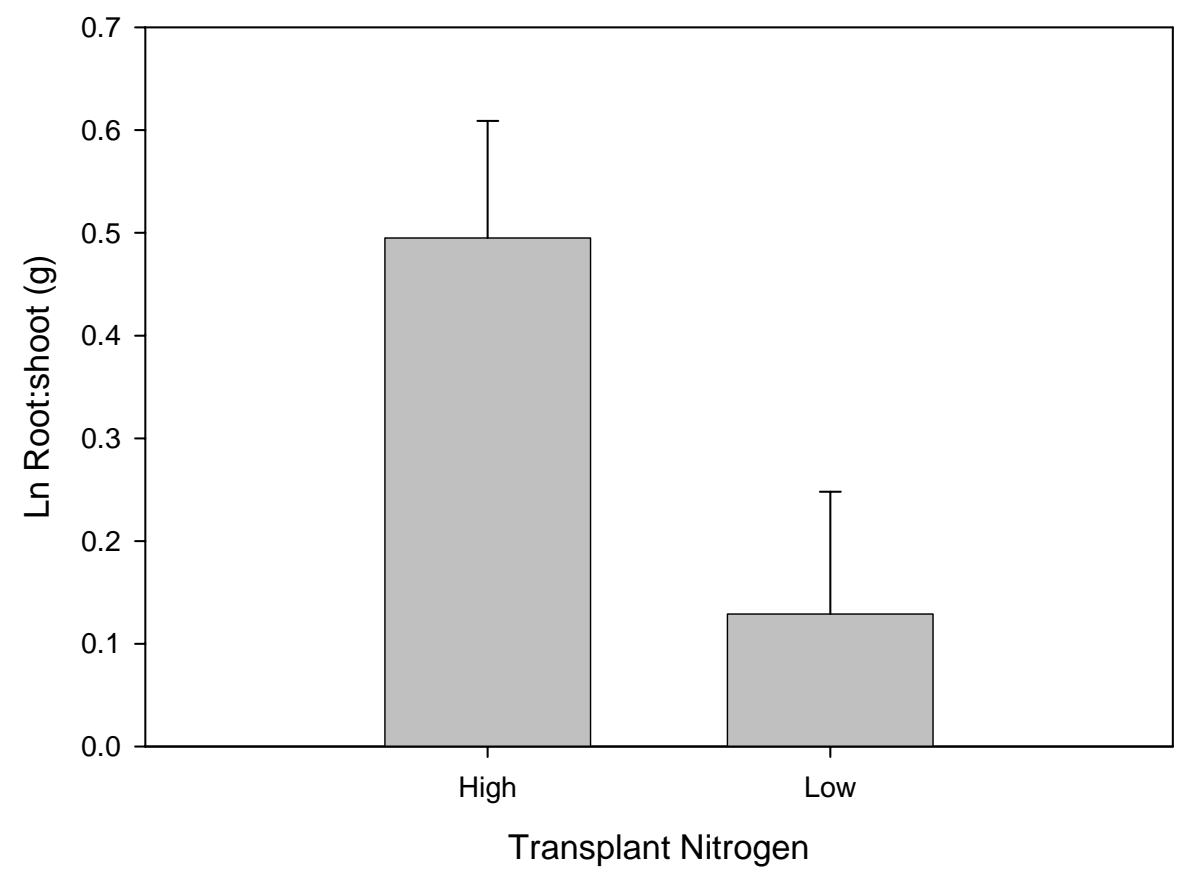


Figure 3.16: The effect of origin nitrogen level on nitrogen concentration within root:shoot ratios.

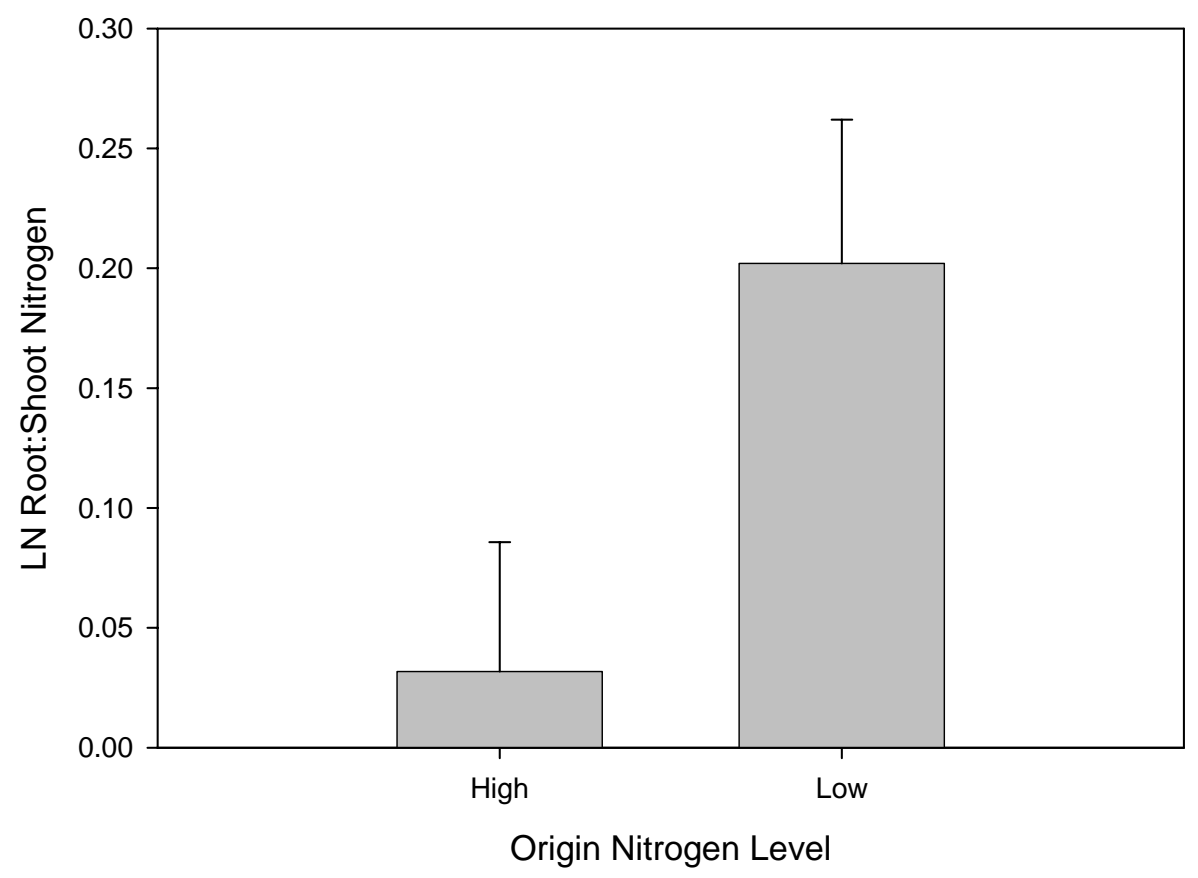

Figure 3.17: The effect of nitrogen on root:shoot $\mathrm{C}: \mathrm{N}$ ratios.

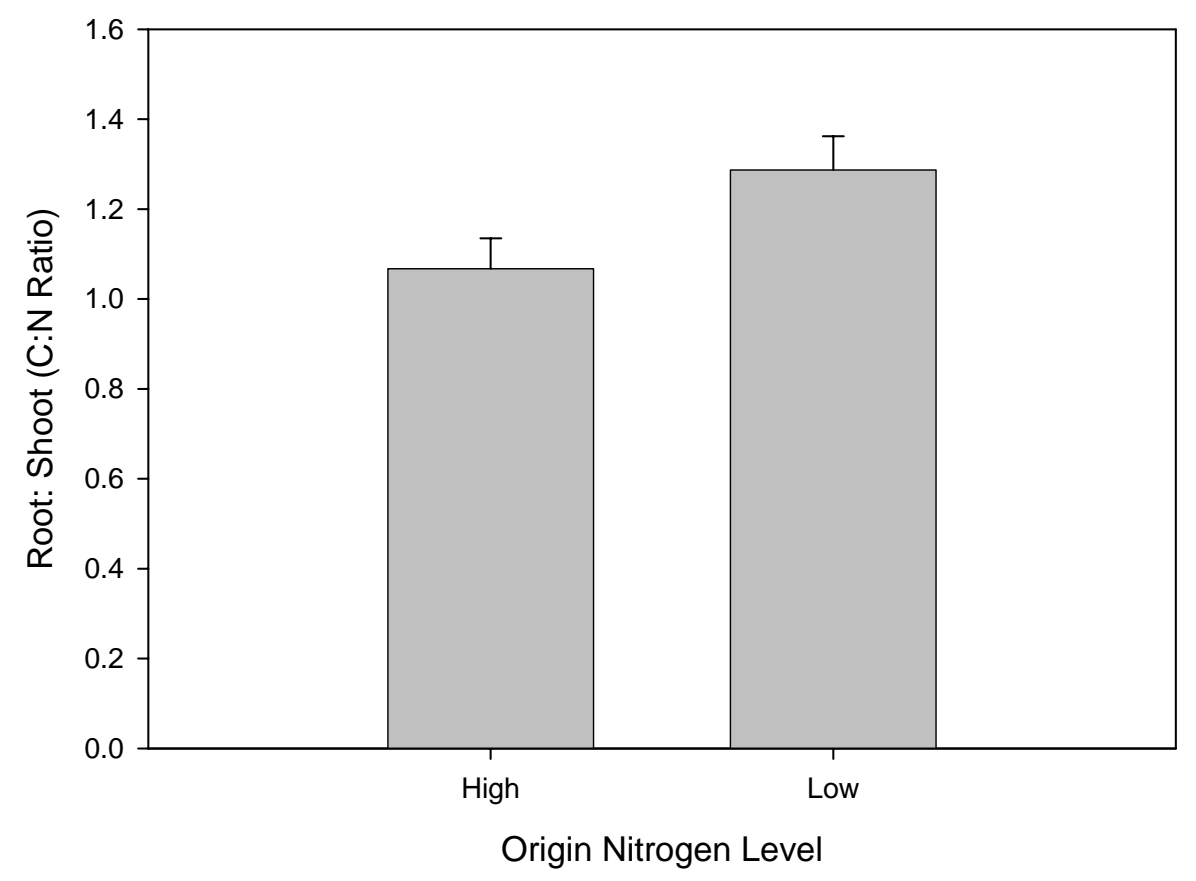




\section{DISCUSSION}

\section{$\underline{\text { Aboveground Characters }}$}

Aboveground growth was strongly influenced by adaptations that were derived from environmental characteristics of their home sites. Specifically, plants from high-nitrogen environments tended to produce more aboveground biomass than low-nitrogen populations. Plant populations form high-nitrogen environments have a higher growth rate due to increased in RAR, as predicted by the Garbutt and McGraw model (chapter 1). I believe that increased tiller growth also provides additional adaptive fitness to prevent competition for other resources such as nitrogen and sunlight. Ervin and Wetzel (2002) found that J. effusus was an effective dominant competitor for aboveground resources by shading out other species with increased tiller number and height.

Conversely, low-nitrogen populations should have an increased efficiency for nitrogen utilization (RUE) and therefore a lower growth rate. Increased use efficiency is in response to the spatial and temporal variability to nitrogen availability. In effect, the populations must be conservative (i.e. efficient) in their utilization of nitrogen in biological processes. This conservativeness negatively correlates with increased growth. The resulting shorter tillers might also reflect a decreased need for aboveground competition for light resources (Lortie and Aarssen 1996, Ryser and Eek 2000).

Overall, our study populations did not strongly respond to the presence or absence of nitrogen. Notably, plants from low-nitrogen sites did not respond positively to the highnitrogen treatment. This implies that populations were unable to shift their functionality to respond to opposing nitrogen conditions rapidly. These results support our models' predictions on how plants will divergently respond to resource availability. 
Elevation also provided an interesting control on the response to nitrogen treatments in our minirhizotron study. Tiller area was greater in high-elevation populations than lowelevation populations. Chapin and Chapin (1981) found that Carex produced larger tillers when local sub-arctic temperatures were warmer. Furthermore, they suggest that these populations increased tiller size to maximize photosynthesis. This scenario is possible for our populations, since warmer greenhouse temperatures and more growing degree-days encountered by high-elevation plants might have activated potential for additional growth.

Aboveground characters significantly differed with respect to origin elevation and origin nitrogen environmental factors. Overall, high-nitrogen populations from high elevations maximized productivity. High nitrogen acquisition combined with warmer temperatures resulted in increased growth for these populations. In low origin elevation populations, low-nitrogen origin sites outperformed high-nitrogen sites. This is due to increased RUE from low-nitrogen populations that are adapted to maintain a lower growth rates, regardless of temperature changes.

\section{Belowground Characters}

Nearly all of the measured belowground characters (length, surface area, diameter and root tips) were influenced by their origin environmental conditions. Root length, diameter, and root tip abundance was highest in plants from high-nitrogen populations. This supports our model, since high-nitrogen populations are expected to maximize their growth and therefore fitness in response to abundant resources and high acquisition rates. Increasing root length, surface area and the number of root tips are the prime routes by which plants can forage the soil for nitrogen. Increased growth in plants from with historically low nitrogen quality was restricted by the negative correlation between growth and resource use 
efficiency. This low growth rate might also result in intra-species competition. Casper and Jackson (1997) found that an individual might begin to suffer competition within its own root system and therefore further decrease its growth rate.

Root diameter did not follow the previous responses to origin nitrogen status. In this case, low-nitrogen populations had greater root diameters than those observed in highnitrogen individuals. Having shorter, but thicker, roots might be a response by plants in these environmental conditions to conserve growth efficiency while maintaining the potential for nitrogen absorption in a resource limited environment. In this scenario, plants accustomed to low nitrogen cannot afford to explore the soil for more nitrogen and therefore must maintain larger roots to intercept what nitrogen is readily available. Low-nitrogen populations grown at low elevations yielded the largest mean root diameter.

Overall, the effect of origin elevation produced growth trends in roots similar to those in tillers. High-elevation populations significantly outperformed low-elevation sites. This suggests that high-elevation sites are maximizing their belowground growth potential in response to growing season conditions (i.e. warmer temperatures, available moisture, increased photosynthetic activity). Chapin and Chapin (1981) found that cold soil environments (high elevations) typically had greater biomass in roots compared to tillers. Interestingly, the number of root tips increased over time in high-elevation sites that suggest maximization of growth potential due to growing season conditions.

Root surface area was greatest in high-nitrogen populations from high-elevation sites. This supports our proposed model where populations from high-nitrogen sites should have increased growth because of increased acquisition rates. In addition, high-elevation sites should maximize this character in an expectedly shorter growing season rather than low- 
elevation sites. This results from adaptation to specific environmental conditions that have directed the plasticity of phenotypic response. Our results concur with Fitter's (1987) geometrical conflict: root systems with the most efficient nutrient exploitation capacity are less efficient at the transport of the nutrient to the rest of the system for utilization.

Overall, the response of $J$. effusus root systems seems to behave in a pattern similar to their aboveground counterparts with respect to origin elevation and nitrogen status. These two environmental factors have placed strong constraints on the genetics of these differing populations, resulting in site-specific adaptations. Furthermore, it appears that growth and performance are more strongly correlated with these adaptive co-occurring conditions rather than independent nitrogen or elevation factors.

Unfortunately, the contribution of root hairs and root turnover to nitrogen foraging could not be assessed from our study. We expected that high resource acquisition rates would match a dramatic increase in root hair proliferation upon resource interception (Marschner 1995). However, this key aspect is nearly impossible to accurately extract and quantify (Pagel and Day, personal communication).

\section{Biomass and Nutrient Dynamics}

Tiller biomass was significantly higher in populations from high-nitrogen sites. This reflects our model predictions that high-nitrogen sites will have higher resource acquisition rates and therefore produce more biomass. Rapid uptake of resources and their conversion to biomass is expected to reduce competition by other plants while maximizing fitness within that specific environment. Root biomass did not reflect the significant differences associated with tradeoffs between RAR and RUE. However, combined plant biomass (above- and belowground portions) again support our model that high-nitrogen populations yield more 
biomass due to increased RAR. Low-nitrogen populations were more efficient in their growth and, therefore, did not produce large quantities of biomass. Plants from low-resource environments place less energy into the quantity of biomass produced, but rather the quality of each structural component, which supports the Garbutt and McGraw physiological response model.

In terms of nutrient dynamics, carbon and nitrogen concentration in tillers and roots did not significantly differ in response to any environmental treatment. Root $\mathrm{C}: \mathrm{N}$ ratios were greater in high-nitrogen treatments. The increased availability of nitrogen translated into higher nitrogen concentration or relative quality despite a plant's adaptive growth strategy. In addition, low-elevation sites were more efficient at fixing carbon per nitrogen acquired. Increased C:N efficiency implies that low-elevation sites maintain higher tissue quality in response to expected competition and longer growing seasons. Not surprisingly, more carbon would be allocated to the root system early in the plant's development and establishment to ensure access to essential, and often limiting, nutrients in the soil (Ervin and Wetzel 1997).

\section{Overall Response}

The overall response of this plant system appears to show strong genetic control because of origin nitrogen and elevation levels. Evolutionary programming of the ecotypes (and resulting phenotypes) has provided a strong divergence in the four distinct home sites. Each home site has adapted and optimized its expressed and potential fitness within its environment. In effect, high-nitrogen/high-elevation populations maximize growth due to increased resource availability and consequently higher acquisition. High-nitrogen/lowelevation populations have a high acquisition rate that maximizes their growth potential. 
Low-nitrogen/high-elevation populations are restricted (in growth) by RUE and cooler temperatures. Low-nitrogen/low-elevation populations are adapted to higher temperatures, but RUE restricts growth. High-elevation sites are also restricted by low temperatures but have the potential to maximize growth within the constraints of each physiological parameter in our model. Futuyma and Moreno (1988) believed that negative genetic correlations might act as another check within the system to ensure greater levels of diversity within the population.

The unique power of this study is that it included whole-plant responses to changing environmental factors. Numerous studies have examined aboveground responses to nitrogen and elevation, while few studies have mirrored this effort belowground (Fitter and Stickland 1992). Nevertheless, as in nearly all aspects of ecological research, there lies the potential for refinement. To refine this study further, both a larger sample population would be beneficial as well as assignment of an additional level of complexity with the inclusion of genotype responses within each site. In addition, inclusion of more than two nitrogen levels along with larger rhizotrons would increase the resolution of our study. Root restriction by pots is known to have strong affect on growth, allocation and physiological parameters (McConnaughay and Bazzaz 1991 Gedroc et al. 1996). Finally, expanding the understanding of plasticity of root morphology (i.e. architecture) and its role in exploitation efficiency are needed to understand fully the role of root systems on nutrient uptake within impacted environments. 


\section{REFERENCES}

Bell, D.L. and S.E. Sultan. 1999. Dynamic phenotypic plasticity for root growth in Polygonum: A comparative study. American Journal of Botany 86:807-819.

Bennington, C.C. and J.B. McGraw. 1995. Natural selection and ecotypic differentiation in Impatiens pallida. Ecological Monographs 65:303-323.

Bennington, C.C. and J.B. McGraw. 1996. Environmental-Dependence of quantitative genetic parameters in Impatiens pallida. Evolution 50:1083-1097.

Berntson, G.M. 1994. Modeling root architecture: Are there tradeoffs between efficiency and the potential for resource acquisition? New Phytologist 127:483-493.

Berntson, G.M. and F.I. Woodward. 1992. The root system architecture and development of Senecio vulgaris in elevated $\mathrm{CO}_{2}$ and drought. Functional Ecology 6:324-333.

Blum, A. 1988. Plant Breeding for Stress Environments. CRC Press, Boca Raton, FL.

Bohm, W. 1979. Methods of Studying Root Systems. Berlin. Springer-Verlag.

Butnor, J.R., J.A. Doolittle, K.H. Johnsen, L. Samuelson, T. Stokes and L. Kress. 2003. Utility of ground-penetrating radar as a root biomass survey tool in forest systems. Soil Science Society of America Journal 67:1607-1615.

Casper, B.B. and R.B. Jackson. 1997. Plant competition underground. Annual Review of Ecological Systematics 28:545-570.

Casper, B.B., H.J. Schenk and R.B. Jackson. 2003. Defining a plant's belowground zone of influence. Ecology 84:2313-2321.

Chapin III, F.S. and M.C. Chapin. 1981. Ecotypic differentiation of growth processes in Carex aquatilis along latitudinal and local gradients. Ecology 62:1000-1009.

Darwin, C. 1859. On the Origin of Species by Means of Natural Selection. Murray, London.

Day, F.P., E.P. Weber, C.R. Hinkle and B.G. Drake. 1996. Effect of elevated $\mathrm{CO}_{2}$ on fine root length and distribution in an oak-palmetto ecosystem in central Florida. Global Change Biology 2:143-145.

Demchik, M. and K. Garbutt. 1999. Growth of woolgrass in acid mine drainage. Journal of Environmental Quality 28:243-249. 
Drew, M.C., L.R. Saker and T.W. Ashley. 1973. Nutrient supply and the growth of the seminal root system in barley. I: The effect of nitrate concentrations on the growth of axes and laterals. Journal of Experimental Botany 24:1189-1202.

Ervin, G.N. and R.G. Wetzel. 1997. Shoot:Root dynamics during growth stages of the rush Juncus effusus L. Aquatic Botany 59:63-73.

Ervin, G.N. and R.G. Wetzel. 2002. Influence of a dominant macrophyte, Juncus effusus, on wetland plant species richness, diversity and community composition. Oecologia 130:626-636.

Essenstat, D.M. and M.M. Caldwell. 1989. Invasive root growth into disturbed soil of two tussock grasses that differ in competitive effectiveness. Functional Ecology 3: 345-353.

Feldman, L.J. 1984. Regulation of root development. Annual Review of Plant Physiology 35:223-242.

Fitter, A.H. 1987. An Architectural approach to the comparative ecology of plant root systems. New Phytologist 106:61-77.

Fitter, A.H. and T.R. Stickland. 1991. Architectural analysis of plant root systems II: Influence of nutrient supply on architecture in contrasting plant species. New Phytologist 118:383-389.

Fitter, A.H. and T.R. Stickland. 1992. Architectural analysis of plant root systems III: Studies on plants under field conditions. New Phytologist 121:243-248.

Fogel, R. 1985. Roots as primary producers in belowground ecosystems. In: Ecological Interactions in Soil (Special publication of the British Ecological Society, No. 4; Eds: A.H. Fitter, D. Atkinson, D.J. Read and M.B. Usher), pp. 23-36. Blackwell, Oxford, UK.

Futuyma, D.F. and G. Moreno. 1988. The evolution of ecological specialization. Annual Review of Ecology and Systematics 19:207-233.

Gedroc, J.J., K.D.M. McConnaughay and J.S. Coleman. 1996. Plasticity in root/shoot partitioning: optimal, ontogenetic, or both? Functional Ecology 10:44-50.

Grime, J.P., J.C. Crick and J.A. Rincon. 1986. The ecological significance of plasticity. In: Plasticity in Plants (D.H. Jennings and T. Trewavas Eds.). Society for Experimental Biology Symposium No. 40. Cambridge University Press, Cambridge, UK.

Gross, K.L., D. Maruca and K.S. Pregitzer. 1992. Seedling growth and root morphology of plants with different life-histories. New Phytologist 120.535-542. 
Jackson, R.B. and M.M. Caldwell. 1989. Timing and degree of root proliferation in fertile-soil microsites of three cold-desert perennials. Oecologia 81:149-153.

Jackson, R.B., J.H. Manwaring and M.M. Caldwell. 1990. Rapid physiological adjustment of roots to localized soil enrichment. Nature 334:58-60.

Johnson, C.M., P.R. Stout, T.C. Broyer and A.B. Carlton. 1957. Comparative chlorine requirements of different plant species. Plant and Soil 8:337-353.

Larigauderie, A. and J.H. Richards. 1994. Root proliferation characteristics of seven perennial arid-land grasses in nutrient-enriched microsites. Oecologia 99:102-111.

Levins, R. 1968. Evolution in a Changing Environment. Princeton University Press, Princeton, N.J.

Lortie, C.J. and L.W. Aarssen. 1996. The specialization hypothesis for phenotypic plasticity in plants. International Journal of Plant Science 1517:484-487.

Lynch, J. and J.J. Van Beem. 1994. Seedling roots of common bean genotypes. Crop Science 33:1253-1257.

Mac Rhizo. Version 3.10b. Regent Instruments Inc. Quebec, Canada.

Marschner, H. 1995. Mineral Nutrition of Higher Plants. Academic Press, New York.

McConnaughay, K.D.M. and F.A. Bazzaz. 1991. Is physical space a soil resource?. Ecology 72:94-103.

McGraw, J.B. and K. Garbutt. 1990. Demographic growth analysis. Ecology 71:11991204.

Nielsen, K.L., J.P Lynch and H.N. Weiss. 1997. Fractal geometry of bean root systems: Correlations between spatial and fractal dimension. American Journal of Botany 84:26-33.

Pregitzer, K.S. 2003. Woody plants, carbon allocation and fine roots. New Phytologist 158:421-424.

Ryser, P. and L. Eek. 2000. Consequences of phenotypic plasticity versus interspecific differences in leaf and root traits for acquisition of aboveground and belowground resources. American Journal of Botany 87:402-411.

SPSS. Version 11.5. SPSS Inc. Chicago, IL.

Sultan, S.E. 1987. Evolutionary implications of phenotypic plasticity in plants. Evolutionary Biology 21:127-176. 
Sultan, S.E. and F.A. Bazzaz. 1993. Phenotypic plasticity in Polygonum persicaria II: Norms of reaction to soil moisture and the maintenance of genetic diversity. Evolution 47:1032-1049.

Turesson, G. 1922. The species and the variety as ecological units. Hereditas 3:100113.

Turesson, G. 1930. The selective effect of climate upon the plant species. Hereditas 14:99-152.

Waisel, Y., A. Eshel and U. Kafkafi. 2002. Plant Roots: The Hidden Half. Marcel Deckker, New York

Wilcox, H. 1968. Morphological studies of the root of red pine, Pinus resinosa1: Growth characteristics and patterns of branching. American Journal of Botany 55:247-254.

Zobel, R. 1991. Genetic control of root systems. In: Plant Roots: The Hidden Half (Y. Waisel, A.Eschel and U. Kafkafi Eds.) Marcel Dekker, New York. 


\section{CHAPTER 4}

CONCLUSIONS AND SYNTHESIS 


\section{CONCLUSIONS}

The Garbutt and McGraw model (discussed in Chapter 1) proposed that plants would respond differently to nitrogen availability due to inherent negative correlations between resource acquisition rates (RAR) and resource utilization efficiency (RUE). Although current literature suggests that phenotypic or physiological plasticity is responsible for changes in response to environmental conditions, not all populations can readily respond to drastic changes in the environment. As a result, tradeoffs in plastic behavior must occur within plant populations to ensure that fitness is maximized. Within the range of a species, multiple environments will be encountered. Plants from high-resource environments should maximize growth in abundant resource environments and in low-resource environments, plants should maximize efficiency over growth. As a result, local conditions drive populations to different peaks in the adaptive landscape.

Utilizing the Garbutt and McGraw model's predictions, the primary objective of this study was to evaluate evolution of plants and their responses to nutrient availability. In addition, we investigated the role of elevation as an additional constraint on performance and fitness of plants with respect to physiological tradeoffs between RUE and RAR. Our final goal was to suggest practical application for remediation of nitrogen-impacted watersheds by appropriate selection of ecotypes of $J$ effusus.

Using the unique power of clonal genotypes of $J$. effusus and reciprocal transplants, this study found that plasticity did occur within our field sites and that populations respond significantly to nitrogen availability. Specifically, high-nitrogen populations outperformed their low-nitrogen counterparts. Low-nitrogen populations were more efficient than those from high-nitrogen origins. 
Although nitrogen is a critical component and constraint on plant fitness, it is only one factor in a suite of interactions that affect phenotypic expression. Elevation appears to have a strong influence on plant growth. Our model predicted that populations from low elevations should maximize growth compared to high-elevation populations due to longer growing seasons, warmer temperatures, and a higher mean soil temperature. Overall, we predicted that our nitrogen resource availability model would be nested within an elevation response control on the population. Unfortunately, the effect of genotypes could not be examined due to constraints in hypothesis testing. The results of our study suggest negative correlations were still present with respect to nitrogen availability. Plants that originated from high-elevation sites grew larger irrespective of the environment in which they were growing. Increased plant growth within high-elevation sites did not agree with our expectations or model but does suggest that differences in elevation affect a different suite of genes, therefore affecting plant fitness on multiple dynamic levels.

The second level of the study examined the importance of belowground growth in the response to nitrogen availability. Roots are typically difficult to examine due to their opaque growth medium, however glass-plate minirhizotrons enabled us to measure multiple growth characters. We predicted that the belowground portion would respond similarly to their aboveground counterparts. Our results suggest differences in origin elevation and origin nitrogen status strongly control the genetic expressions of root system growth. Highelevation populations outperformed low-elevation populations and nitrogen treatments had little effect on growth. We believe that warmer temperatures might have activated growth potential in the short term. 
Overall, this study has found that plants respond differently to nitrogen availability based on their site of origin. In addition, a negative correlation exists between the physiological traits for resource use efficiency and resource acquisition rate as predicted by the Garbutt and McGraw model. Environmental factors attributed to elevation have a stronger control on growth than those due to nitrogen limitations. We also conclude that root systems respond to nitrogen treatments based on historical strategies rather than treatments in the short term. Finally, elevation was determined to be the dominant factor controlling biomass, nutrient allocation and growth. The results of this study important since the impact of elevation on growth have never studied within the Juncaeace family.

A synthesis of the data that emerged from this study suggests that elevation has the strongest control on plant growth in high elevations (Figure 4.1). Conversely, nitrogen appears to have the strongest control on plant growth in low elevations, suggesting a mean response masked the response of elevation in low-nitrogen environments. This trend was observed in both RUE and RAR traits.

The findings of this study should assist in the development of plant selection protocols for remediating nitrogen-impacted watersheds. By effectively selecting individuals from populations that have a historically similar nitrogen and elevation regimes, constructed wetlands can be designed to sequester excess nitrogen (i.e. from agriculture, poultry farms and sewage plants etc.) from the watershed and improve water quality. This will reduce the cost and need for intensive management of water quality improvement programs via this natural and ecologically friendly method. Future studies in this area should emphasize the response of individual genotypes and examine the effects of a suite of environmental 
variables (i.e. phosphorus limitations, competition, etc.) that force populations to varying peaks in the adaptive landscape and affecting overall plant fitness. 
Figure 4.1: Response of Juncus effusus to differing nitrogen and elevation regimes.

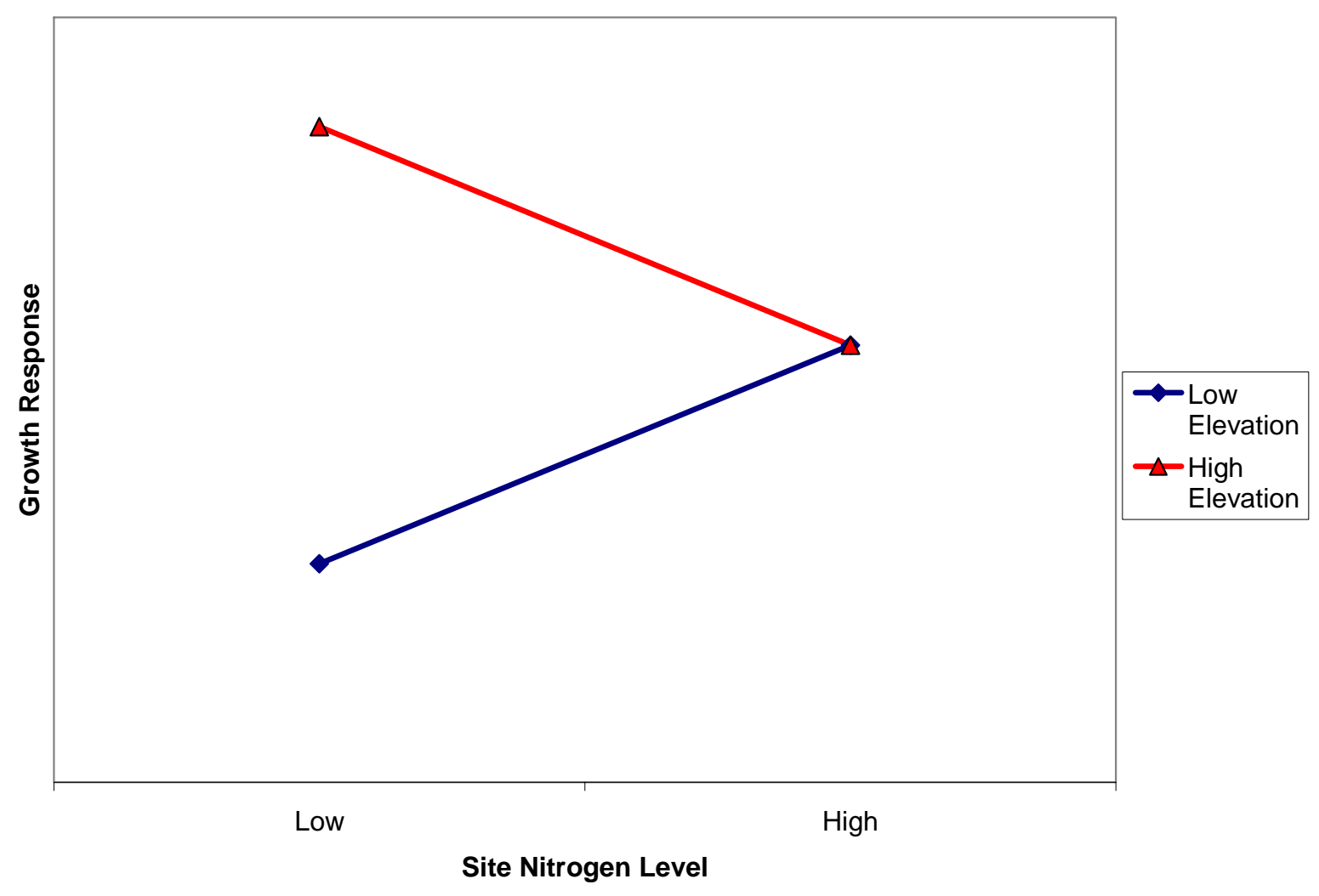

